\title{
Pre-eclampsia is more than a vascular disease
}

\author{
Citation for published version (APA):
}

Chedraui, P. A. (2015). Pre-eclampsia is more than a vascular disease. [Doctoral Thesis, Maastricht University]. Datawyse / Universitaire Pers Maastricht. https://doi.org/10.26481/dis.20150518pc

Document status and date:

Published: 01/01/2015

DOI:

10.26481/dis.20150518pc

Document Version:

Publisher's PDF, also known as Version of record

\section{Please check the document version of this publication:}

- A submitted manuscript is the version of the article upon submission and before peer-review. There can be important differences between the submitted version and the official published version of record.

People interested in the research are advised to contact the author for the final version of the publication, or visit the DOI to the publisher's website.

- The final author version and the galley proof are versions of the publication after peer review.

- The final published version features the final layout of the paper including the volume, issue and page numbers.

Link to publication

\footnotetext{
General rights rights.

- You may freely distribute the URL identifying the publication in the public portal. please follow below link for the End User Agreement:

www.umlib.nl/taverne-license

Take down policy

If you believe that this document breaches copyright please contact us at:

repository@maastrichtuniversity.nl

providing details and we will investigate your claim.
}

Copyright and moral rights for the publications made accessible in the public portal are retained by the authors and/or other copyright owners and it is a condition of accessing publications that users recognise and abide by the legal requirements associated with these

- Users may download and print one copy of any publication from the public portal for the purpose of private study or research.

- You may not further distribute the material or use it for any profit-making activity or commercial gain

If the publication is distributed under the terms of Article $25 \mathrm{fa}$ of the Dutch Copyright Act, indicated by the "Taverne" license above, 
Pre- eclampsia

is more than a

vascular disease

Peter Chedraui 
Research Institute GROW

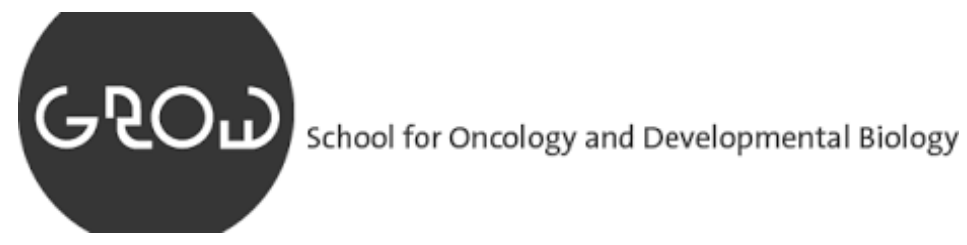

ISBN 9789461594389

Production and print: Datawyse | Universitaire Pers Maastricht

(c) Copyright Peter Chedraui, Maastricht 2015 


\title{
PRE- ECLAMPSIA IS MORE THAN A VASCULAR DISEASE
}

\author{
DISSERTATION \\ to obtain the degree of Doctor at Maastricht University, \\ on the authority of the Rector Magnificus, Prof. Dr. L.L.G. Soete, \\ in accordance with the decision of the Board of Deans, \\ to be defended in public \\ on Monday 18 May, 2015 at 12:00 hours
}

Peter Chedraui

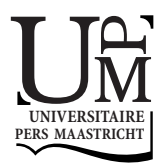




\section{Promotors}

Prof. dr. Boris W. Kramer

Prof. dr. Marc E.A. Spaanderman

\section{Co-Promotor}

Dr. A.W. Danilo Gavilanes

\section{Assessment committee}

Prof. dr. Jan Nijhuis (chairman)

Prof. dr. Camil Castelo-Branco, University of Barcelona - Spain

Prof. dr. Hugo ten Cate

Dr. Yves Garnier, Osnabrück - Germany

Prof. dr. Frans Rademakers 


\section{CONTENTS}

Chapter 1 Introduction

Chapter 2 Vascular homeostasis affected during pre- eclampsia: increased anti-angiogenesis

Chapter 3 In pre- eclampsia there is more to pathogenesis than vascular abnormalities: decreased anti-oxidation

Chapter 4 Endothelial dysfunction during pre- eclampsia is present in the maternal and fetal vasculature

Chapter 4a Plasma and placental nitric oxide levels in women with and without pre-eclampsia living at different altitudes.

Chapter 4b Feto-placental nitric oxide, asymmetric dimethylarginine and vascular endothelial growth factor (VEGF) levels and VEGF gene polymorphisms in severe pre- eclampsia

Chapter 5 The role of genetics in the pathogenesis of pre-eclampsia

Chapter 5a Polymorphisms of the methylenetetrahydrofolate reductase gene (C677T and A1298C) in nulliparous women complicated with preeclampsia.

Chapter 5b Polymorphisms of the methylenetetrahydrofolate reductase gene (C677T and A1298C) in the placenta of pregnancies complicated with pre- eclampsia.

Chapter 6 Discussion and summary

Chapter 7 Valorisation

Chapter 8 Acknowledgments 


\section{ABBREVIATIONS}

$\begin{array}{ll}\text { ADMA } & \text { asymmetric dimethylarginine } \\ \text { CoQ }_{10} & \text { Co-enzyme } Q_{10} \\ \text { G-CSF } & \text { Granulocyte colony stimulating factor } \\ \text { HCy } & \text { Homocysteine } \\ \text { IF } & \text { Interferon } \\ \text { IL } & \text { Interleukin } \\ \text { MCP } & \text { Monocyte chemoattractant protein } \\ \text { MIP } & \text { Macrophage inflammatory Protein } \\ \text { MTHFR } & \text { Methylenetetrahydrofolate reductase } \\ \text { NO } & \text { Nitric oxide } \\ \text { NOS } & \text { Nitric oxide synthase } \\ \text { PE } & \text { Pre- eclampsia } \\ \text { PLGF } & \text { Placental growth factor } \\ \text { SFIt-1 } & \text { Soluble receptor fms-like tyrosin kinase 1 } \\ \text { SGA } & \text { Small for gestational age } \\ \text { SNPs } & \text { Single nucleotide polymorphisms } \\ \text { TNF-R } & \text { Tumor necrosis factor receptor } \\ \text { TNF- } \alpha & \text { Tumor necrosis factor alpha } \\ \text { VEGF } & \text { Vascular endothelial growth factor }\end{array}$


CHAPTER 1

Introduction 

Pre- eclampsia (PE) is a serious issue in female reproductive medicine [1]. To date, despite attempts at intervention it is still a leading cause of maternal and fetal morbidity and mortality [1]. Indeed, to date, there is no treatment for this disease other than the termination of pregnancy, resulting in an increased rate of iatrogenic preterm births. Hence research has focused on prevention and the search for predictive markers that will provide early treatment or intervention.

The Etiology of PE is still unknown; however clinical and in vitro data obtained at various stages of pregnancy have provided insights to the various biochemical abnormalities found in this disease [2]. In general, abnormalities originate in the placenta and have been related to vessels (maternal and placental), anti-oxidation, inflammation and genetics. The role of each will be reviewed and discussed in this thesis in order to further elucidate biochemical and molecular mechanisms involved in the pathogenesis of this disease.

\section{A. EPIDEMIOLOGY OF PRE- ECLAMPSIA AND PATHOGENESIS}

PE is a frequent complication of pregnancy that accounts for 5 to $14 \%$ of all deliveries, and causes adverse maternal and perinatal outcomes [3,4]. Although the exact cause of $P E$ remains undetermined, key maternal and placental pathogenic factors include:

- Immunologic factors,

- Abnormal placental implantation,

- Genetic and environmental factors, and

- Cardiovascular and exaggerated inflammatory changes [3,5-7].

\section{B. IS PRE- ECLAMPSIA PREDICTION FEASIBLE?: THE ROLE OF BIOCHEMICAL MARKERS}

Reduced placental perfusion at early stages of pregnancy is a key event in the development of PE [8]. Defective trophoblastic invasion of the uterine spiral-arteries and arterioles leads to incomplete vascular remodeling and impaired utero-placental blood flow. Consequently, the placenta becomes ischemic and hypoxic and secretes into the maternal plasma an array of factors that are implicated in inducing generalized endothelial cell activation and vascular dysfunction that elicit the maternal clinical syndrome $[10,11]$.

Although the exact mechanisms involved remain unclear, vascular dysfunction found in PE is likely to be a consequence of reduced maternal circulating angiogenic factors $[12,13]$ and increased levels of placental debris [14], reactive oxygen species [15], proinflammatory cytokines [tumor necrosis factor-alpha (TNF- $\alpha$ ), interleukin 6 (IL-6) and interleukin 8 (IL-8)] [16,17] and anti-angiogenic factors [18,19]. 


\section{B.1. Reduced angiogenic factors}

Women with PE display abnormal decidual and placental villous vasculature. In one study [12], serum maternal concentrations of vascular endothelial growth factor (VEGF) and placental growth factor (PLGF) were measured in normal pregnancies and those complicated by isolated idiopathic small-for-gestational-age (SGA) newborn infants, PE alone, or PE with SGA newborn infants at the time of clinical disease and before the onset of clinical signs. Serum VEGF and PLGF levels were found reduced in abnormal pregnancies as compared to control subjects. These findings were observed as early as 15 to 19 weeks of gestation in PE with SGA newborn infants. Authors concluded that decreased PLGF production results in abnormalities of placental angiogenesis through direct and indirect effects on other vascular growth factors [12].

\section{B.2. Increased placental debris}

It has been proposed that during PE there is a systemic inflammatory response involving both leucocytes and endothelium. This response is also present during normal pregnancy, but in a milder form. The inflammatory stimulus is most likely to come from the placenta. In normal pregnancies syncytiotrophoblast apoptotic debris is shed into the maternal circulation and contribute to the suppression of Th1 responses; however during PE this response is increased [14].

\section{B.3. Increase of oxygen species/decreased anti-oxidation}

During PE there is an observed increase in the rate of lipid peroxidation, increased lipid availability, and decrease of several antioxidants such as alpha tocopherol, ascorbate, beta carotene and selenium [20]. In accordance to this, a significant decrease in plasma coenzyme $\mathrm{Q}_{10}\left(\mathrm{CoQ}_{10}\right)$ in women with $\mathrm{PE}$ has recently been reported [21]. $\mathrm{CoQ}_{10}$ is a part of the non-enzymatic defense system against oxygen species (antioxidative function) with mitochondrial complexes I and III reaction mechanisms playing a key role in electron transport [22]. One study performed in Ecuador found lower plasma and higher placental $\mathrm{CoQ}_{10}$ content among PE women living in Quito, Ecuador (2,800 meters above sea level) when compared to normal pregnancies [23].

\section{B.4. Increased pro-inflammatory cytokines}

Generalized maternal endothelial cell dysfunction appears to be the final underlying problem which clinical signs and symptoms. This scenario is presumed to be caused, directly or indirectly, by one or more circulating factors derived from the placenta. Reports indicate that TNF- $\alpha$ may play an important role in causing endothelial activation [16]. One report measured plasma levels of TNF- $\alpha$, IL- 6 and both forms of soluble TNF 
receptors ( $\mathrm{p} 55$ and p75 TNF-R) in 31 women complicated with PE and 31 controls matched for age, parity and gestational age. All measured analytes were found to be significantly higher in PE women than in controls with a wide variation in levels between PE individuals. There was a correlation between IL- 6 and TNF- $\alpha$ or TNF-R levels and between TNF- $\alpha$ and TNF-R levels. Nevertheless, when PE women were subdivided on the basis of the severity of their disease, median plasma concentration values of IL-6, TNF- $\alpha$ and TNF-R were all higher in the group with lower platelet counts [16]. Results of this study are consistent with the concept that the maternal syndrome of PE is associated with excessive release of TNF- $\alpha$ into the circulation which causes endothelial dysfunction.

During PE the immune system is changed with an increased innate activity and there is a hypothesis of a shift towards Th1-type immunity. Jonsson et al [17] measured a spectrum of soluble immunological factors that denote the different aspects of immune activation in the sera of third trimester women with PE and compared with levels in normal pregnant women. The array of pro- and anti-inflammatory cytokines included: IL-1 $\beta$, IL-2, IL-4, IL-5, IL-6, IL-8, IL-10, IL-12 p40, IL-13, IL-15, IL-17, IFN- $\alpha$, IFN- $\gamma$, TNF- $\alpha$, GCSF, MIP-l $\alpha$, MIP-1 $\beta$, MCP-1, eotaxin and RANTES which were measured with multiplex technology. Soluble CD14 and soluble IL-4 receptor levels were measured with ELISA. PE women displayed significantly higher levels of circulating IL-6 ( $p=0.002), I L-8 \quad(p=0.003)$ and soluble IL-4R ( $p=0.037)$, compared to women with normal pregnancies [17]. Hence, the data supports the hypothesis of increased inflammatory responses in PE, demonstrated by the increased levels of IL-6 and IL-8. Higher levels of soluble IL-4 receptor may partly support the hypothesis of a Th1 shift during PE [17].

\section{B.5. Increased anti-angiogenic factors}

Soluble receptor fms-like tyrosine kinase 1 (sFlt-1) and soluble endoglin (sEng) are potent anti-angiogenic factors that are elevated in the plasma of women experiencing PE $[24,25]$. Increased levels of these factors are thought to contribute to maternal vascular dysfunction by binding to and thus reducing circulating levels of free VEGF and PLGR [26].

\section{B.6. Endothelial dysfunction}

Placental ischaemia occurring during PE leads to the release of soluble placental factors, many of which, as already discussed, are classified as anti-angiogenic or proinflammatory. Once these factors reach the maternal circulation, they cause widespread activation and dysfunction of the maternal vascular endothelium that results in enhanced formation of endothelin-1 and superoxide, increased vascular sensitivity to angiotensin II and decreased formation of vasodilators such as nitric oxide (NO) [27]. 
NO is an intracellular gaseous messenger synthesized by NO synthase (NOS) from Larginine and oxygen. NO exerts diverse biological functions in several physiological and pathological processes, especially in vascular pathophysiology [28]. In relation to pregnancy, two important roles have been identified: a) NO produced by syncytiotrophoblast-derived endothelial cells causes dilation of the human placental vasculature [29], and may act as a paracrine agent for the maintenance of uterine quiescence during pregnancy; and b) local placental NO generation seems to be essential to promote cytotrophoblast endovascular invasion, an essential feature of normal placentation [30].

Studies addressing NO levels in women with PE are contradictory some indicating higher [31], others lower levels [32]. In one previous Ecuadorian report, women with PE exhibited higher NO maternal plasma levels [33]. Contradictory results could probably be due to differences in the measurement methods and/or the metabolite analyzed. Nevertheless, there is agreement in that PE is associated with altered NO production and/or activity.

\section{THE ROLE OF GENETICS IN THE PATHOGENESIS OF PE}

Although it is accepted that PE has a placental origin and is multifactorial, a role for underlying genetic predisposition is gaining much interest. Indeed, genetic factors influence all of the pathophysiological mechanisms to date proposed [34]. The inherited nature of PE has been known for many years, and extensive genetic studies have been undertaken in this area [34]. It is now accepted that PE is a complex genetic disorder, occurring as the result of variants at different loci, which individually have small effects but collectively contribute to an individual's susceptibility to disease. It is probable that no single gene or variant will be identified that is responsible for all cases of PE, although different variants may prove to be associated with subsets of disease, such as early onset PE with fetal growth restriction.

To date, more than 70 candidate genes have been selected on the basis of prior biological knowledge of the pathological changes occurring in PE. These can be grouped based on their suggested pathophysiological mechanisms: vasoactive proteins, thrombophilia and hypofibrinolysis, oxidative stress and lipid metabolism, endothelial injury, and immunogenetics (Table 1) [35]. Despite vast research, to date no candidate gene has been universally accepted as a unique causal gene for PE. This may in part be due to ethnic variations within study populations and inconsistency in the definition of PE, and perhaps as a major reason the fact that the majority of candidate gene studies have been grossly underpowered to detect variants with small effects [34]. 
Table 1. Candidate genes and predominant polymorphisms implicated in PE pathogenesis*

\begin{tabular}{llll}
\hline $\begin{array}{l}\text { Proposed underlying } \\
\text { mechanism }\end{array}$ & Name of the gene name & Gene symbolPolymorphism \\
\hline Vasoactive proteins & Angiotensinogen & AGT & 235 Met > Thr \\
& Angiotensin converting enzyme & ACE & I/D intron 16 \\
Thrombophilia and & Factor V Leiden & F5 & 506 Gln > Arg \\
hypofibrinolysis & Methylenetetrahydrofolate reductase & MTHFR & C667T \\
& Prothrombin & F2 & G20210A \\
& Plasminogen activator factor-1 & SERPINE I & Promoter insertion/deletion \\
& Integrin glycoprotein Illa & GPIIIA & C98T \\
Oxidative stress and lipid & Apolipoprotein E & APOE & C886T \\
metabolism & Microsomal epoxide hydrolase & EPHX & 113Tyr > His \\
& Glutathione-S-transferase & GST & A313G \\
Endothelial function & Endothelial nitric oxide synthase 3 & eNOS3 & 298 Glu > Asp \\
& Vascular endothelial growth factor & VEGFR I & TG repeat \\
& receptor I & VEGF & C936T \\
& Vascular endothelial growth factor & & \\
& & & \\
\hline Immunogenetics & Tumour necrosis factor $\alpha$ & TNF & G-308a \\
& Interleukin 10 & G1082A \\
\hline
\end{tabular}

*Adapted from Mutze et al [35].

Single-nucleotide polymorphisms (SNPs) are variations of the genome sequence, which may modify biological responses, and the risk of certain diseases. Numerous SNPs have been studied in PE patients [36,37]. An interesting studied gene in relation to PE is the methylenetetrahydrofolate reductase (MTHFR) gen. The enzyme coded this gene is critical for homocysteine ( $\mathrm{HCy}$ ) metabolism, catalyzing the $\mathrm{NADPH}$-linked reduction of 5,10-MTHF to 5-MTHF, and subsequently the vitamin B12-dependent methylation of $\mathrm{HCy}$ to methionine [38]. A reduction in MTHFR levels or activity by specific gene mutations induces mild to moderate increases in plasma HCy levels [39]. Although several mutations of the MTHFR gene have been described in relation to $P E$, the most frequent ones include: the alanine-to-valine C677T [40], and the glutamate-to-alanine A1298C [41].

Genetic research offers an attractive strategy for studying the pathogenesis of PE as it avoids the ethical and practical difficulties of conducting basic science research during the preclinical phase of PE when the underlying pathological changes occur.

\section{AIMS \& OUTLINE OF THE THESIS}

The aim of this thesis was to assess various biochemical and molecular markers related to vascular, anti-oxidative, endothelial, inflammatory and genetic abnormalities found in gestations complicated with PE. Chapter 2, presents one study that evaluates vascular 
homeostasis and inflammation during PE. Plasma levels of two soluble anti-angiogenic factors (sFlt-1 and sEng) and four pro-inflammatory cytokines (IL-6, IL-8, G-CSF and TNF$\alpha$ ) were measured in nulliparous women complicated with PE and levels compared to those found in normal nulliparous gestations. The results suggest that increased sFlt-1 and Eng levels in maternal plasma are consistent with vascular dysfunction found in gestations complicated with pre- eclampsia. Contrary to expected PE women displayed lowered IL-8 and G-CSF levels. This new finding is analyzed in the discussion.

In a previous research we found lower maternal plasma $\mathrm{CoQ}_{10}$ levels in women complicated with PE [21]. As a continuation, Chapter 3, presents a study that evaluated $\mathrm{CoQ}_{10}$ levels both in plasma and placenta among normal pregnant and PE primigravid women. Furthermore, as a highlight in design, the effect of high or low altitude residency was analyzed. Study found that women with PE (high or low altitude) displayed high placental $\mathrm{CoQ}_{10}$ content, with significant lower plasma $\mathrm{CoQ}_{10}$ levels among those residing in high altitude. The significance of presenting higher placental $\mathrm{CoQ}_{10}$ level content in parallel with higher plasma levels is discussed.

Chapter 4 discusses the fact that endothelial dysfunction during PE is present in maternal and fetal vasculature. Two studies were designed to analyze this. The first measured NO levels in plasma and placenta of PE women and compared these to normal pregnant women. Again as a highlighted feature, effect of high or low attitude was analyzed. This study confirmed previous observations that women with PE displayed higher plasma and placental NO levels and that the differences were associated with altitude of residence. The effect of altitude is discussed. A second study further evaluated markers of endothelial function in the fetal circulation of women with PE. For this, NO, ADMA and VEGF levels were measured in the fetal circulation of pregnant women with severe PE. This study also performed genetic assessment. Indeed, DNA was extracted from umbilical vein to determine the frequency of VEGF gene single nucleotide polymorphisms. It is to highlight in this study that molecular analysis of endothelial function has been performed in women with PE to date only in the maternal side. Studies assessing the umbilical fetal circulation are scarce or lacking. Results found that women with severe PE displayed higher NO and ADMA fetal circulating levels (vein and artery) and lower VEGF umbilical vein levels. There was a significant trend of finding lower VEGF levels in the presence of -2578 CC and -1154 AG genotypes.

In chapter 5, the role of genetics in the pathogenesis of PE is explored with two interesting studies that assessed two single nucleotide polymorphisms of one candidate gene related to thrombophilia, the MTHFR gene (C667T and A1298C) in plasma (the first study) and in placenta (second study) of women complicated with PE.

The first study determined that the prevalence of the CC mutant genotype of the A1298C polymorphism was higher in plasma among PE women. This mutation among PE women was related to increased neck circumference and higher homocysteine (HCy) levels. No differences were found regarding the prevalence of the C677T polymorphisms among cases and control. To complement our first study we further analyzed in 
a second study the prevalence of the same polymorphisms in placental material of PE cases compared to controls. Contrary to our previous study, frequency of the TT mutant genotype of the C677T polymorphism was higher in the placental material of pregnancies complicated with PE.

\section{SUMMARY}

To date the exact cause of PE is unknown. Despite this, studies have shown that PE is a multifactorial disease related to pregnancy which involves various pathways and mechanisms that are interconnected. The present thesis offers valuable candidates for both biomarkers for the evaluation of PE and for polymorphisms which might predispose to acquire this disease.

The present work is a research collaboration between the University of Maastricht The Netherlands and the Catholic University of Guayaquil - Ecuador. 


\section{REFERENCES}

1. Sibai BM, Dekker G, Kupferminic M. Pre-eclampsia. Lancet 2005;365:785-799.

2. Taylor RN, de Groot CJ, Cho YK, Lim KH. Circulating factors as markers and mediators of endothelial cell dysfunction in pre- eclampsia. Semin Reprod Endocrinol 1998;16:17-31.

3. Ngoc NT, Merialdi M, Abdel-Aleem H, Carroli G, Purwar M, Zavaleta N, Campódonico L, Ali MM, Hofmeyr GJ, Mathai M, Lincetto O, Villar J. Causes of stillbirths and early neonatal deaths: data from 7993 pregnancies in six developing countries. Bull World Health Organ 2006;84:699-705.

4. Lindheimer MD, Taler SJ, Cunningham FG. ASH Position Article. Hypertension in pregnancy. J Am Soc Hypertens 2008;2:484-94.

5. Valenzuela FJ, Pérez-Sepúlveda A, Torres MJ, Correa P, Repetto GM, Illanes SE. Pathogenesis of preeclampsia: the genetic component. J Pregnancy 2012;2012:632732.

6. Roberts JM, Escudero C. The placenta in pre- eclampsia. Pregnancy Hypertens 2012;2:72-83.

7. Svensson-Arvelund J, Ernerudh J, Buse E, Cline JM, Haeger JD, Dixon D, Markert UR, Pfarrer C, Vos PD, Faas MM. The Placenta in Toxicology. Part II: Systemic and Local Immune Adaptations in Pregnancy. Toxicol Pathol 2014;42:327-38.

8. Pijnenborg R, Bland JM, Robertson WB, Brosens I. Uteroplacental arterial changes related to interstitial trophoblast migration in early human pregnancy. Placenta 1983;4:397-413.

9. Zhou Y, Damsky CH, Fisher SJ. Pre- eclampsia is associated with failure of human cytotrophoblasts to mimic a vascular adhesion phenotype. One cause of defective endovascular invasion in this syndrome? J Clin Invest 1997;99:2152-64.

10. Pijnenborg R, Vercruysse L, Hanssens $M$. The uterine spiral arteries in human pregnancy: facts and controversies. Placenta 2006;27:939-58.

11. Lyall F. Mechanisms regulating cytotrophoblast invasion in normal pregnancy and pre-eclampsia. Aust $\mathrm{N}$ Z J Obstet Gynaecol 2006;46:266-273.

12. Taylor RN, Grimwood J, Taylor RS, McMaster MT, Fisher SJ, North RA. Longitudinal serum concentrations of placental growth factor: evidence for abnormal placental angiogenesis in pathologic pregnancies. Am J Obstet Gynecol 2003;188:177-82.

13. Nadar SK, Karalis I, Al Yemeni E, Blann AD, Lip GY. Plasma markers of angiogenesis in pregnancy induced hypertension. Thromb Haemost 2005;94:1071-6.

14. Sargent IL, Germain SJ, Sacks GP, Kumar S, Redman CW. Trophoblast deportation and the maternal inflammatory response in pre- eclampsia. J Reprod Immunol 2003;59:153-60.

15. Barden A, Ritchie J, Walters B, Michael C, Rivera J, Mori T, Croft K, Beilin L. Study of plasma factors associated with neutrophil activation and lipid peroxidation in pre- eclampsia. Hypertension 2001;38:803-8.

16. Vince GS, Starkey PM, Austgulen R, Kwiatkowski D, Redman CW. Interleukin-6, tumour necrosis factor and soluble tumour necrosis factor receptors in women with pre- eclampsia. Br J Obstet Gynaecol 1995;102:20-5.

17. Jonsson Y, Rubèr M, Matthiesen L, Berg G, Nieminen K, Sharma S, Ernerudh J, Ekerfelt C. Cytokine mapping of sera from women with pre- eclampsia and normal pregnancies. J Reprod Immunol 2006;70:83-91.

18. Levine RJ, Lam C, Qian C, Yu KF, Maynard SE, Sachs BP, Sibal BM, Epstein FH, Romero R, Thadhani R, et al. CPEP Study Group. Soluble endoglin and other circulating antiangiogenic factors in pre- eclampsia. N Engl J Med 2006;355:992-1005.

19. Thadhani R, Mutter WP, Wolf M, Levine RJ, Taylor RN, Sukhatme VP, Ecker J, Karumanchi SA. First trimester placental growth factor and soluble fms-like tyrosine kinase 1 and risk for pre- eclampsia. J Clin Endocrinol Metab 2004;89:770-5.

20. Spinnato JA, Livingston JC. Prevention of pre- eclampsia with antioxidants: evidence from randomized trials. Clin Obstet Gynecol 2005;48:416-29.

21. Teran E, Racines-Orbe M, Vivero S, Escudero C, Molina G, Calle A. Pre- eclampsia is associated with a decrease in plasma coenzyme $\mathrm{Q}_{10}$ levels. Free Radic Biol Med 2003;35:1453-6. 
22. Brandt U, Okun JG. Role of deprotonation events in ubihydroquinone: cytochrome c oxidoreductase from bovine heart and yeast mitochondria. Biochemistry 1997;36:11234-40.

23. Teran E, Vivero S, Racines-Orbe M, Castellanos A, Chuncha G, Enriquez G, Moya W. Coenzyme $Q_{10}$ is increased in placenta and cord blood during pre- eclampsia. Biofactors 2005;25:153-8.

24. Park CW, Park JS, Shim SS, Jun JK, Yoon BH, Romero R. An elevated maternal plasma, but not amniotic fluid, soluble fms-like tyrosine kinase- 1 (sFlt-1) at the time of mid-trimester genetic amniocentesis is a risk factor for pre- eclampsia. Am J Obstet Gynecol 2005;193:984-89.

25. Woolcock J, Hennessy A, Xu B, Thornton C, Tooher J, Makris A, Ogle R. Soluble Flt-1 as a diagnostic marker of pre- eclampsia. Aust N Z J Obstet Gynaecol 2008;48:64-70.

26. Shibata E, Rajakumar A, Powers RW, Larkin RW, Gilmour C, Bodnar LM, Crombleholme WR, Ness RB, Roberts JM, Hubel CA. Soluble fms-like tyrosine kinase 1 is increased in pre- eclampsia but not in normotensive pregnancies with small-for-gestational-age neonates: relationship to circulating placental growth factor. J Clin Endocrinol Metab 2005;90:4895-903.

27. Palei AC, Spradley FT, Warrington JP, George EM, Granger JP. Pathophysiology of hypertension in preeclampsia: a lesson in integrative physiology. Acta Physiol (Oxf) 2013;208:224-33.

28. Vatish M, Randeva HS, Grammatopoulos DK. Hormonal regulation of placental nitric oxide and pathogenesis of pre-eclampsia. Trends Mol Med 2006;12:223-33.

29. Bachetti T, Comini L, Curello S, Bastianon D, Palmieri M, Bresciani G, Callea F, Ferrari R. Coexpression and modulation of neuronal and endothelial nitric oxide synthase in human endothelial cells. J Mol Cell Cardiol 2004;37:939-45.

30. Many A, Hubel CA, Fisher SJ, Roberts JM, Zhou Y. Invasive cytotrophoblasts manifest evidence of oxidative stress in pre- eclampsia. Am J Pathol 2000;156:321-31.

31. Teran E, Escudero C, Calle A. Endothelial dysfunction and pre- eclampsia. Am J Hypertens 2007;20:1026-7.

32. Gilbert JS, Ryan MJ, LaMarca BB, Sedeek M, Murphy SR, Granger JP. Pathophysiology of hypertension during pre- eclampsia: linking placental ischemia with endothelial dysfunction. Am J Physiol Heart Circ Physiol 2008;294:H541-50.

33. Teran E, Escudero C, Vivero S, Molina G, Calle A. NO in early pregnancy and development of pre- eclampsia. Hypertension 2006;47:e17.

34. Williams PJ, Morgan L. The role of genetics in pre-eclampsia and potential pharmacogenomic interventions. Pharmgenomics Pers Med 2012;5:37-51.

35. Mutze S, Rudnik-Schoneborn S, Zerres K, Rath W. Genes and the pre- eclampsia syndrome. J Perinat Med 2008;36:38-58.

36. El-Sherbiny WS, Nasr AS, Soliman A. Endothelial nitric oxide synthase (eNOS) (Glu298Asp) and urotensin II (UTS2 S89N) gene polymorphisms in pre- eclampsia: prediction and correlation with severity in Egyptian females. Hypertens Pregnancy 2013;32:292-303.

37. Groten T, Schleussner E, Lehmann T, Reister F, Holzer B, Danso KA, Zeillinger R. eNOSI4 and EPHX1 polymorphisms affect maternal susceptibility to pre- eclampsia: analysis of five polymorphisms predisposing to cardiovascular disease in 279 Caucasian and 241 African women. Arch Gynecol Obstet 2014;289:581-93.

38. Barbosa PR, Stabler SP, Machado AL, Braga RC, Hirata RD, Hirata MH, Sampaio-Neto LF, Allen RH, Guerra-Shinohara EM. Association between decreased vitamin levels and MTHFR, MTR and MTRR gene polymorphisms as determinants for elevated total homocysteine concentrations in pregnant women. Eur J Clin Nutr 2008;62:1010-21.

39. Klai S, Fekih-Mrissa N, El Housaini S, Kaabechi N, Nsiri B, Rachdi R, Gritli N. Association of MTHFR A1298C polymorphism (but not of MTHFR C677T) with elevated homocysteine levels and placental vasculopathies. Blood Coagul Fibrinolysis 2011;22:374-8.

40. Frosst P, Blom HJ, Milos R, Goyette P, Sheppard CA, Matthews RG, Boers GJ, den Heijer M, Kluijtmans LA, van den Heuvel LP et al. A candidate genetic risk factor for vascular disease: a common mutation in methylenetetrahydrofolate reductase. Nat Genet 1995;10:111-3. 
41. van der Put NM, Gabreëls F, Stevens EM, Smeitink JA, Trijbels FJ, Eskes TK, van den Heuvel LP, Blom HJ. A second common mutation in the methylenetetrahydrofolate reductase gene: an additional risk factor for neural-tube defects? Am J Hum Genet 1998;62:1044-51. 


\section{CHAPTER 2}

\section{Vascular homeostasis affected during pre- eclampsia: increased anti-angiogenesis}

Increased plasma soluble fms-like tyrosine kinase 1 and endoglin levels in pregnancies complicated with pre-eclampsia.

Chedraui P, Lockwood CJ, Schatz F, Buchwalder LF, Schwager G, Guerrero C, Escobar GS, Hidalgo L.

J Matern Fetal Neonatal Med 2009;22:565-70. 


\section{ABSTRACT}

Background: Increased maternal plasma levels of proinflammatory cytokines as well as the anti-angiogenic agents soluble fms-like tyrosine kinase 1 (sFlt-1) and endoglin (sEng) are associated with promoting vascular dysfunction leading to the maternal syndrome of pre- eclampsia.

Objective and method: Nulliparous women complicated with pre- eclampsia $(n=29)$ and their corresponding controls $(n=29)$ delivering at the Enrique C. Sotomayor Obstetrics and Gynecology Hospital, Guayaquil-Ecuador were requested to participate in a study evaluating plasma levels of soluble anti-angiogenic factors (sFlt-1 and sEng) and pro-inflammatory cytokines: interleukin 6 (IL-6), interleukin 8 (IL-8), granulocyte colony stimulating factor (G-CSF), and tumor necrosis factor-alpha (TNF- $\alpha$ ). Maternal and neonatal data were also assessed and compared among the study groups.

Results: No significant differences in either maternal baseline or delivery characteristics were observed among the study groups. Compared with controls, preeclamptic women exhibited higher plasma levels of sFlt-1 (19.0 $\pm 15.1 \mathrm{vs} .12 \pm 8.3 \mathrm{ng} / \mathrm{mL})$ and of sEng $(20.4 \pm 9.9$ vs. $15.9 \pm 9.4 \mathrm{ng} / \mathrm{mL})$; respectively, $p<0.05$. Women with severe disease displayed higher sFlt-1 and sEng levels when compared with mild ones (34.5 \pm 11.6 vs. $9.5 \pm 1.6 \mathrm{ng} / \mathrm{mL}$, and $29.5 \pm 9.0$ vs. $14.8 .+5.2 \mathrm{ng} / \mathrm{mL}$, respectively; $p<0.001)$. In contrast, women with pre- eclampsia exhibited significant lower IL-8 and G-CSF levels compared with controls. No differences existed between either group in IL-6 levels or TNF- $\alpha$.

Conclusion: Consistent with previous reports, increased sFlt-1 and Eng levels in maternal plasma is consistent with vascular dysfunction found in gestations complicated with pre- eclampsia.

Keywords: Pre- eclampsia, sFlt-1, endoglin, vascular dysfunction, cytokines 


\section{INTRODUCTION}

Pre- eclampsia is the most common disorder of pregnancy complicating an estimated $7 \%$ of all pregnancies worldwide. Despite numerous studies and attempts at intervention, pre- eclampsia remains a leading cause of maternal and fetal morbidity and mortality in both developed and developing countries [1-5]. Reduced placental perfusion at early stages of pregnancy is a key event in the development of this disorder [6,7]. Defective trophoblastic invasion of the uterine spiral-arteries and arterioles leads to incomplete vascular remodeling and impaired utero-placental blood flow. Consequently, the placenta becomes ischemic and hypoxic and secretes into the maternal plasma an array of factors that are implicated in inducing generalized endothelial cell activation and vascular dysfunction that elicit the maternal syndrome [8,9]. Although the exact mechanisms involved remain unclear, vascular dysfunction found in pre- eclampsia is likely to be a consequence of reduced maternal circulating angiogenic factors [10-13] and increased levels of placental debris [14,15], reactive oxygen species [16,17], proinflammatory cytokines [tumor necrosis factor-alpha (TNF- $\alpha$ ), interleukin 6 (IL-6) and interleukin 8 (IL-8)] [18-21] and anti-angiogenic factors [22-24].

Soluble receptor fms-like tyrosine kinase 1 (sFlt-1) and soluble endoglin (sEng) are potent anti- angiogenic factors that are elevated in the plasma of women experiencing pre- eclampsia $[25,26]$. Increased levels of these factors are thought to contribute to maternal vascular dysfunction by binding to and thus reducing circulating levels of free vascular endothelial growth factor (VEGF) and placental growth factor (PLGF) [27]. The aim of the present study was to compare levels of soluble anti- angiogenic factors and pro-inflammatory cytokines in the plasma obtained from women suffering with preeclampsia versus gestational matched control plasma samples.

\section{MATERIALS AND METHODS}

\section{Participants and study design}

This study represents a preliminary collaboration between the Institute of Biomedicine of the Medical Faculty, Universidad Católica, Guayaquil Ecuador (through its teaching facility the Enrique C. Sotomayor Gynecology and Obstetrics Hospital) and the Department of Obstetrics, Gynecology and Reproductive Sciences of Yale University School of Medicine, New Haven, Connecticut, USA. Sotomayor Hospital is a major referral center providing maternal/neonatal healthcare to the low income population of Guayaquil, Ecuador. It has the highest delivery rate in Latin America ( $>30,000$ per year) concomitant with increased rates of high risk pregnancies [28-30]. For this study, nulliparous women with a singleton gestation fulfilling pree- clampsia criteria admitted for delivery to the High Risk Pregnancy, Labor and Delivery Unit were recruited $(n=29)$. Normal 
pregnant women $(n=29)$ delivering in the low risk Unit served as controls (matched for maternal and gestational age). All participants were recruited after signing informed consent of participation. Women with known medical disorders and on any medication before hospital admission (particularly non-steroidal anti-inflammatory drugs) were excluded from the study.

The diagnosis of pre- eclampsia depended on blood pressure $\geq 140 / 90 \mathrm{mmHg}$ on at least two occasions $6 \mathrm{~h}$ apart associated with proteinuria greater than $\mathrm{pp}$ as assessed by dipstick (>300 mg/dL) on two occasions 4-24 h apart [31]. Severity of pre- eclampsia was classified as mild or severe [32]. All preeclamptic women were previously normotensive at the time they became pregnant. Upon hospital admission, a $5 \mathrm{cc}$ blood sample was taken from the antecubital vein of each subject and collected in tubes containing EDTA, which were centrifuged at $3000 \mathrm{rpm}$ at $6^{\circ} \mathrm{C}$ for $20 \mathrm{~min}$. The riesling plasma and cell layers were aliquoted into several micro centrifuge tubes, which were frozen and stored at $-70^{\circ} \mathrm{C}$ until further analysis.

Maternal and neonatal data were recorded on a data sheet upon admission and included: maternal age, blood pressure and dipstick scores, neonatal gestational age and birthweight and route of delivery. The research study protocol was approved by the Institutional Review Board of the Enrique C. Sotomayor Hospital.

\section{Biochemical assays}

Commercial ELISA kits (Quantikine assays by R\&D Systems, Minneapolis, MN) were used to measure immunoreactive levels of human sFlt-1, sEng and IL-6 in the plasma according to instructions provided by the manufacturer. The sFlt-1 assay has a sensitivity of 5.0 $\mathrm{pg} / \mathrm{mL}$, and intra-assay and interassay coefficients of variation of $3.3 \%$ and $7.6 \%$, respectively. The endoglin assay has a sensitivity of $0.007 \mathrm{ng} / \mathrm{mL}$, and intra-assay and inter-assay coefficients of variation of $3.0 \%$ and $6.5 \%$, respectively. The IL- 6 assay has a sensitivity of $0.70 \mathrm{pg} / \mathrm{mL}$, and intra-assay and inter-assay coefficients of variation of $2.6 \%$ and $4.5 \%$, respectively.

A commercial multiplexable bead assay was used to measure the levels of immunoreactive human IL-8, G-CSF, and TNF- $\alpha$ (Bio-Plex cytokine panel; Bio-Rad Laboratories, Hercules, CA). The assay system for IL-8 has a sensitivity of $0.5 \mathrm{pg} / \mathrm{mL}$, intraassay and inter-assay coefficients of variation of $4.0 \%$ and $9.1 \%$, and percent recovery of $92 \%$. The assay system for G-CSF has a sensitivity of $1.1 \mathrm{pg} / \mathrm{mL}$, intra-assay and inter-assay coefficients of variation of $3.5 \%$ and $6.3 \%$, and percent recovery of $99 \%$. The assay system for TNF- $\alpha$ has a sensitivity of $3.0 \mathrm{pg} / \mathrm{mL}$, intra-assay and inter-assay coefficients of variation of $5.0 \%$ and $9.4 \%$, and percent recovery of $98 \%$. 


\section{Statistical analysis}

Statistical analysis was performed using SPSS software (SigmaStat version 3.0 for windows, Chicago Illinois, USA). Data are presented as mean + standard deviation (SD) and percentages (\%). Comparison of means and percentages was performed using the Mann-Whitney $t$-test and the chi-square test, respectively. A $p$-value of $<0.05$ was considered to be statistically significant.

\section{RESULTS}

For this study, a total of 58 nulliparous women were recruited. These included 29 complicated with pre- eclampsia and 29 controls matched for maternal and gestational age. Among preeclamptic women, severe disease was observed in $17 \%(n=5)$, moderate disease in $21 \%(n=6)$ and mild disease in $62 \%(n=18)$. Baseline and delivery characteristics as well as plasma concentrations of sFlt-1, sEng, IL-6, IL-8, G-CSF and TNF- $\alpha$, of the studied subjects are depicted in Table I. No significant differences were found among the various groups in relation to maternal age, body mass index (BMI), income, educational level and delivery characteristics (neonatal gestational age, weight and cesarean section rate).

Compared with controls, matched for maternal and gestational age, preeclamptic women exhibited significantly higher plasma levels of sFlt-1 and sEng (Table I). Furthermore, within the preeclamptic group, the severe cases $(n=11)$ were significantly higher than the mild cases $(n=18)$ for levels of sFlt-1 (34.5 $\pm 11.6 \mathrm{vs} .9 .5 \pm 1.6 \mathrm{ng} / \mathrm{mL}$, respectively; mean $\pm \mathrm{SD}, p<0.001)$ and SEng $(29.5 \pm 9.0 \mathrm{vs}$. $14.8 . \pm 5.2 \mathrm{ng} / \mathrm{mL}$, respectively; mean \pm S.D., $p<0.001$ ) (Figure 1). In contrast, compared with controls, women with pre- eclampsia exhibited significantly lower plasma levels of IL-8 and of G-CSF levels (Table I). No significant differences between cases and controls were detected either in IL-6 or in TNF- $\alpha$ levels (Table I). Within the preeclamptic group, there were no significant differences between moderate-severe cases and mild cases for either IL-6, IL-8, GCSF, or TNF- $\alpha$.

\section{DISCUSSION}

Maternal-fetal interactions create a mild systemic inflammatory state exemplified by activation of both vascular endothelium and leukocytes that is most apparent in the third trimester of uncomplicated human pregnancies [33]. A further increase in systemic inflammation occurs in pre- eclampsia [33], which complicates about 7\% of all pregnancies and is associated with a significantly increased risk for adverse maternal-fetal outcomes $[1,5]$. The initiation of most cases of pre- eclampsia has been related to shal- 
low extravillous trophoblast invasion of the decidua and the resulting incomplete remodeling of the spiral arteries and arterioles $[6,8]$. However, the signs and symptoms of pre- eclampsia generally become apparent later in pregnancy usually in the third trimester [1] prompting significant investigation into identifying early biomarkers that could disclose those women that are likely to or even destined to develop pre- eclampsia.

Several studies have observed a positive correlation between the onset of systemic vascular dysfunction leading to the maternal syndrome of pre- eclampsia with a reciprocal reduction in circulating levels of the angiogenic factors, PLGF and VEGF [10-13] and increased levels of anti-angiogenic factors [26,34]. Elevated plasma anti-angiogenic factors (sFlt-1 and sEng) appear to bind to and lower VEGF and PLGF levels in the maternal plasma $[26,34]$. The resulting anti-angiogenic milieu is implicated in inducing systemic vascular damage, particularly as a target the kidney to induce hypertension and proteinuria of the maternal syndrome of pre- eclampsia [1].

Table I. Demographics, delivery characteristics and plasma analyte concentrations among studied women.

\begin{tabular}{|c|c|c|c|}
\hline Variables & Pre- eclampsia $(n=29)$ & Control $(n=29)$ & $p$-value* \\
\hline \multicolumn{4}{|l|}{ Baseline maternal characteristics } \\
\hline Age (years) & $20.4 \pm 4.5^{+}$ & $20.6 \pm 4.2$ & NS \\
\hline $\mathrm{BMI}\left(\mathrm{kg} / \mathrm{m}^{2}\right)$ & $28.2 \pm 3.3$ & $27.4 \pm 5.9$ & NS \\
\hline Family income (\$US/month) & $128.8 \pm 43.1$ & $168.0 \pm 99.8$ & 0.05 \\
\hline Educational level (years) & $10.0 \pm 3.9$ & $9.9 \pm 3.5$ & NS \\
\hline Number of antenatal visits & $6.6 \pm 2.4$ & $6.3 \pm 2.2$ & NS \\
\hline Systolic blood pressure (mmHg) & $146 \pm 10$ & $109 \pm 11$ & $<0.001$ \\
\hline Diastolic blood pressure (mmHg) & $94 \pm 9$ & $71 \pm 6$ & $<0.001$ \\
\hline Dipstick protein (range) & $2(1-3)$ & $0(0-0)$ & \\
\hline \multicolumn{4}{|l|}{ Delivery characteristics } \\
\hline Gestational age (weeks) & $38.8 \pm 1.1$ & $38.6 \pm 1.5$ & NS \\
\hline Neonatal birth weight (g) & $3,058 \pm 427$ & $2,859 \pm 765$ & NS \\
\hline Cesarean delivery (\%) & $18(62)$ & $16(55.1)$ & NS \\
\hline \multicolumn{4}{|l|}{ Plasma analyte concentration } \\
\hline sFlt-1 (ng/mL) & $19.0 \pm 15.1$ & $12.0 \pm 8.3$ & 0.020 \\
\hline Endoglin (ng/mL) & $20.4 \pm 9.9$ & $15.9 \pm 9.4$ & 0.021 \\
\hline G-CSF (pg/mL) & $30.9 \pm 18.8$ & $64.6 \pm 49.5$ & 0.015 \\
\hline $\mathrm{IL}-8(\mathrm{pg} / \mathrm{mL})$ & $140.4 \pm 112.6$ & $180.1 \pm 82.6$ & 0.021 \\
\hline IL-6 (pg/mL) & $20.8 \pm 20.8$ & $32.7 \pm 32.7$ & NS \\
\hline TNF- $\alpha(p g / m L)$ & $65.6 \pm 29.9$ & $111.3 \pm 173.2$ & NS \\
\hline
\end{tabular}

BMI, body mass index; sFlt-1, soluble fms-like tyrosine kinase 1; G-CSF, granulocyte colony stimulating factor; IL-8, interleukin-8; IL-6, interleukin-6; TNF- $\alpha$, tumor necrosis factor alpha.

*Difference analyzed with Mann-Whitney $t$-test or chi-square test according to the case.

†Mean \pm SD. 


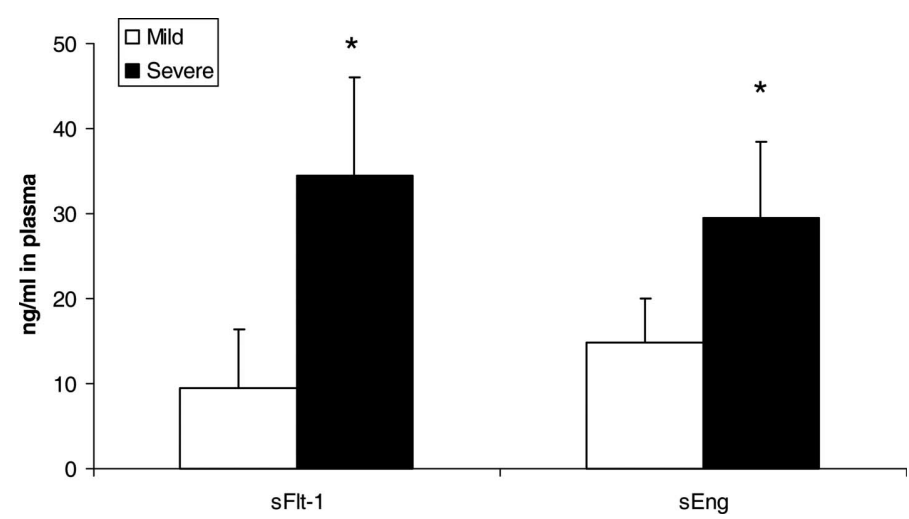

Figure 1. Comparison of sFlt-1 and sEng levels according to pre- eclampsia severity.

The increase in plasma levels of sFlt-1 and sEng in preeclamptic Ecuadorian women evaluated in the current study corresponds to reports in the literature for other populations of women that is consistent with the systemic anti-angiogenic milieu of pre- eclampsia $[15,22,23]$. However, unlike several reports indicating a pre- eclampsia-related elevation in plasma IL-8, G-CSF and IL-6 levels, the current study found that the plasma of preeclamptic Ecuadorian women contained lower IL-8 and G-CSF levels and similar IL6 and TNF- $\alpha$ plasma levels compared with control women. These observations appear to contradict the general concept of pre- eclampsia as a systemic inflammatory state [33] since IL-8 and G-CSF are primarily involved in promoting acute inflammation via neutrophil recruitment and activation [35] and IL-6 helps to mediate the transition between acute and chronic inflammation via reciprocal inhibitory effects on neutrophils and stimulatory effects on monocytes/macrophages [36]. The solution to this apparent contradictory finding may lie in a fundamental difference between the patient population generally available in the USA and most European countries versus that recruited in the current study from Ecuador.

In developed countries such as the USA and most European countries, early diagnosis of the maternal syndrome prompts preterm delivery of the placenta to avoid maternal-fetal complications. In contrast, at Sotomayor Hospital, preeclamptic patients are more often seen and diagnosed at term. The resulting unfortunate delayed early detection of pre- eclampsia is directly related to the reality that $75.5 \%$ of women delivering at Sotomayor Hospital have inadequate prenatal care associated with higher parity, rural residency and general poverty conditions [29]. A direct consequence of this distinction is that published analytical results from preeclamptic and corresponding control plasmas tend to reflect preterm samples in developed countries and term samples in underdeveloped countries. The current results suggest for the first time that the antiangiogenic factors, but not pro-inflammatory cytokines, are maintained at elevated levels in preeclamptic plasma up through the time of delivery at term. 
In summary, the current study confirms previous reports that the anti-angiogenic factors s-Flt1 and sEng are elevated in the plasma of preeclamptic women, and in those with moderate-severe disease. However, unlike several published studies, which have found elevated circulating levels of the proinflammatory cytokines G-CSF, IL-8, IL-6 in preeclamptic specimens, the current study detected lower levels of G-CSF and IL-8 and equivalent IL- 6 and TNF- $\alpha$ levels in plasma of preeclamptic versus control women. These differential results likely reflect a fundamental difference between gestational age at the time of collection of the specimens (i.e. specimens derived from most published studies are pre-term, whereas those from the patient population of Sotomayor Hospital are term). Recent comparisons between preeclamptic and control patients from Sotomayor Hospital found significant differences between the groups in plasma nitric oxide levels [13] and in plasma levels and placental production of Co-enzyme $\mathrm{Q}_{10}$ [12], which have been implicated in the pathogenesis of pre- eclampsia as abnormally secreted angiogenic factors $[10,11]$.

Future studies aimed at obtaining complementary measurements of these endpoints as well as other pre- eclampsia-related biomarkers between the conventional patient and control populations in developed countries and those in underdeveloped countries as exemplified by patients from Sotomayor Hospital may well yield important information in elucidating mechanisms underlying the pathogenesis of pre- eclampsia.

\section{ACKNOWLEDGMENTS}

This research was supported by the Department of Obstetrics, Gynecology and Reproductive Sciences, Yale University School of Medicine, New Haven, Connecticut, USA. 


\section{REFERENCES}

1. Sibai BM, Dekker G, Kupferminic M. Pre-eclampsia. Lancet 2005;365:785-799.

2. Duley L. Maternal mortality associated with hypertensive disorders of pregnancy in Africa, Asia, Latin America and the Caribbean. Br J Obstet Gynaecol 1992;99:547-553.

3. Khan KS, Wojdyla D, Say L, Gulmezoglu AM, Van Look PF. WHO analysis of causes of maternal death: a systematic review. Lancet 2006;367:1066-1074.

4. Lee W, O'Connell CM, Baskett TF. Maternal and perinatal outcomes of eclampsia: Nova Scotia, 19812000. J Obstet Gynaecol Can 2004;26:119-123.

5. Yucesoy G, Ozkan S, Bodur H, Tan T, Caliskan E, Vural B, Corakci A. Maternal and perinatal outcome in pregnancies complicated with hypertensive disorder of pregnancy: a seven year experience of a tertiary care center. Arch Gynecol Obstet 2005;273:43-49.

6. Pijnenborg R, Bland JM, Robertson WB, Brosens I. Uteroplacental arterial changes related to interstitial trophoblast migration in early human pregnancy. Placenta 1983;4:397-413. 7. Zhou Y, Damsky CH, Fisher SJ. Pre- eclampsia is associated with failure of human cytotrophoblasts to mimic a vascular adhesion phenotype. One cause of defective endovascular invasion in this syndrome? J Clin Invest 1997;99:21522164.

8. Pijnenborg R, Vercruysse L, Hanssens $M$. The uterine spiral arteries in human pregnancy: facts and controversies. Placenta 2006;27:939-958.

9. Lyall F. Mechanisms regulating cytotrophoblast invasion in normal pregnancy and pre-eclampsia. Aust $\mathrm{N}$ Z J Obstet Gynaecol 2006;46:266-273.

10. Taylor RN, Grimwood J, Taylor RS, McMaster MT, Fisher SJ, North RA. Longitudinal serum concentrations of placental growth factor: evidence for abnormal placental angiogenesis in pathologic pregnancies. Am J Obstet Gynecol 2003;188:177-182.

11. Nadar SK, Karalis I, Al Yemeni E, Blann AD, Lip GY. Plasma markers of angiogenesis in pregnancy induced hypertension. Thromb Haemost 2005;94:1071-1076.

12. Teran E, Chedraui P, Racines-Orbea M, Vivero S, Villena F, Duchicela F, Nacevilla L, Schwager G, Calle A. Coenzyme $\mathrm{Q}_{10}$ levels in women with pre- eclampsia living at different altitudes. Biofactors 2008;32:185190.

13. Teran E, Chedraui P, Vivero S, Villena F, Duchicela F, Nacevilla L. Plasma and placental nitric oxide levels during normal pregnancy and pre- eclampsia in women living at different altitude. Int J Gynaecol Obstet 2009;104:140-142.

14. Sargent IL, Germain SJ, Sacks GP, Kumar S, Redman CW. Trophoblast deportation and the maternal inflammatory response in pre- eclampsia. J Reprod Immunol 2003;59:153-160.

15. Levine RJ, Qian C, Leshane ES, Yu KF, England LJ, Schisterman EF, Wataganara T, Romero R, Bianchi DW. Two-stage elevation of cellfree fetal DNA in maternal sera before onset of pre- eclampsia. Am J Obstet Gynecol 2004;190:707-713.

16. Barden A, Ritchie J, Walters B, Michael C, Rivera J, Mori T, Croft K, Beilin L. Study of plasma factors associated with neutrophil activation and lipid peroxidation in pre- eclampsia. Hypertension 2001;38:803-808.

17. Hubel CA, McLaughlin MK, Evans RW, Hauth BA, Sims CJ, Roberts JM. Fasting serum triglycerides, free fatty acids, and malondialdehyde are increased in pre- eclampsia, are positively correlated, and decrease within 48 hours post partum. Am J Obstet Gynecol 1996;174:975-982.

18. Vince GS, Starkey PM, Austgulen R, Kwiatkowski D, Redman CW. Interleukin-6, tumour necrosis factor and soluble tumour necrosis factor receptors in women with pre- eclampsia. Br J Obstet Gynaecol 1995;102:20-25.

19. Madazli R, Aydin S, Uludag S, Vildan O, Tolun N. Maternal plasma levels of cytokines in normal and preeclamptic pregnancies and their relationship with diastolic blood pressure and fibronectin levels. Acta Obstet Gynecol Scand 2003;82:797-802. 
20. Benyo DF, Smarason A, Redman CW, Sims C, Conrad KP. Expression of inflammatory cytokines in placentas from women with pre- eclampsia. J Clin Endocrinol Metab 2001;86:2505-2512.

21. Jonsson Y, Rubér M, Matthiesen L, Berg G, Nieminen K, Sharma S, Ernerudh J, Ekerfelt C. Cytokine mapping of sera from women with pre- eclampsia and normal pregnancies. J Reprod Immunol 2006;70:8391.

22. Thadhani R, Mutter WP, Wolf M, Levine RJ, Taylor RN, Sukhatme VP, Ecker J, Karumanchi SA. First trimester placental growth factor and soluble fms-like tyrosine kinase 1 and risk for pre- eclampsia. J Clin Endocrinol Metab 2004;89:770-775.

23. Chaiworapongsa T, Romero R, Kim YM, Kim GJ, Kim MR, Espinoza J, Bujold E, Goncalves L, Gomez R, Edwin $S$, et al. Plasma soluble vascular endothelial growth factor receptor-1 concentration is elevated prior to the clinical diagnosis of pre- eclampsia. J Matern Fetal Neonatal Med 2005;17:3-18.

24. Levine RJ, Lam C, Qian C, Yu KF, Maynard SE, Sachs BP, Sibal BM, Epstein FH, Romero R, Thadhani R, et al. CPEP Study Group. Soluble endoglin and other circulating anti- angiogenic factors in pre- eclampsia. N Engl J Med 2006;355:992-1005.

25. Park CW, Park JS, Shim SS, Jun JK, Yoon BH, Romero R. An elevated maternal plasma, but not amniotic fluid, soluble fms-like tyrosine kinase-1 (sFlt-1) at the time of mid-trimester genetic amniocentesis is a risk factor for pre- eclampsia. Am J Obstet Gynecol 2005;193:984-989.

26. Woolcock J, Hennessy A, Xu B, Thornton C, Tooher J, Makris A, Ogle R. Soluble Flt-1 as a diagnostic marker of pre- eclampsia. Aust N Z J Obstet Gynaecol 2008;48:64-70.

27. Shibata E, Rajakumar A, Powers RW, Larkin RW, Gilmour C, Bodnar LM, Crombleholme WR, Ness RB, Roberts JM, Hubel CA. Soluble fms-like tyrosine kinase 1 is increased in pre- eclampsia but not in normotensive pregnancies with small-for-gestational-age neonates: relationship to circulating placental growth factor. J Clin Endocrinol Metab 2005;90:4895-4903.

28. Hidalgo LA, Chedraui PA, Chavez MJ. Obstetrical and neonatal outcome in young adolescents of low socio- economic status: a case control study. Arch Gynecol Obstet 2005;271:207-211.

29. Paredes I, Hidalgo L, Chedraui P, Palma J, Eugenio J. Factors associated with inadequate prenatal care in Ecuadorian women. Int J Gynaecol Obstet 2005;88:168-172.

30. Chedraui PA, Hidalgo LA, Chavez MJ, San Miguel G. Determinant factors in Ecuador related to pregnancy among adolescents aged 15 or less. J Perinat Med 2004;32:337-341.

31. Schroeder BM. ACOG practice bulletin on diagnosing and managing pre- eclampsia and eclampsia. American College of Obstetricians and Gynecologists. Am Fam Physician 2002;66:330-331.

32. Buhimschi IA, Zhao G, Funai EF, Harris N, Sasson IE, Bernstein IM, Saade GR, Buhimschi CS. Proteomic profiling of urine identifies specific fragments of SERPINA1 and albumin as biomarkers of pre- eclampsia. Am J Obstet Gynecol 2008;199:551.e1-16.

33. Redman CW, Sargent IL. Pre-eclampsia, the placenta and the maternal systemic inflammatory response - a review. Placenta 2003;24:S21-S27.

34. Gu Y, Lewis DF, Wang Y. Placental productions and expressions of soluble endoglin, soluble fms-like tyrosine kinase receptor-1, and placental growth factor in normal and preeclamptic pregnancies. J Clin Endocrinol Metab 2008;93:260-266.

35. Mitchell GB, Albright BN, Caswell JL. Effect of interleukin-8 and granulocyte colony-stimulating factor on priming and activation of bovine neutrophils. Infect Immun 2003;71: 1643-1649.

36. Jones SA. Directing transition from innate to acquired immunity: defining a role for IL-6. J Immunol 2005;175:3463-3468. 


\title{
CHAPTER 3
}

\author{
In pre- eclampsia there is more to \\ pathogenesis than vascular abnormalities: \\ decreased anti-oxidation
}

Coenzyme $Q_{10}$ levels in women with pre-eclampsia living at different altitudes.

Teran E, Chedraui P, Racines-Orbe M, Vivero S, Villena F, Duchicela F, Nacevilla L, Schwager $G$, Calle A.

Biofactors. 2008;32:185-90. 


\section{ABSTRACT}

Background: Pre- eclampsia is a common disorder of pregnancy exhibiting abnormal plasma and placental coenzyme $\mathrm{Q}_{10}\left(\mathrm{CoO}_{10}\right)$ levels when compared to normal pregnancies.

Objective: To evaluate $\mathrm{CoQ}_{10}$ levels both in plasma and placenta among normal pregnant $(n=60)$ and preeclamptic $(n=63)$ primigravid women and determine the effect of high or low altitude residency.

Study design: $\mathrm{CoQ}_{10}$ was determined using High Performance Liquid Chromatography (HPLC) technique and group comparisons were performed.

Results: Preeclamptic women living at high altitude displayed significantly lower $\mathrm{CoQ}_{10}$ plasma levels $(0.64 \pm 0.23$ vs. $0.82 \pm 0.46 \mu \mathrm{mol} / \mathrm{L}, p=0.05)$. No differences were found in $\mathrm{CoQ}_{10}$ plasma levels among women living at sea level. Interestingly, plasma $\mathrm{CoO}_{10}$ levels at low altitude in normal pregnancies were significantly lower than high altitude normal pregnancies. Compared to normal pregnancies, preeclamptic women displayed higher placental $\mathrm{CoQ}_{10}$ content, which was only significant among those living at sea level $(0.120 \pm 0.07$ vs. $0.076 \pm 0.04 \mathrm{ng} / \mathrm{mg}$ protein, $p<0.005)$. Normal pregnant women living at high altitude displayed higher placental $\mathrm{CoQ}_{10}$ content when compared to those residing at sea level $(p<0.0005)$.

Conclusion: Women suffering from pre- eclampsia (high or low altitude) display high placental $\mathrm{CoQ}_{10}$ content, with significant low plasma $\mathrm{CoQ}_{10}$ levels among those residing in high altitude. More research is warranted to establish the cause-effect relationship between $\mathrm{CoQ}_{10}$ levels and pre- eclampsia.

Keywords: Coenzyme $\mathrm{Q}_{10}$, pre- eclampsia, pregnancy, placenta, altitude 


\section{INTRODUCTION}

Pre- eclampsia is a common ( $7 \%$ of all pregnancies) disorder of human pregnancy in which the normal hemodynamic response to pregnancy is compromised. It remains a leading cause of maternal morbidity and mortality, associated with a significant increase in perinatal mortality [3].

Clinical symptoms of pre- eclampsia arise from secondary systemic circulatory disturbances; there is evidence suggesting that its diverse manifestations, including altered vascular reactivity, vasospasm and discrete pathology in many organic systems, are derived from pathological changes within the maternal vascular endothelium [5]. Those changes, in addition to increased hypoxic conditions and oxidative stress, cause maternal symptoms of hypertension, proteinuria, clotting and liver dysfunction.

A key event in the development of pre- eclampsia is the reduction of placental perfusion in the early stages of pregnancy, which is due to defective trophoblastic invasion of uterine spiral-artery-vessel walls, therefore leading to poor development of the immature placenta and its maternal blood supply. This reduced placental perfusion leads to generalized dysfunction of the maternal vascular endothelium by mechanisms that still remain to be elucidated [18]. However, among patients with pre- eclampsia, there is an observed increase in the rate of lipid peroxidation, increased lipid availability, and decrease of several antioxidants such as alpha tocopherol, ascorbate, beta carotene and selenium [12]. Moreover, a significant decrease in plasma coenzyme Q $10\left(\mathrm{CoQ}_{10}\right)$ in women with pre- eclampsia has recently been reported $[11,14]$.

Since $\mathrm{CoQ}_{10}$ is a part of the non-enzymatic defense system against oxygen species (antioxidative function) [7], playing a key role in mitochondrial complexes I and III reaction mechanisms (electron transport) [1], it seems to be logical to hypothesize a role for $\mathrm{CoQ}_{10}$ at the placental level. In this sense, we previously reported lower plasma and higher placental $\mathrm{CoQ}_{10}$ content among preeclamptic women living in Quito, Ecuador $(2,800 \mathrm{~m}$ above sea level) when compared to normal pregnancies [15]. On the other hand, it has recently been demonstrated that the number of uteroplacental vessels in low altitude placentas are significantly decreased compared to placentas at high altitude [16], a finding also reported in pre- eclampsia in which there were more uteroplacental arteries in placental bed biopsies from preeclamptic vs. uncomplicated pregnancies [13]. However, in normal pregnancies at sea level, significantly more arteries were remodeled per placenta than in normal pregnancies at high altitude [17]. Thus, the hypothesis that uteroplacental arterial remodeling would be reduced in high altitude pregnancy was supported, and the findings, as predicted, are intermediate between what is observed in pre- eclampsia and what is normal in healthy sea-level pregnancies [17]. Consistent with previous reports, uteroplacental arterial remodeling was not an 'all or none' phenomena at either high or low altitude [9], rather the proportion of arteries remodeled was reduced at high vs. moderate altitude. 
Thus, it can be hypothesized that $\mathrm{CoQ}_{10}$ content differs not only in pre- eclampsia, but also depends on women's altitude of residency. The aim of the present study was to evaluate the $\mathrm{CoQ}_{10}$ levels both in plasma and placenta among normal pregnant and preeclamptic women residing either at high or low altitude.

\section{PATIENTS AND METHODS}

This study was carried out after approval of the Bioethics Committee of the Biomedical Center, Universidad Central, Quito, Ecuador, in which normal pregnant ( $n=60)$ and preeclamptic ( $n=63$ ) primigravid women admitted to the "Hospital Gineco Obstétrico Isidro Ayora" in Quito, Ecuador and the "Hospital Gineco Obstétrico Enrique C. Sotomayor" in Guayaquil, Ecuador, were recruited after signing informed consent of participation. Out of a total of 123 pregnant women, 63 resided in Quito (2,800 m altitude) and 60 in Guayaquil (sea level). Women with a medical history of cardiovascular or gynecological problems, and on any medication (especially non steroidal antiinflammatory drugs) were excluded from the study. Women with pre- eclampsia registered blood pressures over 140/90 $\mathrm{mmHg}$ on at least two occasions 6 hours apart, and proteinuria greater than ++ as assessed by dipstick ( $>300 \mathrm{mg} / \mathrm{dL}$ ) on two occasions 4 to 24 hours apart. Blood pressure was measured as previously described [8]. For the measurement of $\mathrm{CoQ}_{10}$, a blood sample $(10 \mathrm{ml})$ was obtained from each woman the antecubital venous puncture site, and immediately transferred into a polypropylene vial containing $3.15 \%$ sodium citrate $(1: 9, \mathrm{v} / \mathrm{v})$. These samples were centrifuged at room temperature and $500 \mu \mathrm{l}$ plasma aliquots were frozen at $-40^{\circ} \mathrm{C}$. After delivery of the placenta, a sample (2-3 g) from the maternal side was obtained (any infracted area was avoided), washed twice with saline solution to remove the excess of blood, and transferred into a vial containing Krebs buffer solution. Measurement of $\mathrm{CoQ}_{10}$ content in placenta was carried out with approximately $100 \mathrm{mg}$ of freeze-clamped tissue accurately weighed in the frozen state and subsequently homogenized with $2 \mathrm{ml}$ of Krebs buffer in a glass homogenizer with a manual pestle, as described elsewhere [6]. Briefly, prior to homogenization, $50 \mu$ of ethanolic BHT (2,6-di-tert-butyl-p-cresol; Sigma Aldrich, MO, USA) was added to prevent lipid autoxidation without reducing the ubiquinones. After addition of $1 \mathrm{ml}$ of $0.1 \mathrm{M}$ aqueous sodium dodecyl sulphate (SDS; Sigma-Aldrich, MO, USA) and a brief mixing by homogenization, the sample was transferred to a $10 \mathrm{ml}$ test tube, fitted with a Teflon-lined screw cap. The homogenizer was rinsed with $2 \mathrm{ml}$ of reagent alcohol, which was combined with the homogenate. The mixture was vortexed for $30 \mathrm{~s}$, and $2 \mathrm{ml}$ of hexane (Merck, Darmstadt, Germany) was added, and the tightly screwed test tube was vigorously vortexed for $2 \mathrm{~min}$. It was then centrifuged for $5 \mathrm{~min}$ at $1,000 \mathrm{~g}$ to separate the layers. One milliliter of the hexane layer was transferred to a small vial and dried under nitrogen. The residue was redissolved in methanol/[ethanol/isopropanol 95/5, v/v] (1:1 v/v). Samples were analyzed immediately and 
kept on ice and covered with aluminum foil to prevent photodegradation of ubiquinones. $\mathrm{CoQ}_{10}$ was measured in a high performance liquid chromatography (HPLC) system (Perkin-Elmer, CN, USA) equipped with a Lichrosorb ${ }^{\circledR}$ RP18 (5 $\mu \mathrm{m}, 125 \times 4$ mm; Phenomenex, CA, USA) column and with a guard column (Merck, Darmstadt, Germany), as previously described [14]. Samples were measured in duplicates and the mean value was used for statistical analysis.

Data was analyzed using GraphPad InStat version 3.01 for Windows (GraphPad Software, CA) and presented as mean \pm standard deviations (S.D). Comparison of continuous data was performed with unpaired student T test. A $p$ value of $<0.05$ was considered as statistically significant.

\section{RESULTS}

Characteristics of women and neonates included in the study are presented in Table 1. Placental and neonatal weight at delivery from women with pre- eclampsia living in high altitude were found to be significantly lower. Preeclamptic women living at high altitude showed significantly lower $\mathrm{CoQ}_{10}$ plasma levels $(0.64 \pm 0.23$ vs. $0.82 \pm 0.46 \mu \mathrm{mol} / \mathrm{L}, p=$ $0.05)$. Contrarily, there were no differences in plasma $\mathrm{CoQ}_{10}$ levels among women living at sea level (normal: $0.50 \pm 0.18$ vs. pre- eclampsia: $0.51 \pm 0.19 \mu \mathrm{mol} / \mathrm{L}, p=N S$ ). Interestingly, plasma levels of $\mathrm{CoQ}_{10}$ in normal pregnant women living at sea level were significantly lower that those in normal pregnant women living at high altitude $(p=0.001)$ and comparable to those found in pre- eclampsia at high altitude ( $p=N S$, Fig. 1). Placental $\mathrm{CoQ}_{10}$ content was found to be significantly higher among preeclamptic women living at sea level compared to those with normal pregnancies $(0.120 \pm 0.07$ vs. $0.076 \pm$ $0.04 \mathrm{ng} / \mathrm{mg}$ protein, $p<0.005)$. The same trend was found among women living at high altitude although this was not found to be significant $(0.159 \pm 0.13$ vs. $0.135 \pm 0.07$ $\mathrm{ng} / \mathrm{mg}$ protein, $p=N S$ ). Although placental $\mathrm{CoQ}_{10}$ content was found to be significantly higher among normal pregnant women at high altitude compared to those residing at sea level $(p<0.0005)$, no differences were found among preeclamptic women, either at high altitude or sea level (Fig. 2).

\section{DISCUSSION}

Despite the limitations of this study (cross-sectional design and small sample size) it is the first to determine $\mathrm{CoQ}_{10}$ levels, both in plasma and placenta, simultaneously in pregnant women residing either at sea level or at high altitude. In preeclamptic women residing at high altitude, there were lower $\mathrm{CoQ}_{10}$ plasma levels when compared to normal pregnancies. However, it might be important to emphasize that this difference was still present, although plasma levels in normal pregnant women residing at high altitude 
in the present report were slightly lower than those previously reported [15]. It is possible that gestational age at which samples were taken was responsible for this difference (unpublished data). In the present series, there were unexpected findings, not only the absence of differences in $\mathrm{CoQ}_{10}$ plasma levels between normal pregnant and preeclamptic women living at sea level; also for the relatively low $\mathrm{CoQ}_{10}$ plasma levels found in normal pregnant women residing at sea level. The latest results, that is in clear discrepancy with previous reports in pregnant women living close to the sea level $[10,11]$, could not be interpreted without having the $\mathrm{CoQ}_{10}$ plasma levels in a group of Ecuadorian non-pregnant women residing at sea level, an additional control group not planned in this study. Contrarily to plasma levels, placental $\mathrm{CoQ}_{10}$ content appeared to be higher in preeclamptic women as compared to normal pregnancies, independently of the altitude of women's residency. This might be a surprising finding, as plasma concentrations of $\mathrm{CoQ}_{10}$ are significantly influenced by dietary uptake [19], while tissue levels of $\mathrm{CoQ}_{10}$ depend mainly on de novo synthesis [20]. Therefore, dietary $\mathrm{CoQ}_{10}$ concentrations could mask tissue deficiencies. On the other hand, it has been suggested that higher tissue concentrations of ubiquinone may be a result of a higher metabolic rate [2]. In this sense, higher placental $\mathrm{CoQ}_{10}$ contents were found among sea level residing Italian pregnant women with HELLP syndrome (a severe complication of preeclampsia) when compared to normal pregnancies, but plasma levels were not measured [4].

Table 1: Characteristics of gravids and neonates included in the study

\begin{tabular}{|c|c|c|c|c|c|c|}
\hline \multirow[t]{2}{*}{ Parameter } & \multirow[b]{2}{*}{$\begin{array}{c}\text { Normal } \\
n=60\end{array}$} & \multirow[b]{2}{*}{$\begin{array}{c}\text { PE } \\
n=63\end{array}$} & \multicolumn{2}{|c|}{ Quito } & \multicolumn{2}{|c|}{ Guayaquil } \\
\hline & & & $\begin{array}{c}\text { Normal } \\
n=30\end{array}$ & $\begin{array}{c}\text { PE } \\
n=33\end{array}$ & $\begin{array}{c}\text { Normal } \\
n=30\end{array}$ & $\begin{array}{c}\text { PE } \\
n=30\end{array}$ \\
\hline $\begin{array}{l}\text { Maternal age } \\
\text { (years) }\end{array}$ & $20.7 \pm 4.4^{a}$ & $20.6 \pm 4.4$ & $20.6 \pm 4.6$ & $20.6 \pm 4.4$ & $20.7 \pm 4.2$ & $20.6 \pm 4.5$ \\
\hline $\begin{array}{l}\text { Systolic blood } \\
\text { pressure }(\mathrm{mmHg})\end{array}$ & $110.2 \pm 9.3$ & $144.9 \pm 11^{b}$ & $110.7 \pm 6.8$ & $143.6 \pm 11.4^{b}$ & $109.7 \pm 11.3$ & $146.3 \pm 10.7^{b}$ \\
\hline $\begin{array}{l}\text { Diastolic blood } \\
\text { pressure }(\mathrm{mmHg})\end{array}$ & $96.8 \pm 10.5$ & $72.1 \pm 6.6^{b}$ & $73 \pm 7$ & $98.9 \pm 7^{b}$ & $71.3 \pm 6.2$ & $94.5 \pm 9.7^{b}$ \\
\hline $\begin{array}{l}\text { Neonatal } \\
\text { gestational age at } \\
\text { delivery (weeks) }\end{array}$ & $38.5 \pm 1.6$ & $38.6 \pm 1.3$ & $38.7 \pm 1.1$ & $38.2 \pm 1.9$ & $38.6 \pm 1.5$ & $38.8 \pm 1$ \\
\hline $\begin{array}{l}\text { Neonatal weight } \\
\text { at delivery (grs) }\end{array}$ & $2,980.8 \pm 597.8$ & $2,908.8 \pm 454.4$ & $3,097 \pm 364.7$ & $2,757.8 \pm 429.1^{b}$ & $2,864 \pm 752.2$ & $3,073 \pm 429 \cdot 1^{c}$ \\
\hline $\begin{array}{l}\text { Placental weight } \\
\text { (grs) }\end{array}$ & $576.4 \pm 98.5$ & $556 \pm 130.8$ & $580.1 \pm 98.5$ & $503.5 \pm 120.1^{b}$ & $572.6 \pm 100$ & $614 \pm 118^{c}$ \\
\hline
\end{tabular}

${ }^{\mathrm{a}}$ Mean \pm standard deviation; ${ }^{\mathrm{b}} p<0.05$ compared to normal gestations (non paired $t$ student's test); PE: preeclampsia; ${ }^{c} p<0.05$ compared to PE or normal gestations from Quito. 


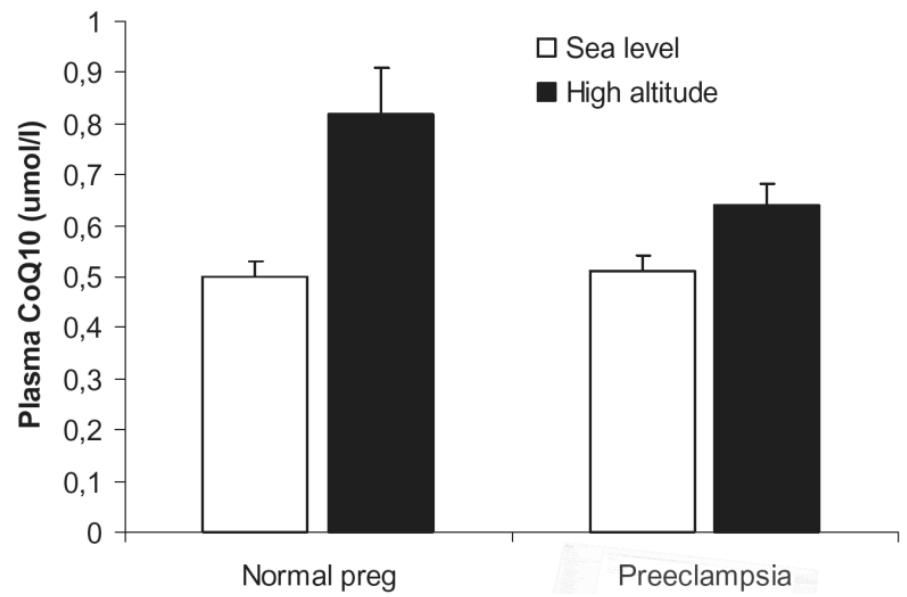

Fig. 1. Coenzyme $\mathrm{Q}_{10}$ plasma levels in normal pregnancies and during pre- eclampsia according to their residency (sea level or high altitude).

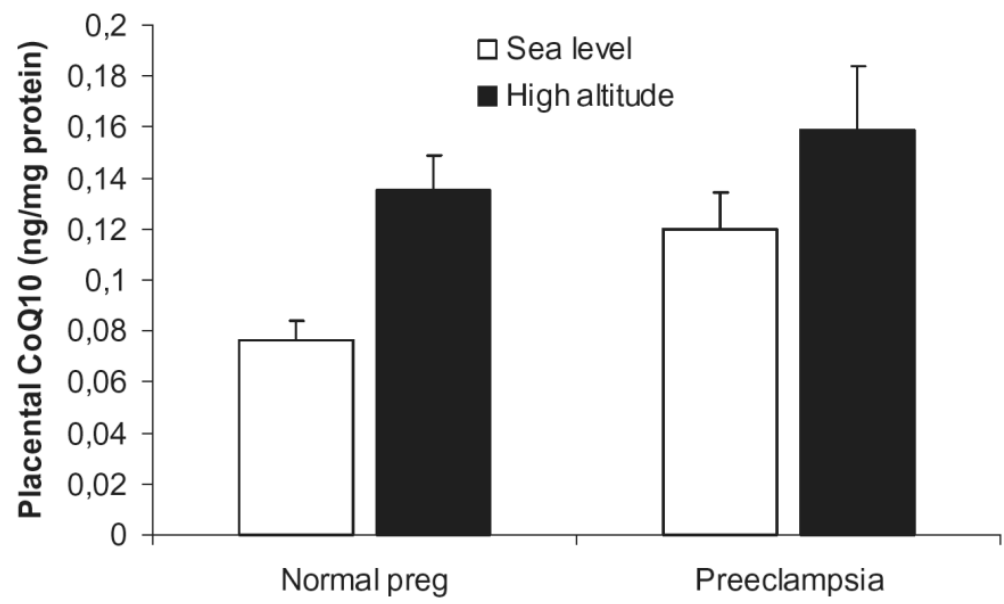

Fig. 2. Coenzyme $Q_{10}$ placental content in normal pregnancies and during pre- eclampsia according to their residency (sea level and high altitude).

The observations in our study allow us to hypothesize that $\mathrm{CoQ}_{10}$ plasma levels are not directly related to placental $\mathrm{CoQ}_{10}$ content. Moreover, it is also plausible to assume that placental development is totally an energy dependent process and that $\mathrm{CoO}_{10}$ could be an essential element in its physiological role. If this is true, then the next obvious questions to be considered should be: what occurs during pre- eclampsia? Are these high placental levels a late compensatory mechanism?

In conclusion it was determined that (1) during pregnancy there is no relationship between plasma $\mathrm{CoQ}_{10}$ levels and placental $\mathrm{CoQ}_{10}$ content and (2) women complicated with pre- eclampsia (high or low altitude) displayed high placental $\mathrm{CoQ}_{10}$ content, with 
significantly low plasma $\mathrm{CoQ}_{10}$ levels among those residing at high altitude. More research is warranted to establish the cause-effect relationship between $\mathrm{CoQ}_{10}$ levels and pre- eclampsia.

\section{ACKNOWLEDGMENTS}

Financial support provided by "Secretaria Nacional de Ciencia y Tecnología (SENACYT)", Ecuador through grant PIC-05-036. 


\section{REFERENCES}

[1] U. Brandt and J.G. Okun, Role of deprotonation events in ubihydroquinone: cytochrome c oxidoreductase from bovine heart and yeast mitochondria, Biochemistry 36 (1997), 11234-11240.

[2] L. Ernster, Ubiquinol as a biological antioxidant: a review, in: Oxidative Processes and Antioxidants, R. Paoletti, ed., Raven Press, Ltd., New York. 1994, pp. 185-198.

[3] S.A. Friedman, R.N. Taylor and J.M. Roberts, Pathophysiology of pre-eclampsia, Clin Perinatol 4 (1991), 661-682.

[4] S.R. Giannubilo, A.L. Tranquilli, C. Santolini, F. Prinicipi, R. Mancinelli and G.P. Littarru, Placental $\mathrm{CoQ}_{10}$ levels in HELLP syndrome, Biofactors 25 (2005), 159-163.

[5] J.P. Granger, B.T. Alexander, M.T. Llinas, W.A. Bennett and R.A. Khalil, Pathophysiology of pre- eclampsia: linking placental ischemia/hypoxia with microvascular dysfunction, Microcirculation 9 (2002), 147-160.

[6] J.K. Lang, K. Gohil and L. Packer Simultaneous determination of tocopherols, ubiquinols, and ubiquinones in blood, plasma, tissue homogenates, and subcellular fractions, Anal Biochem 157 (1986), 106-116.

[7] G. Lenaz, M. Cavazzoni, M.L. Genova, M. D’Aurelio, M. Merlo Pich, F. Pallotti, G. Formiggini, M. Marchetti, G. Parenti Castelli and C. Bovina, Oxidative stress, antioxidant defences and aging, Biofactors 8 (1998), 195-204.

[8] P. Lopez-Jaramillo, M. Narvaez, R.M. Weigel and R. Yepez, Calcium supplementation reduces the risk of pregnancy- induced hypertension in an Andes population, Br J Obstet Gynaecol 96 (1989), 648-655.

[9] J.W. Meekins, R. Pijnenborg, M. Hanssens, I.R. McFadyen and A. van Asshe, A study of placental bed spiral arteries and trophoblast invasion in normal and severe pre- eclamptic pregnancies, Br J Obstet Gynaecol 101 (1994), 669-674.

[10] G. Noia, G.P. Littarru, M. De Santis, A. Oradei, C. Mactromarino, C. Trivellini and A. Caruso, Coenzyme $Q_{10}$ in pregnancy, Fetal Diagn Ther 11 (1996), 264-270.

[11] P.R. Palan, D.W. Shaban, T. Martino and M.S. Mikhail, Lipid-soluble antioxidants and pregnancy: maternal serum levels of coenzyme $\mathrm{Q}_{10}$, alpha-tocopherol and gamma- tocopherol in pre- eclampsia and normal pregnancy, Gynecol Obstet Invest 58 (2004), 8-13.

[12] J.A. Spinnato and J.C. Livingston, Prevention of pre- eclampsia with antioxidants: evidence from randomized trials, Clin Obstet Gynecol 48 (2005), 16-429.

[13] K.A. Starzyk, C.M. Salafia, J.C. Pezzullo, J.M. Lage, V. Parkash, L. Vercruysse, M. Hanssens and R. Pijnenborg, Quantitative differences in arterial morphometry define the placental bed in pre- eclampsia. $\mathrm{Hu}$ man Pathol 28 (1997),353-358.

[14] E. Teran, M. Racines-Orbe, S. Vivero, C. Escudero, G. Molina and A. Calle, Pre- eclampsia is associated with a decrease in plasma coenzyme $\mathrm{Q}_{10}$ levels, Free Radic Biol Med 35 (2003), 1453-1456.

[15] E. Teran, S. Vivero, M. Racines-Orbe, A. Castellanos, G. Chuncha, G. Enriquez and W. Moya, Coenzyme $\mathrm{Q}_{10}$ is increased in placenta and cord blood during pre- eclampsia, Biofactors 25 (2005), 153-158.

[16] M.C. Tissot van Patot, J. Bendrick-Peart, V.E. Beckey, N. Serkova and L. Zwerdlinger Greater vascularity, lowered HIF-1/DNA binding, and elevated GSH as markers of adaptation to in vivo chronic hypoxia, $\mathrm{Am} \mathrm{J}$ Physiol Lung Cell Mol Physiol 287 (2004), L525-L532.

[17] M. Tissot van Patot, A. Grilli, P. Chapman, E. Broad, W. Tyson, D.S. Heller, L. Zwerdlinger and S. Zamudio, Remodelling of uteroplacental arteries is decreased in high altitude placentae, Placenta 24 (2003), 326-335.

[18] M. Vatish, H.S. Randeva and D.K. Grammatopoulos, Hormonal regulation of placental nitric oxide and pathogenesis of pre-eclampsia, Trends Mol Med 12 (2006), 223-232.

[19] C. Weber, A. Bysted and G. Lamer, The coenzyme $Q_{10}$ content of the average Danish diet, Int J Vitam Nutr Res 67 (1997), 123-193.

[20] Y. Zang, F. Aberg, E.-L. Appelkvist, G. Dallner and L. Ernster, Uptake of dietary coenzyme Q supplement is limited in rats, J Nutr 154 (1995), 446-534. 



\section{CHAPTER 4}

Endothelial dysfunction during pre- eclampsia is present in the maternal and fetal

vasculature 



\section{CHAPTER 4A}

Plasma and placental nitric oxide levels in women with and without pre-eclampsia living at different altitudes.

Teran E, Chedraui P, Vivero S, Villena F, Duchicela F, Nacevilla $L$.

Int J Gynaecol Obstet 2009;104:140-2. 


\section{ABSTRACT}

Objective: To investigate the nitric oxide (NO) levels in the plasma and the placentas of pregnant women with pre- eclampsia and women without pre-eclampsia, and to determine the effect of high or low altitude of residence.

Methods: NO was determined by chemoluminescence and group comparisons were performed.

Results: Women with pre-eclampsia $(n=63)$ had higher plasma NO levels (38.6 \pm 17.44 vs $30.6 \pm 12.44 \mu \mathrm{mol} / \mathrm{L}, P=0.004$ ) and higher placental NO levels (38.5 $\pm 17.0 \mathrm{vs}$ $24.3 \pm 7.16 \mathrm{ng} / \mathrm{mg}$ protein, $P<0.05)$ compared with women without pre-eclampsia. $A$ similar trend was found when comparisons were made according to altitude of residence. NO levels were significantly higher in the plasma of pre-eclamptic women living at sea level ( $41.11 \pm 18.78$ vs $28.96 \pm 9.57 \mu \mathrm{mol} / \mathrm{L}, P=0.003)$, and in the placentas of women living at high altitude (39.51 \pm 16.98 vs $21.91 \pm 6.64 \mathrm{ng} / \mathrm{mg}$ protein, $P<0.0001)$.

Conclusion: Women with pre-eclampsia had higher plasma and placental NO levels and the differences were associated with altitude of residence.

Keywords: Altitude, Nitric Oxide, Pre-eclampsia, Placenta, Pregnancy 


\section{INTRODUCTION}

Pre-eclampsia is a common disorder of human pregnancy (affecting about $7 \%$ of all pregnancies), in which the normal hemodynamic response is compromised. It remains a leading cause of maternal and fetal morbidity and mortality [1]. Reduced placental perfusion in the early stages of pregnancy is a key event in the development of this disorder. Defective trophoblastic invasion of the uterine spiral artery vessel walls leads to poor placental development (decreased maternal blood supply), which ultimately produces generalized vascular endothelial dysfunction by mechanisms that remain to be elucidated [2].

Several factors may be important in the physiological mechanisms of placental angiogenesis and regulation of vascular tone, and these factors could have major roles in the pathogenesis of abnormal placental functioning. One of these factors is nitric oxide (NO), the intracellular gaseous messenger synthesized by NO synthase (NOS) from Larginine and oxygen. NO exerts diverse biological functions in several physiological and pathological processes, especially in vascular pathophysiology [3]. NO produced by syncytiotrophoblast-derived endothelial cells is thought to cause dilation of the human placental vasculature [4], and may act as a paracrine agent for the maintenance of uterine quiescence during pregnancy. Additionally, local placental NO generation may be essential to promote cytotrophoblast endovascular invasion, an essential feature of normal placentation [5].

During ischemia-reperfusion and exposure to high altitude, a change in the balance of the levels of reactive oxygen species (ROS) and NO occurs [6]. In contrast to ischemia-reperfusion, ROS levels increase during hypoxia, returning to pre-hypoxic values after re- establishing normoxia. Hence, hypoxia leads to an alteration of the ROS-NO balance, which is eventually restored during the acclimatization process through the upregulation of inducible NOS (iNOS) [7]. The findings of Serrano et al. [8], in a study of the rat cerebellum after reoxygenation at sea level, indicate the involvement of a different type of NOS, which produces dissimilar NO production at high altitude and can lead to an increased formation of nitrotyrosine. In addition, there may be beneficial effects at the tissue level [9] with increased numbers of mitochondria and enhanced function resulting from higher levels of NO [10]. However, data derived from tissue hypoxiareperfusion models suggest that excess NO may be detrimental [10], specifically in the production of additional oxidative and free radical-medicated tissue damage. To the best of our knowledge, studies measuring placental NO levels, either at sea level or at altitude, are lacking. Thus, it can be hypothesized that NO levels differ not only in preeclampsia, but are also dependent on the women's altitude of residence. The aim of the present study was to evaluate NO levels in the plasma and placentas of pregnant women with and without pre-eclampsia residing at high or low altitude. 


\section{MATERIALS AND METHODS}

The study was carried out with approval granted by the Bioethics Committee of the Biomedical Center in Quito, Ecuador. Primigravid pregnant women without preeclampsia $(n=60)$ and those with pre- eclampsia $(n=63)$, who were admitted to the Hospital Gineco-Obstetrico Isidro Ayora (Quito, Ecuador) and the Hospital Gineco- Obstetrico Enrique C. Sotomayor (Guayaquil, Ecuador), were recruited after signing an informed consent form. Of the 123 pregnant women enrolled, 63 resided in Quito (2800 m altitude) and 60 in Guayaquil (sea level). Women with known medical disorders and those receiving medication before hospital admission (especially non-steroidal antiinflammatory drugs) were excluded from the study. Women with pre- eclampsia had blood pressures greater than 140/90 $\mathrm{mm} \mathrm{Hg}$ on at least 2 occasions 6 hours apart, and proteinuria levels producing a $2+$ reaction on a standard urine dipstick ( $>300 \mathrm{mg} / \mathrm{dL}$ ) on 2 occasions 4-24 hours apart. Blood pressure was measured as previously described [11]. Upon hospital admission a 10-mL blood sample was taken from each participant from the antecubital vein, and the sample was immediately transferred into a polypropylene vial containing $3.15 \%$ sodium citrate $(1: 9 \mathrm{v} / \mathrm{v})$. Samples were centrifuged at room temperature and the $500 \mu \mathrm{L}$ plasma aliquots were frozen at $-40{ }^{\circ} \mathrm{C}$. After delivery of the placenta, a 2-3-g sample from the maternal side was obtained (any infracted area was avoided), washed twice with saline solution to remove excess blood, and transferred into a vial containing Kreb buffer solution. Measurement of the placental NO was performed using approximately $100 \mathrm{mg}$ of freeze-clamped tissue accurately weighed in the frozen state, and subsequently homogenized in a glass homogenizer with $2 \mathrm{~mL}$ of Kreb buffer and a pestle. The supernatant was used for the measurements. Plasma and supernatant NO values were determined by a chemoluminescence technique (Sievers NOA- 280; Sievers, Boulder, CO, USA) as previously described [12]. Samples were measured in duplicate and mean values were used for statistical analysis.

Data were analyzed using GraphPad InStat version 3.01 for Windows (GraphPad Software, CA, USA) and presented as means \pm SD. Comparison of continuous data was performed using the non-parametric Mann-Whitney test. $P<0.05$ was considered statistically significant.

\section{RESULTS}

The characteristics of women and neonates included in the study are presented in Table 1. Of the women with pre-eclampsia $(n=63), 47.6 \%$ had severe disease and there was no statistical difference found between those living at high altitude (54.5\%) or at sea level (40\%).

Placental and neonatal weights of the pre-eclamptic women delivering at high altitude were significantly lower than women who did not have pre-eclampsia living at the 
same altitude. Women with pre eclampsia $(n=63)$ had higher plasma and placental NO levels compared with women without pre-eclampsia (38.6 \pm 17.44 vs $30.6 \pm 12.44$ $\mu \mathrm{mol} / \mathrm{L}, P=0.004 ;$ and $38.5 \pm 17.0$ vs $24.3 \pm 7.16 \mathrm{ng} / \mathrm{mg}$ of protein, $P<0.05)$. A similar trend was found once distributed by altitude of residence, with significantly higher NO levels found in the plasma of pre-eclamptic women living at sea level (41.11 \pm 18.78 vs $28.96 \pm 9.57 \mu \mathrm{mol} / \mathrm{L}, P=0.003$; Table 1 ) and in the placentas of women living at high altitude (39.51 \pm 16.98 vs $21.91 \pm 6.64 \mathrm{ng} / \mathrm{mg}$ of protein, $P<0.0001 ;$ Fig. 1 ).

Table 1 Characteristics of neonates and pregnant women with pre-eclampsia and those without pre-eclampsia living at high altitude and at sea level ${ }^{a}$

\begin{tabular}{|c|c|c|c|c|c|c|}
\hline \multirow[t]{2}{*}{ Parameter } & \multirow[b]{2}{*}{$\begin{array}{l}\text { Without PE } \\
\qquad(n=60)\end{array}$} & \multirow[b]{2}{*}{$\begin{array}{l}\text { With PE } \\
(n=63)\end{array}$} & \multicolumn{2}{|c|}{ High altitude } & \multicolumn{2}{|c|}{ Sea level } \\
\hline & & & $\begin{array}{l}\text { Without PE } \\
\qquad(n=30)\end{array}$ & $\begin{array}{l}\text { With PE } \\
(n=33)\end{array}$ & $\begin{array}{l}\text { Without PE } \\
\qquad(n=30)\end{array}$ & $\begin{array}{l}\text { With PE } \\
(n=30)\end{array}$ \\
\hline Maternal age, $y$ & $20.7 \pm 4.4$ & $20.6 \pm 4.4$ & $20.6 \pm 4.6$ & $20.6 \pm 4.4$ & $20.7 \pm 4.2$ & $20.6 \pm 4.5$ \\
\hline Gestational age, wk & $39 \pm 1.1$ & $38.2 \pm 1.9$ & $39 \pm 1.1$ & $38.2 \pm 1.9$ & $38.6 \pm 1.5$ & $39.1 \pm 1.0$ \\
\hline Systolic blood pressure, mm Hg & $110.2 \pm 9.3$ & $144.9 \pm 11^{b}$ & $110.7 \pm 6.8$ & $143.6 \pm 11.4^{b}$ & $109.7 \pm 11.3$ & $146.3 \pm 10.7^{b}$ \\
\hline Diastolic blood pressure, $\mathrm{mm} \mathrm{Hg}$ & $72.1 \pm 6.6$ & $96.8 \pm 10.5^{b}$ & $73 \pm 7.0$ & $98.9 \pm 7 b$ & $71.3 \pm 6.2$ & $94.5 \pm 9.7$ \\
\hline $\begin{array}{l}\text { Neonatal gestational age at } \\
\text { delivery, wk }\end{array}$ & $38.5 \pm 1.6$ & $38.6 \pm 1.3$ & $38.7 \pm 1.1$ & $38.2 \pm 1.9$ & $38.6 \pm 1.5$ & $38.8 \pm 1.0$ \\
\hline Neonatal weight at delivery, g & $2980.8 \pm 597.8$ & $2908.8 \pm 454.4$ & $3097 \pm 364.7$ & $2757.8 \pm 429.1^{b}$ & $2864 \pm 752.2$ & $3073 \pm 429.1^{c}$ \\
\hline Placental weight, g & $576.4 \pm 98.5$ & $556 \pm 130.8$ & $580.1 \pm 98.5$ & $503.5 \pm 120.1^{b}$ & $572.6 \pm 100$ & $614 \pm 118^{c}$ \\
\hline Plasma nitric oxide, $\mu \mathrm{mol} / \mathrm{L}$ & $30.6 \pm 12.44$ & $38.6 \pm 17.44^{b}$ & $34.3 \pm 14.11$ & $38.21 \pm 14.97$ & $28.96 \pm 9.57$ & $41.11 \pm 18.78^{b}$ \\
\hline $\begin{array}{l}\text { Placental nitric oxide, } \mathrm{ng} / \mathrm{mg} \text { of } \\
\text { protein }\end{array}$ & $24.3 \pm 7.16$ & $38.5 \pm 17.0 \mathrm{~b}$ & $21.91 \pm 6.64$ & $39.51 \pm 16.98^{b}$ & $30.33 \pm 13.65^{c}$ & $37.34 \pm 17.15$ \\
\hline
\end{tabular}

Abbreviation: PE, pre-eclampsia.

${ }^{a}$ Values are given as mean \pm SD. ${ }^{b} P<0.05$ comparing women without pre-eclampsia. ${ }^{c} P<0.05$ comparing women with pre-eclampsia or without pre-eclampsia at high altitude.

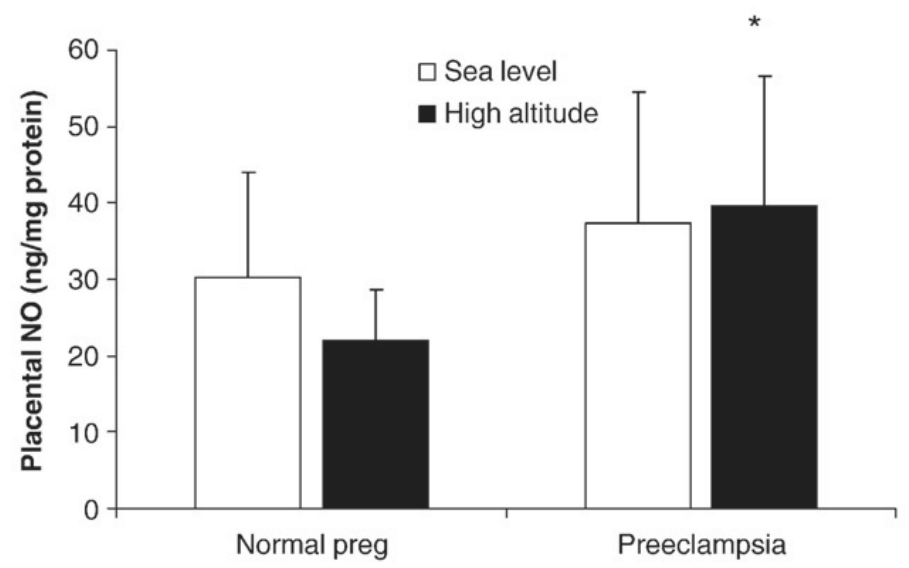

${ }^{*} P<0.0001$ comparing pregnant women without pre-eclampsia at high altittude.

Fig. 1. NO content in placental tissue from pregnant women without pre-eclampsia and pregnant women with pre-eclampsia residing at high altitude and at sea level. 


\section{DISCUSSION}

The results of this study showed that compared with pregnant women without preeclampsia, women with pre-eclampsia exhibit significantly higher plasma NO levels. Although this is in agreement with our previous observations [12-15], the reported levels of NO in relation to pre-eclampsia are contradictory [16], which is probably due to differences in the measurement methods and/or the metabolite analyzed. Nevertheless, there is agreement that pre-eclampsia is associated with altered NO production and/or activity.

Moreover, plasma and placental NO measurements were performed in women residing at sea level and at high altitude. The NO level was found to be higher in the placentas of women with pre- eclampsia $(n=63)$, and was more pronounced among women living at high altitude, and interestingly, these women also had neonates and placentas of a lower weight compared with those of pre-eclamptic women living at sea level.

The expression of iNOS and endothelial nitric oxide synthase (eNOS) has been previously reported to be significantly lower in the placentas of growth-restricted fetuses [17], but not in placentas from women with pre-eclampsia. Fetal-placental NOS activity and the NO concentration in the umbilical circulation have been found to be altered in pregnancies complicated by pre-eclampsia [17]. One study of women with preeclampsia specifically described a decreased or unchanged placental NOS activity [18]. $\mathrm{NO}$ in the fetal-placental circulation is derived from eNOS activity, found predominantly in the syncytiotrophoblast [19]. Overall, it is possible to conclude that plasma NO activity is altered in women with pre-eclampsia. It is also altered in the placenta, ie, the NO levels were higher in the placentas of women with pre-eclampsia. However, a recent study demonstrated that NOS knockout mice do not develop hypertension during pregnancy, perhaps due to the possible recruitment of compensatory vasodilator substances (eg, prostacyclin) [20]. Moreover, in placentas from women with pre-eclampsia, decreased antioxidant capacities [21-23] and abnormally high rates of superoxide synthesis have been reported [24]. Therefore, based on the finding that women with preeclampsia living at high altitude had higher placental NO levels and associated lower placental and neonatal weights, compared with those living at sea level, we hypothesize that the placental NO is not fully utilized and could react with a ROS (ie, superoxide), to produce deleterious effects. This hypothesis could be supported by other important changes in the mechanisms regulating NOS activation and vasodilatation found during pre-eclampsia. Together with other contributing factors, such as angiotensin II receptor upregulation, angiotensin receptor agonistic auto-antibodies, and endothelin-1 upregulation [3], this could trigger placental oxidative stress and contribute to vascular resistance dysregulation resulting in increased sensitivity to vasopressor agents.

Despite the limitations of this study, namely its cross-sectional design and small sample size, women with pre-eclampsia were found to have higher plasma and placen- 
tal NO levels, with significant differences found depending upon the altitude of residence. More research in this area is required.

\section{Acknowledgments}

The authors acknowledge the financial support of the Secretaria Nacional de Ciencia y Tecnología - SENACYT, Ecuador, through grant PIC-05-036. 


\section{REFERENCES}

[1] Friedman SA, Taylor RN, Roberts JM. Pathophysiology of pre- eclampsia. Clin Perinatol 1991;18(4):661-82.

[2] Lyall F. Mechanisms regulating cytotrophoblast invasion in normal pregnancy and pre-eclampsia. Aust $\mathrm{N}$ Z J Obstet Gynaecol 2006;46(4):266-73.

[3] Vatish M, Randeva HS, Grammatopoulos DK. Hormonal regulation of placental nitric oxide and pathogenesis of pre-eclampsia. Trends Mol Med 2006;12(5):223-33.

[4] Bachetti T, Comini L, Curello S, Bastianon D, Palmieri M, Bresciani G, et al. Co- expression and modulation of neuronal and endothelial nitric oxide synthase in human endothelial cells. J Mol Cell Cardiol 2004;37(5):939-45.

[5] Many A, Hubel CA, Fisher SJ, Roberts JM, Zhou Y. Invasive cytotrophoblasts manifest evidence of oxidative stress in pre- eclampsia. Am J Pathol 2000;156(1):321-31.

[6] Schneider JC, Blazy I, Dechaux M, Rabier D, Mason NP, Richalet JP. Response of nitric oxide pathway to Larginine infusion at the altitude of 4,350 m. Eur Respir J 2001;18(2):286-92.

[7] Gonzalez NC, Wood JG. Leukocyte-endothelial interactions in environmental hypoxia. Adv Exp Med Biol 2001;502:39-60.

[8] Serrano J, Encinas JM, Salas E, Fernandez AP, Castro-Blanco S, Fernandez-Vizarra P, et al. Hypobaric hypoxia modifies constitutive nitric oxide synthase activity and protein nitration in the rat cerebellum. Brain Res 2003;976(1):109-19.

[9] Sumbayev VV, Yasinska IM. Mechanisms of hypoxic signal transduction regulated by reactive nitrogen species. Scand J Immunol 2007;65(5):399-406.

[10] Nisoli E, Clementi E, Carruba MO, Moncada S. Defective mitochondrial biogenesis: a hallmark of the high cardiovascular risk in the metabolic syndrome? Circ Res 2007;100(6):795-806.

[11] Lopez-Jaramillo P, Narvaez M, Weigel RM, Yepez R. Calcium supplementation reduces the risk of pregnancy-induced hypertension in an Andes population. Br J Obstet Gynaecol 1989;96(6):648-55.

[12] Teran E, Escudero C, Calle A. Endothelial dysfunction and pre- eclampsia. Am J Hypertens 2007;20(9):1026-7.

[13] Teran E, Escudero C, Vivero S, Molina G, Calle A. NO in early pregnancy and development of pre- eclampsia. Hypertension 2006;47(4):e17.

[14] Teran E, Escudero C, Moya W. Abnormal release of nitric oxide from nitrosoproteins during pre- eclampsia. Int J Gynecol Obstet 2006;92(3):260-1.

[15] Teran E, Escudero C, Vivero S, Enriquez A, Calle A. Intraplaletet cyclic guanosine- 3',5'-monophosphate levels during pregnancy and pre- eclampsia. Hypertens Preg 2004;23(3):303-8.

[16] Gilbert JS, Ryan MJ, LaMarca BB, Sedeek M, Murphy SR, Granger JP. Pathophysiology of hypertension during pre- eclampsia: linking placental ischemia with endothelial dysfunction. Am J Physiol Heart Circ Physiol 2008;294(2):H541-50.

[17] SchiessI B, Mylonas I, Hantschmann P, Kuhn C, Schulze S, Kunze S, et al. Expression of endothelial NO synthase, inducible NO synthase, and estrogen receptors alpha and beta in placental tissue of normal, preeclamptic, and intrauterine growthrestricted pregnancies. J Histochem Cytochem 2005;53(12):1441-9.

[18] Faxen M, Nisell H, Kublickiene KR. Altered mRNA expression of ecNOS and iNOS in myometrium and placenta from women with pre- eclampsia. Arch Gynecol Obstet 2001;265(1):45-50.

[19] Norris LA, Higgins JR, Darling MR, Walshe JJ, Bonnar J. Nitric oxide in the uteroplacental, fetoplacental, and peripheral circulations in pre- eclampsia. Obstet Gynecol 1999;93(6):958-63.

[20] Shesely EG, Gilbert C, Granderson G, Carretero CD, Carretero OA, Beierwaltes WH. Nitric oxide synthase gene knockout mice do not become hypertensive during pregnancy. Am J Obstet Gynecol 2001;185(5): 1198-203.

[21] Zusterzeel PL, Rutten H, Roelofs HM, Peters WH, Steegers EA. Protein carbonyls in decidua and placenta of pre-eclamptic women as markers for oxidative stress. Placenta 2001;22(2-3):213-9. 
[22] Gratacos E, Casals E, Deulofeu R, Cararach V, Alonso PL, Fortuny A. Lipid peroxide and vitamin E patterns in pregnant women with different types of hypertension in pregnancy. Am J Obstet Gynecol 1998; 178(5):1072-6.

[23] Walsh SW. Maternal-placental interactions of oxidative stress and antioxidants in pre- eclampsia. Semin Reprod Endocrinol 1998;16(1):93-104.

[24] Sikkema JM, van Rijn B, Franx A, Bruinse HW, de Roos R, Stroes ES, et al. Placental superoxide is increased in pre-eclampsia. Placenta 2001;22(4):304-8. 



\section{CHAPTER 4B}

Feto-placental nitric oxide, asymmetric dimethylarginine and vascular endothelial growth factor (VEGF) levels and VEGF gene polymorphisms in severe pre- eclampsia

Chedraui P, Solis EJ, Bocci G, Gopal S, Russo E, Escobar GS, Hidalgo L, Pérez-López FR, Genazzani AR, Mannella $P$, Simoncini T.

J Matern Fetal Neonatal Med 2013;26:226-32. 


\section{ABSTRACT}

Objective: To measure plasma nitric oxide (NO), asymmetric dimethylarginine (ADMA) and vascular endothelial growth factor (VEGF) levels and VEGF gene polymorphisms in fetal circulation in severe pre- eclampsia.

Methods: Cord vessels of singleton gestations complicated with severe pre- eclampsia 36 weeks or more $(n=31)$ and controls were sampled upon delivery for analyte measuring. Additionally, DNA was extracted from umbilical vein whole blood to determine the frequency of VEGF gene single nucleotide polymorphisms (SNPs): $-2578 \mathrm{~A} / \mathrm{C}$, $-1498 \mathrm{C} / \mathrm{T},-1154 \mathrm{~A} / \mathrm{G},-634 \mathrm{C} / \mathrm{G}$ and $+936 \mathrm{C} / \mathrm{T}$. Coefficient correlations between analyte levels and placental and neonatal weight were calculated.

Results: NO plasma levels in umbilical vessels (artery and vein) were significantly higher in pre- eclampsia cases as compared to controls ( $4.67 \pm 3.0$ vs. $0.82 \pm 0.90 ; 4.46$ \pm 3.0 vs. $0.82 \pm 0.99 \mathrm{mmol} / \mathrm{L}$, respectively, $p=0.0001$ both). ADMA levels displayed a similar increased trend in both fetal vessels, but this did not reach statistical significance ( $2.57 \pm 1.03$ vs. $2.34 \pm 0.57 ; 2.74 \pm 0.94$ vs. $2.42 \pm 0.59 \mathrm{mmol} / \mathrm{L}$, respectively, $p>0.05)$. VEGF was significantly lower in artery but not in vein in pre- eclampsia cases (200.48 \pm 225.62 vs. $338.61 \pm 287.03 \mathrm{pg} / \mathrm{mL}, p=0.04)$. A significant positive correlation was found between NO and ADMA levels (artery and vein) among pre- eclampsia cases. Overall, the frequency of the studied VEGF gene SNPs did not differ among pre-eclamptic cases and controls; nevertheless, a significant trend toward lower umbilical vein VEGF levels was observed in pre-eclampsia cases in the presence of -2578 CC and - 1154 AG genotypes.

Conclusion: Near term gestations complicated with severe pre- eclampsia presented higher NO levels in fetal circulation, which correlated to ADMA and lower artery VEGF values. More research is warranted to confirm that selected VEGF SNPs may be associated with lower umbilical vein VEGF.

Keywords: Asymmetric dimethylarginine, nitric oxide, pre- eclampsia, umbilical vessels, vascular endothelial growth factor 


\section{INTRODUCTION}

Despite attempts at intervention, pre-eclampsia is still a leading cause of maternal and fetal morbidity and mortality [1]. Reduced placental perfusion at early stages of pregnancy is a key event in its development [2], in which defective trophoblastic invasion of the uterine spiral-arteries and arterioles leads to incomplete vascular remodeling and impaired utero-placental blood flow. Although the intrinsic involved mechanisms are still unclear, vascular dysfunction found in pre-eclampsia is likely to be a consequence of reduced maternal circulating angiogenic factors [3] and increased levels of placental debris [4], reactive oxygen species [5], pro-inflammatory cytokines [6], and antiangiogenic factors [7]. Nitric oxide (NO) synthesis is involved in some of these proposed pathological mechanisms. However, how NO exerts its effects over vascular development and placental function in pre- eclampsia is still unclear [8]. In pre-eclampsia, increased maternal and fetal serum NO levels may be a compensatory protective mechanism to maintain blood flow and reduce platelet aggregation in the fetal and maternal circulation. In addition, NO production is directly related to pre-eclampsia severity [9]. Asymmetric dimethylarginine (ADMA) is an aminoacid that circulates in plasma, is excreted in urine, and is found in various tissues and cells. It inhibits NO synthase (NOS) and has been proposed as a marker of endothelial dysfunction. ADMA is increased in women with pre-eclampsia, even before clinical manifestation $[10,11]$. On the other hand, vascular endothelial growth factor (VEGF) mediates important signaling pathways during fetal growth and in the maternal circulatory system. VEGF concentration is deranged in gestations complicated with pre- eclampsia [12].

Genetic background may also influence pre- eclampsia development and the concomitant endothelial dysfunction. Hypertension and angiogenesis are linked, since microcirculatory vasoconstriction is in part due to defective angiogenic processes [13]. Single nucleotide polymorphisms (SNPS) of the promoter region of the VEGF gene are related to higher or lower VEGF production and to altered risk of developing diseases characterized by deranged angiogenesis [14]. In particular, the VEGF -2578 CC genotype has been associated with higher VEGF expression than the AA genotype, which is consistent for a protective effect of VEGF in atherosclerosis development [15]. Recent studies suggest that some VEGF genotypes are more common in women with pre-eclampsia [16]. However, it is currently unknown whether such genetic asset is related to abnormal circulating amounts of VEGF during pre-eclampsia.

The aim of the present study was to measure plasma NO, ADMA, and VEGF levels in fetal circulation in gestations compli- cated with severe pre- eclampsia. Additionally, the frequency of common SNPs of the VEGF gene and their relation to circulating umbilical vein VEGF levels were also analyzed. 


\section{MATERIALS AND METHODS}

\section{Study design and population}

The present pilot research collaboration was carried out at the Enrique C. Sotomayor Obstetrics and Gynecology Hospital, Guayaquil, Ecuador. Sotomayor Hospital is a major referral center that provides maternal and neonatal healthcare to the low-income population of Guayaquil, Ecuador. It has the highest delivery rate in Latin America (>30 000 per year) in addition to increased rates of high risk pregnancies [17].

For this study, singleton gestations fulfilling severe pre- eclampsia criteria admitted for delivery to the High Risk Pregnancy Labor and Delivery Unit were recruited. Normal pregnant women delivering in the low risk Unit served as controls which were matched for maternal and gestational age, parity, and laboring status. All participants were recruited after signing informed consent. Women with known medical disorders and on any medication before hospital admission (particularly non-steroidal anti-inflammatory drugs) were excluded from the study.

ACOG criteria was used to define severe pre- eclampsia as a blood pressure $\geq$ 160/110 mmHg on two occasions at least 6 hours apart and proteinuria +++ or more on at least two random samples 4 hours apart [18].

Maternal and neonatal information was recorded on a data sheet and included: maternal age, blood pressure and dipstick scores, neonatal gestational age and birth weight and route of delivery. The Institutional Review Board of the Enrique C. Sotomayor Hospital approved the research study protocol.

\section{Biochemical assays}

\section{Blood samples}

Upon infant delivery a $25 \mathrm{~cm}$ fetal cord segment was double clamped from which a $5 \mathrm{ml}$ blood sample was taken from each cord vessel (artery and vein). Tubes were immediately centrifuged at $3,000 \mathrm{rpm}$ at $6^{\circ} \mathrm{C}$ for 20 minutes. The plasma and cell layers were aliquoted into several micro-centrifuge tubes, which were frozen and stored at $-70^{\circ} \mathrm{C}$ until further analysis.

Nitrite assay

Nitric oxide production was determined by a nitrite assay using 2, 3-diaminonaphthalene. Fluorescence of 1-(H)-naphthotriazole was measured by excitation and emission wavelengths of 365 and $450 \mathrm{~nm}$. Standard curves were constructed with sodium

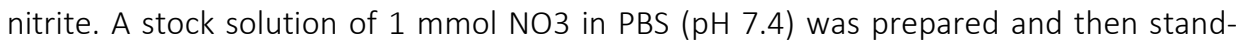
ards (from 0 to $50 \mu \mathrm{M} / \mathrm{L}$ ) were obtained by diluting the stock solution in PBS solution ( $\mathrm{pH}$ 7.4). Plasma, blank, standard, and control samples ( $250 \mu \mathrm{l}$ each) were diluted by adding $250 \mu \mathrm{l}$ PBS to plastic vials. Each mixture was then thoroughly mixed and the 
plasma centrifuged in spin filter columns for 60 minutes at room temperature. Subsequently, $100 \mu \mathrm{l}$ Griess reagent, $1 \%$ sulphanilamide $+0.1 \%$ naphthylethylenediamine dihydrochloride prepared in $3.1 \%$ H3PO4 solution was added to each vial. Reagents were mixed on a shaker for one minute at $185 \mathrm{rpm}$ and plates incubated for 10 minutes at $37^{\circ} \mathrm{C}$. Samples were placed in a spectrophotometer and the absorbance was read at $490 \mathrm{~nm}$. Non-specific fluorescence was determined in the presence of NG-monomethylL-arginine $(3 \mathrm{mmol} / \mathrm{L})$. All samples, kit controls and standards were analyzed in duplicates.

\section{Enzyme-linked immunosorbent assay}

Acylation was conducted in the 96-well reaction plate supplied with the kit according to the instructions of the manufacturer. Standards, kit controls and samples (20 $\mu \mathrm{l})$ were mixed with $25 \mu \mathrm{l}$ acylation buffer and $25 \mu$ l equalizing reagent. Subsequently, $25 \mu \mathrm{l}$ of acylation reagent was added and the reaction plate incubated for 30 minutes at room temperature on an orbital shaker. Diluted equalizing reagent $(100 \mu \mathrm{l})$ was added and incubation continued for 45 minutes. After incubation, samples were ready for the enzyme-linked immunosorbent assay (ELISA) analysis.

The ADMA-ELISA kit (Biovendor, Cat. No.: REA201/96) consists of a split-type reaction plate $(12 \times 8)$ coated with ADMA, six standards $(0-5 \mu \mathrm{M})$, rabbit anti-ADMA antiserum, goat anti-rabbit-lgG-peroxidase conjugate, TMB substrate solution, stop solution, and wash buffer. Aliquots $(50 \mu \mathrm{l})$ of the acylated standards, kit controls or samples were processed according to the instructions of the kit manufacturer. Absorbances were measured with a microplate reader using a wavelength of $450 \mathrm{~nm}$ (reference wavelength $620 \mathrm{~nm}$ ). All samples, kit controls, and standards were analyzed in duplicates.

The VEGF-A-ELISA kit (Antigenix America, Cat. No. RH88820CKC) consists of a splittype reaction plate $(12 \times 8)$ coated with VEGF-A polyclonal antibodies, goat anti-VEGF-A antiserum, anti-goat- Biotin-Conjugate, TMB substrate solution, stop solution, streptavidin-HRP, and wash buffer. Absorbances were measured with a microplate reader using a wavelength of $450 \mathrm{~nm}$ (reference wavelength $620 \mathrm{~nm}$ ). All samples, kit controls, and standards were analyzed in duplicates.

\section{VEGF genotyping}

DNA was extracted from whole blood of the umbilical vein using QIAamp DNA Blood Mini Kit (Qiagen, Valencia, CA, USA). Genotyping was performed using the Taqman platform using specific and validated primers (Applied Biosystems, Carlsbad, CA, USA) with an ABI PRISM 7900HT Sequence Detection System. The investigated SNPs were the following: -2578 A/C (rs699947; TaqMan SNP genotyping assay C_8311602_10), -1498 C/T (rs833061; C_1647381_10), -1154 A/G (rs1570360; C_1647379_10), -634 C/G (rs2010963; C_8311614_10), +936 C/T (rs3025039; C_16198794_10). PCR reaction was carried out according to the protocol of the manufacturer. Allelic distribution for VEGF SNPs was in Hardy-Weinberg equilibrium. 


\section{Statistical analysis}

Statistical analysis was performed using SPSS statistical package (Version 19.0 for Windows, SPSS Inc, Chicago, IL, USA). Data are presented as means, standard deviations, medians, interquartile ranges, coefficients, and percentages. The Kolmogorov Smirnov test was used to assess the normality of data distribution. According to this, continuous data were compared with student's $t$-test (parametric), the Mann-Whitney test (nonparametric) or the Kruskal-Wallis test (various non-parametric samples). Chi-square, Yates' corrected chi-square, and Fisher's exact tests were used to compare percentages (including SNP frequency comparisons between cases and controls). Rho Spearman coefficients were calculated to determine correlations between analyte levels (NO, ADMA, and VEGF) and placental and neonatal weight. A $p$ value of $<0.05$ was considered as statistically significant.

\section{RESULTS}

During the study period a total of 62 women were recruited. These included 31 women with severe pre- eclampsia and 31 controls matched for maternal and gestational age, parity, and laboring status. General characteristics of studied women are depicted on Table I. Arm circumference $(\mathrm{cm})$ as well as blood pressure levels were significantly higher among women with pre-eclampsia. No significant differences were found for the other studied parameters. None of the pre-eclampsia cases presented clinical complications (i.e. oliguria, renal insufficiency, pulmonary edema, or neurological problems). As compared to controls, at birth, placental weight and neonatal weight and ponderal index were lower in women complicated with severe pre- eclampsia (Table II). Equally the percentage of neonates with low birth weight $(<2500 \mathrm{~g})$ was higher in the preeclampsia group.

NO plasma levels in umbilical vessels (artery and vein) were significantly higher in pre- eclampsia cases than in controls $(p=0.0001)$. There was a non-significant trend toward higher ADMA levels in both umbilical vessels among women with pre-eclampsia. VEGF levels were found to be significantly lower only in umbilical artery of pre- eclampsia cases (Table III; Figure 1a, b, and c). Artery and vein NO levels displayed a positive and significant correlation with ADMA levels. No other significant correlation was found (Table IV).

There was no statistical difference between cases and controls in the distribution of the five investigated SNPS of the VEGF gene assessed from whole blood of the umbilical venous circulation (Table V). Interestingly, lower umbilical vein VEGF levels were found in pre-eclampsia cases in the presence of the VEGF -1154 AG and -2578 CC genotypes (Table VI). No differences were observed in the distribution of any of the analyzed SNPs 
or VEGF levels when pre-eclamptic women with small for gestational age fetuses were compared to those only with pre-eclampsia.

Table I. Basal characteristics of studied women.

\begin{tabular}{lcccc}
\hline Parameters & All $(\mathrm{n}=62)$ & Cases $(\mathrm{n}=31)$ & Controls $(\mathrm{n}=31)$ & $p$ Value* \\
\hline Age (years) & $25.7 \pm 6.4[26.0]$ & $25.9 \pm 6.4[26.0]$ & $25.4 \pm 6.5[26.0]$ & $0.78^{\mathrm{a}}$ \\
Parity & $1.4 \pm 1.6[1.0]$ & $1.4 \pm 1.6[1.0]$ & $1.4 \pm 1.6[1.0]$ & $1.0^{\mathrm{b}}$ \\
Residency (\%) & & & & \\
Urban & $11(17.7)$ & $6(19.4)$ & $5(16.1)$ & $0.73^{\mathrm{c}}$ \\
Urban-marginal & $35(56.5)$ & $19(61.3)$ & $16(51.6)$ & $0.44^{\mathrm{c}}$ \\
Rural & $16(25.8)$ & $6(19.4)$ & $10(32.3)$ & $0.24^{\mathrm{c}}$ \\
Patient was in labor upon & $20(32.3)$ & $10(32.3)$ & $10(32.3)$ & $1.0 \mathrm{c}$ \\
recruitment (\%) & $10.5 \pm 3.4[11.0]$ & $10.8 \pm 3.5[12.0]$ & $10.2 \pm 3.4[10.0]$ & $0.49^{\mathrm{b}}$ \\
Educational level (years) & $5.4 \pm 2.2[6.0]$ & $5.1 \pm 2.0[5.0]$ & $5.7 \pm 2.3[6.0]$ & $0.15^{\mathrm{b}}$ \\
Number of antenatal visits & $28.4 \pm 2.1[28.0]$ & $29.2 \pm 2.0[29.0]$ & $27.6 \pm 1.9[28.0]$ & $0.004^{\mathrm{b}}$ \\
Arm circumference (cm) & $132.9 \pm 27.3[135.0]$ & $156.2 \pm 17.2[150.0]$ & $109.5 \pm 9.7[110.0]$ & $0.0001^{\mathrm{b}}$ \\
Systolic blood pressure $(\mathrm{mmHg})$ & $83.6 \pm 16.2[85.0]$ & $97.7 \pm 7.9[100.0]$ & $69.5 \pm 8.0[70.0]$ & $0.0001^{\mathrm{b}}$ \\
Diastolic blood pressure $(\mathrm{mmHg})$ & & &
\end{tabular}

Data are presented as mean \pm standard deviations [medians] or percentages $n(\%)$.

${ }^{*} p$ Value after comparing cases and controls as determined with Student t-test ${ }^{\mathrm{a}}$, the Mann-Whitney test ${ }^{\mathrm{b}}$ or the chi-square test ${ }^{c}$.

Table II. Neonatal outcome of studied women.

\begin{tabular}{|c|c|c|c|}
\hline Parameters & Cases $(n=31)$ & Controls $(n=31)$ & $p$ Value* \\
\hline Gestational age (weeks) & $37.3 \pm 1.9[38.0]$ & $37.9 \pm 1.5[38.0]$ & $0.14^{\mathrm{a}}$ \\
\hline Neonatal weight (g) & $2669.8 \pm 623.9[2873.0]$ & $2945.1 \pm 496.8$ [2995.0] & $0.02^{b}$ \\
\hline Ponderal index $\left(\mathrm{g} / \mathrm{cm}^{3}\right)$ & $2.5 \pm 0.3[2.6]$ & $2.8 \pm 0.7[2.8]$ & $0.02^{\mathrm{a}}$ \\
\hline Low birth weight < $2500 \mathrm{~g}(\%)$ & $11(35.5)$ & $5(16.2)$ & $0.04^{c}$ \\
\hline Preterm (\%) & $9(29.0)$ & $5(16.2)$ & $0.22^{c}$ \\
\hline Small-for-gestational age (\%) & $5(16.1)$ & $1(3.2)$ & $0.19^{d}$ \\
\hline Placental weight (g) & $667.3 \pm 57.2[650.0]$ & $685.6 \pm 38.4[690.0]$ & $0.02^{b}$ \\
\hline Apgar score $<7$ at first minute (\%) & $7(22.6)$ & $2(6.4)$ & $0.14^{d}$ \\
\hline Apgar score $<7$ at 5 minutes (\%) & $2(6.4)$ & $0(0)$ & $0.49^{\mathrm{e}}$ \\
\hline Neonatal death (\%) & $0(0)$ & $0(0)$ & $0.90^{\mathrm{e}}$ \\
\hline Admittance to NICU (\%) & $0(0)$ & $0(0)$ & $0.90^{\mathrm{e}}$ \\
\hline
\end{tabular}

Data are presented as mean \pm standard deviations [medians] or percentages $n(\%)$.

${ }^{*} p$ Value after comparing cases and controls as determined with the Mann-Whitney test ${ }^{\mathrm{a}}$, the student t-test ${ }^{\mathrm{b}}$, the chi-square test ${ }^{c}$, Yates' corrected chi-square test ${ }^{d}$ or Fisher's exact test ${ }^{e}$. NICU, neonatal intensive care unit. 
Table III. NO, ADMA, and VEGF levels in umbilical vessels: cases and controls.

\begin{tabular}{lccc}
\hline Parameter & Cases & Controls & $p$ Value \\
\hline Nitric oxide (mmol/L) & & & \\
Artery & $4.67 \pm 3.00$ & $0.82 \pm 0.90$ & 0.0001 \\
Vein & $4.46 \pm 3.00$ & $0.82 \pm 0.99$ & 0.0001 \\
ADMA (mmol/L) & & \\
Artery & $2.57 \pm 1.03$ & $2.34 \pm 0.57$ & 0.79 \\
Vein & $2.74 \pm 0.94$ & $2.42 \pm 0.59$ & 0.21 \\
VEGF $(\mathrm{pg} / \mathrm{mL})$ & & \\
Artery & $200.48 \pm 225.62$ & $338.61 \pm 287.03$ & 0.04 \\
Vein & $144.49 \pm 351.95$ & $130.51 \pm 235.17$ & 0.88 \\
\hline
\end{tabular}

${ }^{*} p$ Value after comparing cases in controls with the Mann-Whitney test.ADMA, asymmetric dimethylarginine; VEGF, vascular endothelial growth factor.

Table IV. Rho Spearman coefficients between artery and vein analyte levels (cases and controls) and placental and neonatal weight.

\begin{tabular}{|c|c|c|c|c|c|c|}
\hline & NO artery & NO vein & ADMA artery & ADMA vein & VEGF artery & VEGF vein \\
\hline \multicolumn{7}{|l|}{ Cases } \\
\hline ADMA & $0.39(0.04)^{*}$ & $0.47(0.01)$ & - & - & $-0.17(0.43)$ & $-0.07(0.77)$ \\
\hline VEGF & $0.05(0.79)$ & $-0.04(0.86)$ & $-0.17(0.43)$ & $-0.07(0.77)$ & - & - \\
\hline Placental weight (g) & $0.10(0.63)$ & $0.22(0.28)$ & $-0.26(0.20)$ & $-0.02(0.90)$ & $-0.05(0.81)$ & $-0.03(0.90)$ \\
\hline Neonatal weight (g) & $-0.17(0.40)$ & $-0.28(0.17)$ & $-0.08(0.70)$ & $0.09(0.65)$ & $0.33(0.10)$ & $0.09(0.65)$ \\
\hline \multicolumn{7}{|l|}{ Controls } \\
\hline ADMA & $0.14(0.48)$ & $0.05(0.80)$ & - & - & $0.05(0.80)$ & $-0.27(0.18)$ \\
\hline VEGF & $0.11(0.58)$ & $-0.32(0.11)$ & $0.05(0.80)$ & $-0.27(0.18)$ & - & - \\
\hline Placental weight (g) & $-0.07(0.73)$ & $0.08(0.67)$ & $0.30(0.14)$ & $-0.14(0.50)$ & 0.17 (0.39) & $0.04(0.83)$ \\
\hline Neonatal weight (g) & $-0.08(0.68)$ & $0.04(0.85)$ & $-0.11(0.60)$ & $-0.08(0.71)$ & $0.32(0.11)$ & $-0.11(0.59)$ \\
\hline
\end{tabular}

* $p$ Values in parenthesis.

Table V. Single nucleotide polymorphisms of the promoter region of the VEGF gene among studied women.

\begin{tabular}{|c|c|c|c|c|c|}
\hline \multirow{2}{*}{$\begin{array}{l}\text { SNP position and } \\
\text { genotype }\end{array}$} & \multicolumn{2}{|c|}{ Pre- eclampsia } & \multicolumn{2}{|c|}{ Controls } & \multirow[b]{2}{*}{$p$ Value* } \\
\hline & Genotype frequency & Allelic frequency & Genotype frequency & Allelic frequency & \\
\hline \multicolumn{6}{|l|}{$\operatorname{VEGF}(-2578 \mathrm{~A} / \mathrm{C})$} \\
\hline AA & $3(9.7 \%)$ & $A=35.5 \%$ & $3(9.7 \%)$ & $A=35.5 \%$ & 0.66 \\
\hline$A C$ & $16(51.6 \%)$ & $16(51.6 \%)$ & 1.0 & & \\
\hline $\mathrm{CC}$ & $12(38.7 \%)$ & $C=64.5 \%$ & $12(38.7 \%)$ & $C=64.5 \%$ & 1.0 \\
\hline \multicolumn{6}{|l|}{$\operatorname{VEGF}(-1498 \mathrm{C} / \mathrm{T})$} \\
\hline $\mathrm{CC}$ & $3(9.7 \%)$ & $C=38.7 \%$ & $4(12.9 \%)$ & $C=38.7 \%$ & 1.0 \\
\hline CT & $18(58.0 \%)$ & $16(51.6 \%)$ & 0.60 & & \\
\hline$T \mathrm{~T}$ & $10(32.3 \%)$ & $\mathrm{T}=61.3 \%$ & $11(35.5 \%)$ & $\mathrm{T}=61.3 \%$ & 0.78 \\
\hline
\end{tabular}




\begin{tabular}{|c|c|c|c|c|c|}
\hline \multirow{2}{*}{$\begin{array}{l}\text { SNP position and } \\
\text { genotype }\end{array}$} & \multicolumn{2}{|c|}{ Pre- eclampsia } & \multicolumn{2}{|c|}{ Controls } & \multirow[b]{2}{*}{$p$ Value* } \\
\hline & Genotype frequency & Allelic frequency & Genotype frequency & Allelic frequency & \\
\hline \multicolumn{6}{|l|}{ VEGF (-1154 A/G) } \\
\hline GG & $0(0 \%)$ & $\mathrm{G}=12.9 \%$ & $1(3.2 \%)$ & $\mathrm{G}=16.1 \%$ & 1.0 \\
\hline$A G$ & $8(25.8 \%)$ & $8(25.8 \%)$ & 1.0 & & \\
\hline AA & $23(74.2 \%)$ & $A=87.1 \%$ & $22(71.0 \%)$ & $A=83.9 \%$ & 0.77 \\
\hline \multicolumn{6}{|l|}{ VEGF (-634 C/G) } \\
\hline GG & $11(35.5 \%)$ & $G=64.5 \%$ & $17(54.8 \%)$ & $G=74.2 \%$ & 0.12 \\
\hline CG & $18(58.0 \%)$ & $12(38.7 \%)$ & 0.12 & & \\
\hline $\mathrm{CC}$ & $2(6.5 \%)$ & $C=35.5 \%$ & $2(6.5 \%)$ & $C=25.8 \%$ & 1.0 \\
\hline \multicolumn{6}{|l|}{$\operatorname{VEGF}(+936 \mathrm{C} / \mathrm{T})$} \\
\hline $\mathrm{CC}$ & $15(48.4 \%)$ & $C=67.7 \%$ & $17(54.8 \%)$ & $C=74.2 \%$ & 0.61 \\
\hline $\mathrm{CT}$ & $12(38.7 \%)$ & $12(38.7 \%)$ & 1.0 & & \\
\hline $\mathrm{TT}$ & $4(12.9 \%)$ & $\mathrm{T}=32.3 \%$ & $2(6.5 \%)$ & $\mathrm{T}=25.8 \%$ & 0.66 \\
\hline
\end{tabular}

${ }^{*} p$ Value as determined by the chi-square or the Fisher's exact test when comparing genotype frequency of cases vs. controls.

Table VI. Umbilical vein VEGF levels according to SNP genotype of the promoter region of the VEGF gene among studied women.

\begin{tabular}{|c|c|c|c|c|}
\hline Position and genotype & $\begin{array}{c}\text { VEGF levels (pg/mL) } \\
\text { all women }\end{array}$ & $\begin{array}{c}\text { VEGF levels (pg/mL) } \\
\text { pre-eclampsia }\end{array}$ & $\begin{array}{c}\text { VEGF levels (pg/mL) } \\
\text { controls }\end{array}$ & $p$ Value* \\
\hline \multicolumn{5}{|l|}{ VEGF $(-2578 \mathrm{~A} / \mathrm{C})$} \\
\hline AA & 40.9 [79.2] & 52.5 [171.7] & $29.2[-]$ & 0.70 \\
\hline$A C$ & 34.9 [130.3] & 34.5 [151.6] & 54.1 [121.6] & 0.98 \\
\hline $\mathrm{CC}$ & 57.6 [127.7] & $33.8[84.8]$ & $101.1[193.2]$ & 0.04 \\
\hline$p$ Value** & 0.96 & 0.43 & 0.14 & \\
\hline \multicolumn{5}{|l|}{$\operatorname{VEGF}(-1498 \mathrm{C} / \mathrm{T})$} \\
\hline $\mathrm{CC}$ & $52.5[101.0]$ & $52.5[171.7]$ & $50.5[86.5]$ & 0.85 \\
\hline $\mathrm{CT}$ & 34.4 [139.5] & $26.3[144.6]$ & $54.1[145.1]$ & 0.60 \\
\hline $\mathrm{TT}$ & 66.7 [106.9] & $50.9[95.1]$ & $93.8[130.2]$ & 0.19 \\
\hline$p$ Value & 0.67 & 0.77 & 0.40 & \\
\hline \multicolumn{5}{|l|}{$\operatorname{VEGF}(-1154 \mathrm{~A} / \mathrm{G})$} \\
\hline GG & 10.2 & - & $10.2[-]$ & - \\
\hline$A G$ & $10.6[24.1]$ & $8.5[20.5]$ & 23.5 [118.5] & 0.23 \\
\hline AA & 86.4 [128.0] & 75.8 [151.0] & 93.8 [123.2] & 0.54 \\
\hline$p$ Value & 0.003 & 0.02 & 0.04 & \\
\hline \multicolumn{5}{|l|}{ VEGF $(-634 \mathrm{C} / \mathrm{G})$} \\
\hline GG & 35.0 [95.8] & 23.5 [193.8] & $41.3[75.1]$ & 0.46 \\
\hline$C G$ & 81.1 [134.7] & 50.9 [114.3] & 136.7 [186.2] & 0.19 \\
\hline $\mathrm{CC}$ & 63.9 [186.9] & $43.9[-]$ & $136.7[-]$ & 0.66 \\
\hline$p$ Value & 0.58 & 0.78 & 0.16 & \\
\hline
\end{tabular}




\begin{tabular}{|c|c|c|c|c|}
\hline Position and genotype & $\begin{array}{c}\text { VEGF levels (pg/mL) } \\
\text { all women }\end{array}$ & $\begin{array}{c}\text { VEGF levels (pg/mL) } \\
\text { pre-eclampsia }\end{array}$ & $\begin{array}{l}\text { VEGF levels }(\mathrm{pg} / \mathrm{mL}) \\
\text { controls }\end{array}$ & $p$ Value* \\
\hline \multicolumn{5}{|l|}{ VEGF $(+936 \mathrm{C} / \mathrm{T})$} \\
\hline $\mathrm{CC}$ & $44.1[129.8]$ & $52.5[165.2]$ & $36.3[117.1]$ & 0.84 \\
\hline $\mathrm{CT}$ & $51.3[126.3]$ & $16.3[91.5]$ & 110.4 [114.8] & 0.10 \\
\hline $\mathrm{TT}$ & 63.9 [146.9] & 55.7 [101.8] & $175.0[-]$ & 0.53 \\
\hline$p$ Value & 0.94 & 0.63 & 0.35 & \\
\hline
\end{tabular}

Data are presented as medians [interquartile ranges]. ${ }^{*} p$ Value as determined by the Mann-Whitney test when comparing cases vs. controls. ${ }^{* *} p$ Value obtained using the Kruskal-Wallis test after intragroup comparison.
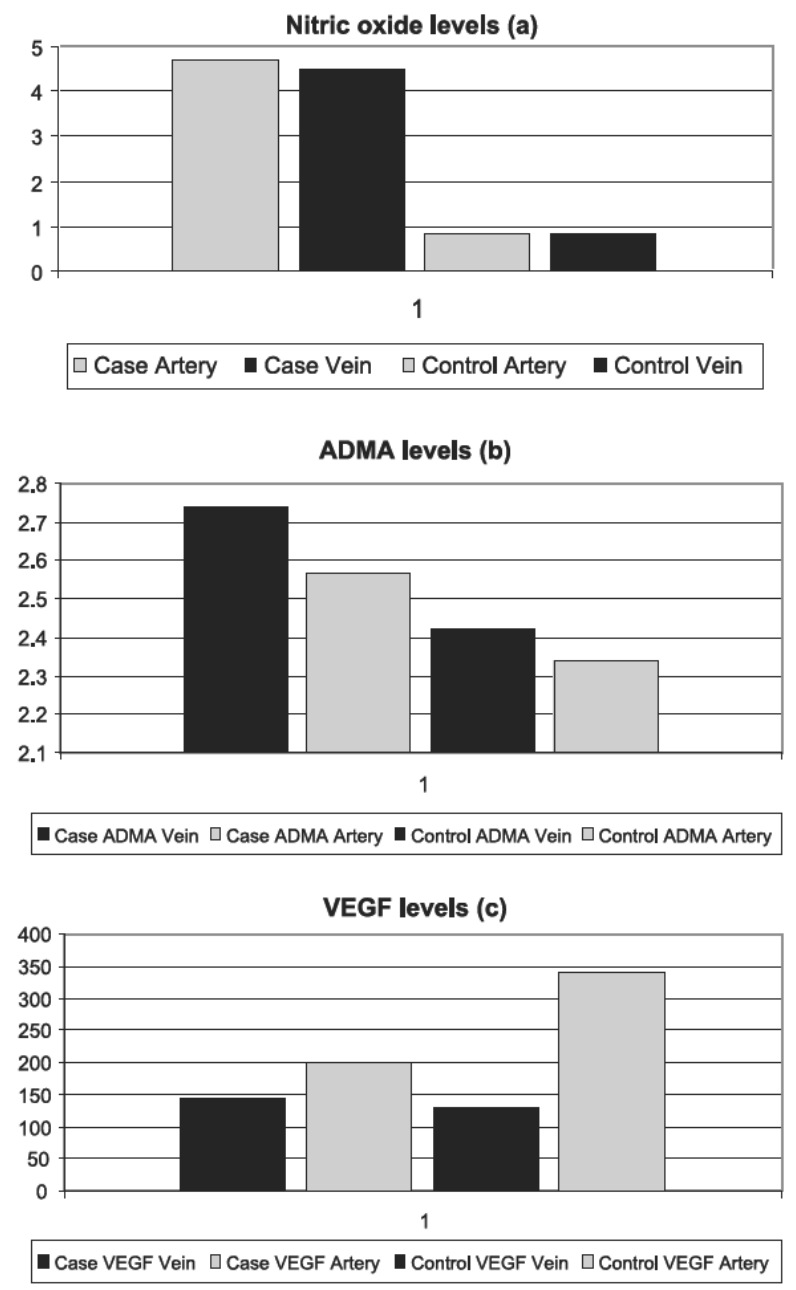

Figure 1. Levels in fetal circulation of NO (a), ADMA (b), and VEGF (c). 


\section{DISCUSSION}

Endothelial dysfunction is a feature of several disorders of pregnancy. Overt maternal and feto-placental endothelial dysfunction characterizes pre-eclampsia [19], which is associated to a higher risk for adverse maternal-fetal outcomes [1,20]. Pre-eclampsia is thought to derive from shallow extravillous trophoblast invasion of the decidua and incomplete remodeling of spiral arteries and arterioles [21]. Defective angiogenesis and the related fetoplacental vascular dysfunction are therefore considered key steps. However, the signs and symptoms of pre-eclampsia generally become apparent in the third trimester of pregnancy [1], which calls for the identification of early biomarkers capable of screening women at higher risk for pre-eclampsia. Several studies have observed a correlation between the onset of vascular dysfunction and pre-eclampsia with a reduction in circulating levels of angiogenic factors, such as placental growth factor (PLGF) and VEGF [3,22], and increased levels of anti-angiogenic factors [23]. Trofoblast cells isolated from pre-eclampsia placentas when cultured under regular oxygen condition produce more soluble endoglin, soluble fms-like tyrosine kinase receptor-1, and PLGF as compared to normal trofoblast cells [23]. These changes may contribute to systemic vascular damage, possibly determining some of the modifications found in the kidney that lead to hypertension and proteinuria typical of pre-eclampsia [1].

Increased NO together with the lower VEGF umbilical plasma levels observed in the present pre-eclamptic Ecuadorian series is in agreement with what is found in the literature for other populations, however, mostly reported from maternal circulation, consistent with the general anti-angiogenic state found in pre-eclampsia [4]. To note is the fact that not many studies can be found in the literature that report fetal umbilical cord circulating levels of the analytes measured in our research. Consistent with our findings, Braekke et al. [24] have reported higher umbilical vein ADMA levels among pre- eclampsia cases as compared controls. Interestingly, ADMA levels were found to be three times higher in fetal circulation than in the maternal circulation, suggesting that the placenta is the primary source of ADMA [24]. Another study failed to demonstrate higher ADMA levels in fetal circulation in women with pre-eclampsia yet higher levels related to prematurity and low birth weight [25]. Of interest was finding in this study [25] that ADMA levels were 4 fold higher in controls as compared to those of lactating women and healthy children and adults, implicating a physiological role for higher ADMA levels in maintaining vascular tone and blood redistribution to vital organs during birth, thereby favoring the circulatory transition from fetal to neonatal life [25]. The present study cannot answer whether the higher rate of small for gestational age found in preeclamptic pregnancies is related to altered amounts of feto-placental growth factors. Specifically, while lower umbilical concentrations of VEGF were observed in the present and other pre-eclampsia studies, such concentrations did not significantly correlate to placental or neonatal weight. 
Elevated umbilical plasma NO levels may represent an adaptive response of the fetus and placenta to maintain adequate blood supply in face of increased uterine and systemic vascular resistances and to the alleged defective angiogenesis affecting placental circulation. Whether this change is cause or consequence of pre-eclampsia is not known, but may also be seen in other pathological conditions related to pregnancy, such as fetal growth restriction, suggesting that it may rather represent a fetal response to adverse conditions imposed to pregnancy [26]. One of the biochemical changes that may elicit a feto-placental activation of the NO system may well be the increased amount of ADMA (the endogenous NOS inhibitor) which also displayed an elevated trend in umbilical blood. Indeed, previous studies have found that higher ADMA levels early during pregnancy may be associated to later development of pre-eclampsia [27].

Genetic background affects the likelihood of developing gestational hypertension and pre- eclampsia. Moreover, studies have associated pre-eclampsia to the development of subsequent cardiovascular risk [28]. Hence distribution of common SNPs of the VEGF gene was analyzed in the present research. These SNPs have also been related to cardiovascular disease [14]. Even if selected trends were noted, the limited sample size did not allow us to identify significant differences in the distribution of SNPs among analyzed groups. However, a potential strength of our study was finding a significant trend toward lower umbilical vein VEGF levels in pre-eclampsia cases in the presence of -2578 CC and -1154 AG genotypes. This is in agreement with the findings of other groups $[16,29]$. Contrary to this, Garza-Veloz et al. [30] have failed to demonstrate an association between pre-eclampsia and VEGF allele, genotype, or haplotype frequencies. Lower cord VEGF levels found in our in vivo model seem to fit well with previous in vitro findings reporting that in pre-eclampsia endogenous VEGF release is reduced at the placental site [31]. Although women with the 1154 allele have an increased risk for recurrent pregnancy losses [32], correlation between lower cord VEGF levels and the VEGF 1154 AG genotype is lacking in the literature.

Another interesting feature of our study was enrolling near term severe preeclamptic patients. About $75 \%$ of women delivering at Sotomayor Hospital have inadequate prenatal care due to low social and economic status [17]. This leads to delayed identification of pre-eclampsia and the development of overt disease, which is often diagnosed at the time of hospital admission for spontaneous labor. While most preeclampsia studies drawn from developed countries report data of women at lower gestational ages, our analysis shows that altered feto-placental levels of NO, ADMA, and VEGF were observed in pre-eclampsia near term.

As for the limitations of the present study one can mention the small sample size which does not allow drawing definitive conclusions in reference to the analyzed polymorphisms. Unfortunately, due to resource limitations, NOS polymorphisms were not explored, which may also be seen as a potential limitation. Nevertheless, exploring VEGF, NO, and ADMA levels and the VEGF polymorphisms on the fetal/placental side may be 
seen as strengths, providing insights for future research, which should include more cases and a broader range of analyzed polymorphisms (including NOS).

In summary, this study found elevated levels of NO and ADMA in the feto-placental circulation of pre-eclamptic women, along with lower VEGF levels. This biochemical pattern may suggest a combination of a defective angiogenesis coupled with a fetoplacental endothelial adaptive response aimed at maintaining an adequate blood flow to the fetus. A genetic predisposition toward lower umbilical vein VEGF levels is also suggested by the association with the VEGF -2578 CC and -1154 AG genotypes. These findings, despite the aforementioned limitations, contribute to the characterization of the biological basis of pre-eclampsia, and may help toward the future development of new strategies for the screening and treatment of pregnant women with this severe condition.

\section{Acknowledgments}

The authors thank Paola Orlandi, PhD, for her invaluable help with gene polymorphism analysis, participating women and authorities of the Sotomayor Hospital for making this initiative possible.

\section{Declaration of Interest}

The authors report no conflicts of interest. This research was partially supported by AECID ("Agencia Española de Cooperación Internacional para el Desarrollo") through grant B/017543/08 from the "Ministerio Español de Asuntos Exteriores y Cooperación" to Faustino R. Pérez-López, by the PRIN ("Progetti di Ricerca di Interesse Nazionale") grant 2004057090-007 by "Ministero Istruzione Università Ricerca" (MIUR) to Tommaso Simoncini and by grant provided by the SINDE ("Sistema de Investigación y Desarrollo"), Universidad Católica de Santiago de Guayaquil, Ecuador (SIU \# 68 Resolución Administrativa 038-2009) to Peter Chedraui. 


\section{REFERENCES}

1. Sibai B, Dekker G, Kupferminc M. Pre-eclampsia. Lancet 2005;365:785-799.

2. Zhou Y, Damsky CH, Fisher SJ. Pre- eclampsia is associated with failure of human cytotrophoblasts to mimic a vascular adhesion phenotype. One cause of defective endovascular invasion in this syndrome? J Clin Invest 1997;99:2152-2164.

3. Nadar SK, Karalis I, Al Yemeni E, Blann AD, Lip GY. Plasma markers of angiogenesis in pregnancy induced hypertension. Thromb Haemost 2005;94:1071-1076.

4. Levine RJ, Qian C, Leshane ES, Yu KF, England LJ, Schisterman EF, Wataganara T, et al. Two-stage elevation of cell-free fetal DNA in maternal sera before onset of pre- eclampsia. Am J Obstet Gynecol 2004;190:707-713.

5. Barden A, Ritchie J, Walters B, Michael C, Rivera J, Mori T, Croft K, Beilin L. Study of plasma factors associated with neutrophil activation and lipid peroxidation in pre- eclampsia. Hypertension 2001;38:803-808.

6. Madazli R, Aydin S, Uludag S, Vildan O, Tolun N. Maternal plasma levels of cytokines in normal and preeclamptic pregnancies and their relationship with diastolic blood pressure and fibronectin levels. Acta Obstet Gynecol Scand 2003;82:797-802.

7. Chedraui P, Lockwood CJ, Schatz F, Buchwalder LF, Schwager G, Guerrero C, Escobar GS, Hidalgo L. Increased plasma soluble fms-like tyrosine kinase 1 and endoglin levels in pregnancies complicated with pre- eclampsia. J Matern Fetal Neonatal Med 2009;22:565-570.

8. Krause BJ, Hanson MA, Casanello P. Role of nitric oxide in placental vascular development and function. Placenta 2011;32:797-805.

9. Shaamash AH, Elsnosy ED, Makhlouf AM, Zakhari MM, Ibrahim OA, EL-dien HM. Maternal and fetal serum nitric oxide (NO) concentrations in normal pregnancy, pre-eclampsia and eclampsia. Int J Gynaecol Obstet 2000;68:207-214.

10. Slaghekke F, Dekker G, Jeffries B. Endogenous inhibitors of nitric oxide and pre- eclampsia: a review. J Matern Fetal Neonatal Med 2006;19:447-452.

11. Anderssohn M, Maass LM, Diemert A, Lüneburg N, Atzler D, Hecher K, Böger RH. Severely decreased activity of placental dimethylarginine dimethylaminohydrolase in pre-eclampsia. Eur J Obstet Gynecol Reprod Biol 2012;161:152-156.

12. Furuya M, Kurasawa K, Nagahama K, Kawachi K, Nozawa A, Takahashi T, Aoki I. Disrupted balance of angiogenic and antiangiogenic signalings in pre- eclampsia. J Pregnancy 2011;2011:123717.

13. Khakoo AY, Sidman RL, Pasqualini R, Arap W. Does the reninangiotensin system participate in regulation of human vasculogenesis and angiogenesis? Cancer Res 2008;68:9112-9115.

14. Pasqualetti G, Danesi R, Del Tacca M, Bocci G. Vascular endothelial growth factor pharmacogenetics: a new perspective for anti-angiogenic therapy. Pharmacogenomics 2007;8:49-66.

15. Howell WM, Ali S, Rose-Zerilli MJ, Ye S. VEGF polymorphisms and severity of atherosclerosis. J Med Genet 2005;42:485-490.

16. Sandrim VC, Palei AC, Cavalli RC, Araújo FM, Ramos ES, Duarte G, Tanus-Santos JE. Vascular endothelial growth factor genotypes and haplotypes are associated with pre-eclampsia but not with gestational hypertension. Mol Hum Reprod 2009;15:115-120.

17. Paredes I, Hidalgo L, Chedraui P, Palma J, Eugenio J. Factors associated with inadequate prenatal care in Ecuadorian women. Int J Gynaecol Obstet 2005;88:168-172.

18. ACOG Committee on Practice Bulletins--Obstetrics. ACOG practice bulletin. Diagnosis and management of pre- eclampsia and eclampsia. Number 33, January 2002. Obstet Gynecol 2002;99:159-167.

19. Redman CW, Sargent IL. Pre-eclampsia, the placenta and the maternal systemic inflammatory responsea review. Placenta 2003;24 Suppl A:S21-S27.

20. Yücesoy G, Ozkan S, Bodur H, Tan T, Caliskan E, Vural B, Corakçi A. Maternal and perinatal outcome in pregnancies complicated with hypertensive disorder of pregnancy: a seven year experience of a tertiary care center. Arch Gynecol Obstet 2005;273:43-49. 
21. Pijnenborg R, Vercruysse L, Hanssens $M$. The uterine spiral arteries in human pregnancy: facts and controversies. Placenta 2006;27:939-958.

22. Teran E, Chedraui P, Vivero S, Villena F, Duchicela F, Nacevilla L. Plasma and placental nitric oxide levels in women with and without pre-eclampsia living at different altitudes. Int J Gynaecol Obstet 2009;104:140-142.

23. Gu Y, Lewis DF, Wang Y. Placental productions and expressions of soluble endoglin, soluble fms-like tyrosine kinase receptor-1, and placental growth factor in normal and preeclamptic pregnancies. J Clin Endocrinol Metab 2008;93:260-266.

24. Braekke K, Ueland PM, Harsem NK, Staff AC. Asymmetric dimethylarginine in the maternal and fetal circulation in pre- eclampsia. Pediatr Res 2009;66:411-415.

25. Tsukahara H, Ohta N, Tokuriki S, Nishijima K, Kotsuji F, Kawakami H, Ohta N, et al. Determination of asymmetric dimethylarginine, an endogenous nitric oxide synthase inhibitor, in umbilical blood. Metab Clin Exp 2008;57:215-220.

26. Ness RB, Sibai BM. Shared and disparate components of the pathophysiologies of fetal growth restriction and pre- eclampsia. Am J Obstet Gynecol 2006;195:40-49.

27. Savvidou MD, Hingorani AD, Tsikas D, Frölich JC, Vallance P, Nicolaides KH. Endothelial dysfunction and raised plasma concentrations of asymmetric dimethylarginine in pregnant women who subsequently develop pre-eclampsia. Lancet 2003;361:1511-1517.28. Bellamy L, Casas JP, Hingorani AD, Williams DJ. Pre-eclampsia and risk of cardiovascular disease and cancer in later life: systematic review and metaanalysis. BMJ 2007;335:974.

29. Bányász I, Szabó S, Bokodi G, Vannay A, Vásárhelyi B, Szabó A, Tulassay T, Rigó J. Genetic polymorphisms of vascular endothelial growth factor in severe pre-eclampsia. Mol Hum Reprod 2006;12:233-236.

30. Garza-Veloz I, Castruita-De la Rosa C, Cortes-Flores R, Martinez-Gaytan V, Rivera-Muñoz JE, GarciaMayorga EA, Meza-Lamas E, et al. No association between polymorphisms/haplotypes of the vascular endothelial growth factor gene and pre- eclampsia. BMC Pregnancy Childbirth 2011;11:35.

31. Brownbill P, Mills TA, Soydemir DF, Sibley CP. Vasoactivity to and endogenous release of vascular endothelial growth factor in the in vitro perfused human placental lobule from pregnancies complicated by pre- eclampsia. Placenta 2008;29:950-955.

32. Galazios G, Papazoglou D, Tsikouras P, Kolios G. Vascular endothelial growth factor gene polymorphisms and pregnancy. J Matern Fetal Neonatal Med 2009;22:371-378. 



\section{CHAPTER 5}

The role of genetics in the pathogenesis of pre- eclampsia 



\section{CHAPTER 5A}

Polymorphisms of the methylenetetrahydrofolate reductase gene (C677T and A1298C) in nulliparous women complicated with pre- eclampsia.

Chedraui P, Salazar-Pousada D, Villao A, Escobar GS, Ramirez C, Hidalgo L, Pérez-López FR, Genazzani AR, Simoncini T.

Gynecol Endocrinol 2014;30:392-6. 


\section{ABSTRACT}

Objective: To determine the prevalence of C677T and A1298C Single-nucleotide polymorphisms (SNPs) of the MTHFR gene in nulliparous women complicated with preeclampsia (PE).

Methods: One hundred fifty gestations complicated with PE and their corresponding controls without the disease were recruited for the genotyping of C677T and A1298C polymorphisms of the MTHFR gene using restriction fragment length polymorphism polymerase chain reaction. Secondarily, homocysteine (HCy) plasma levels were measured in preeclamptic women displaying the CC genotype of the A1298C polymorphism (homozygous) and compared to $\mathrm{HCy}$ levels determined among controls with the normal AA genotype for the A1298C variant.

Results: Only the mutant CC genotype of the A1298C polymorphism was associated to higher risk of presenting $\mathrm{PE}$, as frequency of this genotype was significantly higher among cases than controls $(15.3 \%$ versus $0.7 \%, p<0.05)$. All PE women with a neck circumference $\geq 32 \mathrm{~cm}$ presented the mutant CC A1298C polymorphism as compared to none among preeclamptics with a lower neck circumference $(p=0.0001)$. Women with the mutant CC A1298C SNP displayed higher plasma HCy levels as compared to controls with normal AA A1298C genotype ( $8.4 \pm 2.6$ versus $7.5 \pm 2.7 \mathrm{mmoL} / \mathrm{L} p=0.04$ ).

Conclusion: Prevalence of the CC mutant genotype of the A1298C polymorphism was higher among PE women. This mutation among PE women was related to increased neck circumference and higher $\mathrm{HCy}$ levels. Future research should aim at linking these gestational findings with obesity and cardiovascular risk.

Keywords: Genetics, homocysteine, polymorphisms, pre- eclampsia, pregnancy 


\section{INTRODUCTION}

Pre- eclampsia (PE) is a frequent complication of pregnancy that accounts for $5-14 \%$ of all deliveries, and causes adverse maternal and perinatal outcomes [1-3]. Although the exact cause of PE remains undetermined, key pathogenic factors include: immunologic factors, abnormal placental implantation, genetic and environmental factors and cardiovascular and exaggerated inflammatory changes [4-10].

Single-nucleotide polymorphisms (SNPS) are variations of the genome sequence, which may modify biological responses and the risk of certain diseases. Numerous SNPS have been studied in preeclamptic patients [5,11-15]. The methylenetetrahydrofolate reductase (MTHFR) enzyme is critical for homocysteine (HCy) metabolism, catalyzing the NADPH-linked reduction of 5,10-MTHF to 5-MTHF, and subsequently the vitamin B12-dependent methylation of $\mathrm{HCy}$ to methionine $[5,16]$. A reduction in MTHFR levels or activity by specific gene mutations induces mild to moderate increases in plasma HCy levels [17]. Although several mutations of the MTHFR gene have been described in relation to $P E$, the most frequent ones include: the alanine-to-valine C677T [18] and the glutamate-to-alanine A1298C [19]. While both SNPs induce milder forms of MTHFR deficiency $[19,20]$, the A1298C SNP (located in the enzyme regulatory domain) as compared to the C677T variant (located in the enzyme catalytic domain), does not result in either a thermolabile protein or increased HCy blood levels [21]. Interestingly, reports indicate that C677T/A1298C compound heterozygosity has similar clinical impact as C677T homozygosity [20,22].

Data related to the genetic assessment of women complicated with PE from developing countries are scarce or lacking. Hence, the aim of this study was to determine the prevalence of C677T and A1298C polymorphisms of the MTHFR gene in nulliparous women complicated with PE. Secondarily, plasma HCy levels were measured in preeclamptic women displaying the homozygous CC genotype of the A1298C polymorphism and compared to $\mathrm{HCy}$ levels determined among controls with the normal AA genotype for the A1298C variant.

\section{METHODS}

\section{Design and subjects}

This research was carried out at the Institute of Biomedicine, Universidad Católica de Santiago de Guayaquil in collaboration with the Enrique C. Sotomayor Obstetrics and Gynecology Hospital, Guayaquil, Ecuador. This Hospital is a major referral center that provides maternal and neonatal healthcare to the low-income population of Guayaquil, Ecuador. This facility has one of the highest delivery rate in Latin America (> 30000 per year) in addition to increased rates of high-risk pregnancies. 
Nulliparous women with singleton gestations fulfilling PE criteria admitted for delivery to the High Risk Pregnancy Labor and Delivery Unit were recruited. Nulliparous women without PE delivering in the low risk Unit served as controls. All participants were recruited after signing informed consent. Women denying participating were excluded from the study.

ACOG criteria was used to define PE as a blood pressure $\geq 140 / 90 \mathrm{mmHg}$ and proteinuria + or more on at least two random samples four hours apart. PE was defined as severe if blood pressure was $\geq 160 / 110 \mathrm{mmHg}$ and proteinuria was +++ or more [3]. Maternal socio-demographic, pregnancy and obstetrical and neonatal outcome data was recorded on a specific data sheet. Research study protocol was reviewed and approved by the Institutional Review Board of the Enrique C. Sotomayor Hospital.

\section{Blood sampling and biochemical assay}

A 10-15 $\mathrm{ml}$ peripheral venous blood sample was obtained from each participant, which was then centrifuged at $5^{\circ} \mathrm{C}$ for $10 \mathrm{~min}$ at $3000 \mathrm{rpm}$. Obtained plasma and white cells were decanted into $0.5 \mathrm{ml}$ aliquots, which were then stored at $-70^{\circ} \mathrm{C}$ until further analysis. HCy plasma levels were measured with a microparticle chemiluminescent immunoassay using an ARCHITEC autoanalyzer (ARCHITEC $i$ System, Abbott Diagnostic Laboratories, Abbott Park, Chicago, IL).

\section{Single nucleotide polymorphism (SNP) genotyping}

DNA was extracted from whole blood using the PureLink genomic kit (Invitrogen ${ }^{\circledR}$, Carlsbad, CA), which was then amplified through conventional polymerase chain reaction (PCR) technique using the following primers: 5'TGAAGGAGAAGGTGTCTGCGGGA3' and 5'AGGACGGT GCGGTGAGAGTG3' for C677T; and 5'TGATGAAATCGGC TCCCGCA3' and 5'TGATGATGAAATCGACTCCCGCA3' for A1298C. The amplified product (a $198 \mathrm{bp}$ fragment of exon 4 of the MTHFR gene) was used for the genotyping of the C677T and A1298C polymorphisms using restriction fragment length polymorphism PCR. Allelic distribution for C677T and A1298C SNPs was in Hardy-Weinberg equilibrium.

\section{Statistical analysis}

Statistical analysis was performed using the Statistical Package for the Social Sciences version 19.0 (IBM SPSS, Armonk, NY). Data are presented as mean \pm standard deviations, frequencies, percentages, odds ratios and 95\% confidence intervals. The Kolmogorov-Smirnov test was used to determine the normality of data distribution. According to this, continuous data were compared with student's $t$ test (parametric) or the Mann Whitney $U$ test (non parametric). Chi-square, Yates' corrected chi-square and Fisher's exact tests were used to compare percentages (including the comparison of genotype 
frequencies between cases and controls). A $p$ value of $<0.05$ was considered as statistically significant.

\section{RESULTS}

A total of three hundred pregnant women were recruited during the study period ( $n=$ 150 cases of PE and $n=150$ controls). Socio-demographic and obstetrical outcome data of studied women are depicted on Table 1 . Women with PE lived more frequently in rural areas or had a family history of hypertension and had fewer prenatal visits than controls. Anthropometric measures (neck and mid-arm circumference) were significantly higher in PE women. C-section rate was also significantly increased among women with PE as compared to controls.

Neonatal gestational age and weight was significantly lower among PE women. The rate of preterm birth, small for gestational age infants, low birth weight and low Apgar scores (first and five minutes) were significantly higher among PE women as compared to controls (Table 2). There were no neonatal deaths in either studied groups.

Genotype frequencies of the studied MTHFR gene polymorphisms (C677T and A1298C) among cases and controls are depicted on Table 3. No significant differences were observed among cases and controls in relation to genotype frequencies for the C677T polymorphism. Contrary to this, the mutant CC genotype of the A1298C polymorphism was associated to a higher risk of presenting PE (OR: 25.3 , 95\% Cl: $3.53-$ $512.4, p=0.0001)$, as prevalence of this genotype was found to be significantly higher among PE cases as compared to controls (15.3\% versus $0.7 \%, p<0.05)$. Among cases, frequency of C677T and $\mathrm{A} 1298 \mathrm{C}$ genotypes did not differ when women were stratified according to PE severity, the presence of a small for gestational age neonate or history of family hypertension. However, all PE women with a neck circumference $\geq 32 \mathrm{~cm}$ presented the mutant CC genotype of the $\mathrm{A} 1298 \mathrm{C}$ polymorphism as compared to none among PE women with a neck circumference $<32 \mathrm{~cm}(p=0.0001)$. Women with the mutant CC genotype $\mathrm{A} 1298 \mathrm{C}$ polymorphism displayed higher plasma HCy levels as compared to controls with the normal A1298C genotype (homozygous for AA) $(8.4 \pm 2.6$ versus $7.5 \pm 2.7 \mathrm{mmoL} / \mathrm{L} p=0.04$, Mann-Whitney $U$ test). 
Table 1. Socio-demographic and obstetrical outcome data of studied women.

\begin{tabular}{|c|c|c|c|}
\hline Socio-demographic & $\begin{array}{c}\text { Cases } \\
n=150\end{array}$ & $\begin{array}{l}\text { Controls } \\
n=150\end{array}$ & $p$ Value* \\
\hline Age (years) & $19.9 \pm 5.0$ & $19.4 \pm 4.4$ & 0.33 \\
\hline Cohabiting & $97(64.7)$ & $90(60.0)$ & 0.40 \\
\hline Lives in rural area & $70(46.7)$ & $44(29.3)$ & 0.001 \\
\hline Educational level (years) & $10.1 \pm 3.0$ & $10.0 \pm 3.2$ & 0.76 \\
\hline Alcohol consumption during pregnancy & $5(3.3)$ & $7(4.7)$ & 0.55 \\
\hline Cigarette consumption during pregnancy & $1(0.7)$ & $3(2.0)$ & 0.61 \\
\hline Employed & $16(10.7)$ & $16(10.7)$ & 1.0 \\
\hline Age at menarche (years) & $12.7 \pm 1.3$ & $12.6 \pm 1.4$ & 0.62 \\
\hline Sometime contraceptive use & $23(15.3)$ & $20(13.3)$ & 0.62 \\
\hline Family history of hypertension & $37(24.7)$ & $14(9.3)$ & 0.0001 \\
\hline Number of prenatal visits & $5.1 \pm 2.3$ & $5.9 \pm 2.1$ & 0.002 \\
\hline \multicolumn{4}{|l|}{ Pregnancy and obstetrical outcome } \\
\hline Systolic blood pressure (mmHg) & $151.8 \pm 17.6$ & $109 \pm 12.3$ & 0.0001 \\
\hline Diastolic blood pressure (mmHg) & $99.1 \pm 15.0$ & $68.1 \pm 10.0$ & 0.0001 \\
\hline Severe pre- eclampsia & $110(73.3)$ & - & \\
\hline Mild pre- eclampsia & $40(26.7)$ & - & \\
\hline Neck circumference $(\mathrm{cm})$ & $33.6 \pm 3.5$ & $31.5 \pm 3.1$ & 0.0001 \\
\hline Neck circumference $\geq 32 \mathrm{~cm}$ (median) & $114(76.0)$ & $76(50.7)$ & 0.0001 \\
\hline Mid-arm circumference $(\mathrm{cm})$ & $27.8 \pm 4.0$ & $25.9 \pm 3.3$ & 0.0001 \\
\hline Delivery by c-section & $121(80.7)$ & $53(35.3)$ & 0.0001 \\
\hline
\end{tabular}

Data are presented as mean \pm standard deviations or $n(\%)$.

${ }^{*} p$ Value as determined according to case with the Mann-Whitney $U$ test, the Student's $T$ test or the chisquare or Yates' corrected chi-square test.

Table 2. Neonatal outcome among studied women.

\begin{tabular}{|c|c|c|c|}
\hline Parameter & $\begin{array}{c}\text { Cases } \\
n=150\end{array}$ & $\begin{array}{c}\text { Controls } \\
n=150\end{array}$ & $p$ Value* \\
\hline Gestational age (weeks) & $36.7 \pm 3.3$ & $38.7 \pm 1.7$ & 0.0001 \\
\hline Neonatal birthweight (gr) & $2406.1 \pm 765.5$ & $2975.3 \pm 502.4$ & 0.0001 \\
\hline Female gender & $77(51.3)$ & $74(49.3)$ & 0.72 \\
\hline Stillbirths & $4(2.7)$ & $0(0.0)$ & 0.12 \\
\hline Preterm & $47(31.3)$ & $12(8.0)$ & 0.0001 \\
\hline Small for gestational age & $61(40.7)$ & $15(10.0)$ & 0.0001 \\
\hline Low birthweight $(<2,500 \mathrm{gr})$ & $72(48.0)$ & $26(17.3)$ & 0.0001 \\
\hline Apgar $<7$ at first minute & $48(32.0)$ & $15(10.0)$ & 0.0001 \\
\hline Apgar $<7$ in five minutes & $21(14.0)$ & $3(2.0)$ & 0.0001 \\
\hline Admittance to NICU & $8(5.3)$ & $3(2.0)$ & 0.12 \\
\hline
\end{tabular}

Data are presented as mean \pm standard deviations or $n(\%)$.

${ }^{*} p$ Value as determined according to case with the Mann $U$ Whitney test, Student's $T$ test, chi-square or Fisher's exact test. NICU, neonatal intensive care unit. 
Table 3. Genotype frequencies of the studied MTHFR gene polymorphisms (C677T and A1298C) among cases and controls.

\begin{tabular}{lccccc}
\hline Genotype & Cases & Controls & & & \\
& $n=150$ & $n=150$ & Odds ratio & $95 \% \mathrm{Cl}$ & $p$ Value \\
\hline C677T & $59(39.3)$ & $47(31.3)$ & 1 & & 0.07 \\
CC & $73(48.7)$ & $91(60.7)$ & 0.64 & $0.38-1.08$ & 0.67 \\
CT & $18(12.0)$ & $12(8.0)$ & 1.19 & $0.49-2.95$ & 0.14 \\
TT & $91(60.7)$ & $103(68.7)$ & 0.70 & $0.43-1.16$ & 0.34 \\
CT + TT & $100(66.7)$ & $110(73.3)$ & 1 & & 0.0001 \\
A1298C & $27(18.0)$ & $39(26.0)$ & 0.76 & $0.42-1.38$ & 0.2 \\
AA & $23(15.3)$ & $1(0.7)$ & 25.30 & $3.53-512.4$ & $0.81-2.33$ \\
AC & $50(33.3)$ & $40(26.7)$ & 1.38 & & \\
CC & & & & \\
AC + CC & & & & \\
\hline
\end{tabular}

Data are presented as $n(\%)$ and odds ratios and 95\% confidence intervals $(\mathrm{Cl})$.

\section{DISCUSSION}

PE is a mysterious disease that produces severe or even fatal obstetrical complications and beyond pregnancy it has been associated to future increased cardiovascular risk [23-26]. In developing countries, such as Ecuador, its prevalence tends to be higher than in developed populations and in relation to factors such as inadequate prenatal care, genetic factors, ethnicity, malnutrition and low socio-economical income [3,2729]. Highlighting this, our PE cases displayed fewer prenatal visits and higher rates of rural residency and family history of hypertension and adverse maternal and neonatal outcomes.

This study aimed at examining among nulliparous women complicated with PE the prevalence of two known SNPs of the MTHFR gene (C677T and A1298C). The prevalence of the mutant CC genotype of the $\mathrm{A} 1298 \mathrm{C}$ polymorphism was found to be higher in our PE women as compared to controls. Prevalence did not vary in accordance to disease severity nor to the presence of small gestational age neonates or a family history of hypertension. In addition, women with this mutant genotype displayed higher plasma HCy levels as compared to controls with the normal AA genotype (A1298C). These findings correlate with those observed in a group of Tunisian women with several pregnancy complications including recurrent pregnancy loss, PE, placental abruption and fetal intrauterine growth restriction [17].

The MTHFR enzyme catalyzes the irreversible conversion of 5,10-MTHF into 5MTHF, which is the methyl donor for remethylation of HCy to methionine. Certain common polymorphisms within the MTHFR gene (C677T or A1298C) result in reduced enzymatic remethylation of $\mathrm{HCy}$ to methionine and, consequently, are associated with higher HCy blood levels [24]. Around 30\% of Europeans, $10 \%$ of Africans and $50 \%$ of 
Chinese people display C677T and/or A1298C variants of the MTHFR gene, with increased cardiovascular risk and altered metabolic processes among homozygous cases [18-22,30]. Although reports indicate that the A1298C variant seems to only cause problems when it is associated with the C677T variant [31], our study found no difference in the prevalence of the C677T genotypes when PE women were compared to controls. Other MTHFR variants have been less studied and are probably not of relevance.

In a meta-analysis including 51 studies, the C677T MTHFR polymorphism was associated to an overall increased risk for PE among Caucasian and East Asian populations. Unfortunately, the study only analyzed a small sample for Latin, East Asian, South Asian and African populations [32]. In a small sample of a Mexican Maya-Mestizo population, the MTHFR 677T allele and the 677TT genotype were significantly more frequent among controls, suggesting an association with a decreased risk of PE [33]. This study is to the best of our knowledge the first to assess MTHFR polymorphisms among PE complicated gestations within a low-income Mestizo Ecuadorian population in which although prevalence of the $\mathrm{A} 1298 \mathrm{C}$ mutant CC genotype was found to be higher among PE cases, the mutant TT genotype for C677T was not. Our results are in agreement with others showing that C677T polymorphisms did not correlate to uterine artery Doppler values and bilateral or unilateral notch occurrences at 12 and 22 weeks of pregnancy [34], or the risk of intrauterine fetal death, PE and preterm delivery [35-38].

Our study not only found that the CC mutant genotype of the A1298C variant was significantly associated with PE yet these women displayed higher HCy plasma levels. In accordance to this, Klai et al. [17] have reported that women with the MTHFR A1298C mutation have a higher risk of placental vasculopathies and elevated HCy levels. Contrary to this, Said et al. [39] reported among an Australian cohort that nulliparous women with homozygous MTHFR A1298C polymorphism had a lower risk for poor obstetric outcomes (PE, fetal growth restriction, placental abruption and stillbirth).

Hyperhomocysteinemia and folic acid and vitamin $B_{12}$ deficiency along with increased blood pressure are risk factors for thrombotic events and the development of PE $[40,41]$. The mechanisms underlying hyperhomocysteinemia may relate to genetic polymorphisms, vitamin B12 and folic acid deficiency, oxidative stress and endothelial dysfunction. We have previously reported that PE patients display significantly lower erythrocyte folic acid levels together with higher serum HCy levels as compared to controls [42]. Hyperhomocysteinemia and MTHFR polymorphisms in women with PE have previously been reported, fact that is in agreement with our data. Despite the aforementioned, hyperhomocysteinemia itself cannot be solely explained by those mutations [43-46]. It is clear that women with PE have higher HCy blood concentrations than those with uncomplicated pregnancies; however, as found in our series, relationship between HCy levels and PE severity is not clear [47].

The global risk of PE increases significantly with increasing BMI and younger age. Thus, extreme obese teenagers have almost four times the risk of developing PE as 
compared to nonobese pregnant women aged $20-24$ years [46]. Obesity is also a risk factor for preterm birth; and in multivariable regression analysis, the most important intermediate variable is PE [48]. In this study, two indirect measures of obesity - neck and mid-arm circumference - were significantly higher in cases than in the controls suggesting an association between obesity and PE risk. Ursavas et al. [49] have reported neck circumference as an independent risk factor for gestational hypertension and PE. In addition, our series found that a higher neck circumference, thus increased weight (cut off value of $32 \mathrm{~cm}$ ), was associated with a higher prevalence of the mutant CC genotype A1298C variant and moreover these women displayed higher HCy levels. Elucidating a link between these gestational findings and future cardiovascular risk is certainly wanted.

As for the limitations of this study, one can mention the lack of vitamin B12 and folic acid measurements, which would have given more information about the individual metabolic status and its relation to the studied polymorphisms. Analyzing proinflammatory cytokines and adipocytokines (i.e. leptin) would have aided at giving more insights regarding the relationship between PE, obesity and cardiovascular risk [46,5052]. Finally, another concern is the difficulty to assessing obesity in pregnant women [53], moreover if one lacks prenatal or early pregnancy weight. Despite this, we obviated this problem by using indirect anthropometric parameters of obesity, which have been validated by others $[54,55]$. Despite these limitations, our study has the strength of being the first to provide data of the genetic assessment of polymorphisms in PEcomplicated gestations from a homogeneous low-income Ecuadorian Mestizo population.

In conclusion, prevalence of the CC mutant genotype for the A1298C polymorphism was higher among PE women. This mutation among PE women was related to increased neck circumference and higher HCy levels. Future research should aim at linking these gestational findings with obesity and cardiovascular risk.

\section{Authors' role}

P. C., F. R. P-L. and T. S.: study conception and design; D. S-P and A. V acquisition of clinical data; G. S. E and C. R. laboratory work; P. C., L. H., F. R. P-L., A. G. and T. S.: analysis and interpretation of data; P. C. and F. R. P-L.: drafting of manuscript; L. H. and A. G.: critical revision; P. C. and F. R. P-L.: final adjustments; all authors approved the final version.

\section{Acknowledgements}

Authors thank the women who participated in this initiative. 


\section{Declaration of interest}

The authors declare no conflicts of interest.

This research was supported by the Universidad Católica de Santiago de Guayaquil, Guayaquil, Ecuador, through grant no. SIU-165-2729-2011 (Proyecto GenRAE: Genética de Resultantes Adversas del Embarazo) provided to Luis Hidalgo by the Sistema de Investigación y Desarrollo. Partial support was also received by AECID ("Agencia Española de Cooperación Internacional para el Desarrollo") through grant B/017543/08 provided to Faustino R. Pérez-López by the "Ministerio Español de Asuntos Exteriores y Cooperación") and by the PRIN ("Progetti di Ricerca di Interesse Nazionale") grant 2004057090-007 provided to Tommaso Simoncini by the "Ministero Istruzione Università Ricerca" (MIUR). 


\section{REFERENCES}

1. Ngoc NT, Merialdi M, Abdel-Aleem H, et al. Causes of stillbirths and early neonatal deaths: data from 7993 pregnancies in six developing countries. Bull World Health Organ 2006;84:699-705.

2. Lindheimer MD, Taler SJ, Cunningham FG. ASH position article. Hypertension in pregnancy. J Am Soc Hypertens 2008;2:484-94.

3. Turner JA. Diagnosis and management of pre-eclampsia: an update. Int J Women's Health 2010;2:327-37.

4. Taylor RN, de Groot CJ, Cho YK, Lim KH. Circulating factors as markers and mediators of endothelial cell dysfunction in pre- eclampsia. Semin Reprod Endocrinol 1998;16:17-31.

5. Barbosa PR, Stabler SP, Machado AL, et al. Association between decreased vitamin levels and MTHFR, MTR and MTRR gene polymorphisms as determinants for elevated total homocysteine concentrations in pregnant women. Eur J Clin Nutr 2008;62:1010-21.

6. Valenzuela FJ, Pérez-Sepúlveda A, Torres MJ, et al. Pathogenesis of pre- eclampsia: the genetic component. J Pregnancy 2012;2012:632732.

7. Roberts JM, Escudero C. The placenta in pre- eclampsia. Pregnancy Hypertens 2012;2:72-83.

8. Barakonyi A, Miko E, Szereday L, et al. Cell death mechanisms and potentially cytotoxic natural immune cells in Human pregnancies complicated by pre- eclampsia. Reprod Sci 2014;21:155-66.

9. Svensson-Arvelund J, Ernerudh J, Buse E, et al. The placenta in toxicology. Part II: systemic and local immune adaptations in pregnancy. Toxicol Pathol 2014;42:327-38.

10. Ostlund E, Al-Nashi M, Hamad RR, et al. Normalized endothelial function but sustained cardiovascular risk profile 11 years following a pregnancy complicated by pre- eclampsia. Hypertens Res 2013;36:1081-7.

11. Chedraui P, Solis EJ, Bocci G, et al. Feto-placental nitric oxide, asymmetric dimethylarginine and vascular endothelial growth factor (VEGF) levels and VEGF gene polymorphisms in severe pre- eclampsia. J Matern Fetal Neonatal Med 2013;26:226-32.

12. El-Sherbiny WS, Nasr AS, Soliman A. Endothelial nitric oxide synthase (eNOS) (Glu298Asp) and urotensin II (UTS2 S89N) gene polymorphisms in pre- eclampsia: prediction and correlation with severity in Egyptian females. Hypertens Pregnancy 2013;32:292-303.

13. Groten T, Schleussner E, Lehmann T, et al. eNOSI4 and EPHX1 polymorphisms affect maternal susceptibility to pre- eclampsia: analysis of five polymorphisms predisposing to cardiovascular disease in 279 Caucasian and 241 African women. Arch Gynecol Obstet 2014;289:581-93.

14. Song GG, Kim JH, Kim YH, et al. Associations between vascular endothelial growth factor gene polymorphisms and pre-eclampsia susceptibility: a meta-analysis. Hum Immunol 2013;74:1206-13.

15. Yang J, Shang J, Zhang S, et al. The role of the renin-angiotensin- aldosterone system in pre- eclampsia: genetic polymorphisms and microRNA. J Mol Endocrinol 2013;50:R53-66.

16. Jacques PF, Bostom AG, Williams RR, et al. Relation between folate status, a common mutation in methylenetetrahydrofolate reductase, and plasma homocysteine concentrations. Circulation 1996;93:7-9.

17. Klai S, Fekih-Mrissa N, El Housaini S, et al. Association of MTHFR A1298C polymorphism (but not of MTHFR C677T) with elevated homocysteine levels and placental vasculopathies. Blood Coagul Fibrinolysis 2011;22:374-8.

18. Frosst $\mathrm{P}, \mathrm{Blom} \mathrm{HJ}$, Milos $\mathrm{R}$, et al. A candidate genetic risk factor for vascular disease: a common mutation in methylenetetrahydrofolate reductase. Nat Genet 1995;10:111-3.

19. van der Put NM, Gabreels F, Stevens EM, et al. A second common mutation in the methylenetetrahydrofolate reductase gene: an additional risk factor for neural-tube defects? Am J Hum Genet 1998;62:1044-51.

20. Chango A, Boisson F, Barbe F, et al. 2000. The effect of 677C-4T and 1298A-4C mutations on plasma homocysteine and 5,10- methylenetetrahydrofolate reductase activity in healthy subjects. Br J Nutr 2000;83:593-6.

21. Friso S, Girelli D, Trabetti E, et al. A1298C methylenetetrahydrofolate reductase mutation and coronary artery disease: relationships with C677T polymorphism and homocysteine/folate metabolism. Clin Exp Med 2002;2:7-12. 
22. Chen M, Xia B, Rodriguez-Gueant RM, et al. Genotypes 677TT and 677CT + 1298AC of methylenetetrahydrofolate reductase are associated with the severity of ulcerative colitis in central China. Gut 2005;54:733-4.

23. Newstead J, von Dadelszen P, Magee LA. Pre- eclampsia and future cardiovascular risk. Expert Rev Cardiovasc Ther 2007;5:283-94.

24. Thomas $\mathrm{P}$, Fenech $\mathrm{M}$. Methylenetetrahydrofolate reductase, common polymorphisms, and relation to disease. Vitam Horm 2008;79:375-92.

25. Mongraw-Chaffin ML, Cirillo PM, Cohn BA. Pre- eclampsia and cardiovascular disease death: prospective evidence from the child health and development studies cohort. Hypertension 2010;56:166-71.

26. Smith GN, Pudwell J, Walker M, Wen SW. Ten-year, thirty-year, and lifetime cardiovascular disease risk estimates following a pregnancy complicated by pre- eclampsia. J Obstet Gynaecol Can 2012;34:830-5.

27. Ghulmiyyah L, Sibai B. Maternal mortality from pre- eclampsia/eclampsia. Semin Perinatol 2012;36:56-9.

28. Mission JF, Marshall NE, Caughey AB. Obesity in pregnancy: a big problem and getting bigger. Obstet Gynecol Surv 2013;68:389-99.

29. Savitz DA, Danilack VA, Engel SM, et al. Descriptive epidemiology of chronic hypertension, gestational hypertension, and pre- eclampsia in New York state, 1995-2004. Matern Child Health J 2013. [Epub ahead of print].

30. The tech museum of innovation: what are the A1298C mutation and C677T mutation? Available from: http://genetics.thetech.org/ask/ask425 [last accessed 12 Oct 2013].

31. Palmirotta R, Leone B, De Marchis ML, et al. An importance of identification of double variant methylenetetrahydrofolate reductase gene C677T and A1298C in cis configuration for pharmacogenetic studies. Blood Coagul Fibrinolysis 2013;24:784-6.

32. Wang XM, Wu HY, Qiu XJ. Methylenetetrahydrofolate reductase (MTHFR) gene C677T polymorphism and risk of pre- eclampsia: an updated meta-analysis based on 51 studies. Arch Med Res 2013;44:159-68.

33. Canto $P$, Canto-Cetina $T$, Juárez-Velázquez R, et al. Methylenetetrahydrofolate reductase C677T and glutathione S-transferase P1 A313G are associated with a reduced risk of pre- eclampsia in MayaMestizo women. Hypertens Res 2008;31:1015-9.

34. Stonek F, Hafner E, Metzenbauer M, et al. Carriage of the methylenetetrahydrofolate reductase (MTHFR) C677T polymorphism does not influence the first and second trimester uterine artery Doppler flow. Eur J Obstet Gynecol Reprod Biol 2008;140:178-82.

35. Prasmusinto D, Skrablin S, Hofstaetter C, et al. The methylenete- trahydrofolate reductase 677 C $-4 T$ polymorphism and pre- eclampsia in two populations. Obstet Gynecol 2002;99:1085-92.

36. Dávalos IP, Moran MC, Martínez-Abundis E, et al. Methylenetetrahydrofolate reductase C677T polymorphism and Factor $V$ Leiden variant in Mexican women with pre- eclampsia/ eclampsia. Blood Cells Mol Dis 2005;35:66-9.

37. Stonek F, Hafner E, Philipp K, et al. Methylenetetrahydrofolate reductase C677T polymorphism and pregnancy complications. Obstet Gynecol 2007;110:363-8.

38. Jääskeläinen E, Keski-Nisula L, Toivonen S, et al. MTHFR C677T polymorphism is not associated with placental abruption or pre- eclampsia in Finnish women. Hypertens Pregnancy 2006;25:73-80.

39. Said JM, Higgins JR, Moses EK, et al. Inherited thrombophilias and adverse pregnancy outcomes: a casecontrol study in an Australian population. Acta Obstet Gynecol Scand 2012;91:250-5.

40. Hogg BB, Tamura T, Johnston KE, et al. Second-trimester plasma homocysteine levels and pregnancyinduced hypertension, pre- eclampsia, and intrauterine growth restriction. Am J Obstet Gynecol 2000;183:805-9.

41. Vollset SE, Refsum H, Irgens LM, et al. Plasma total homocysteine, pregnancy complications, and adverse pregnancy outcomes: the Hordaland homocysteine study. Am J Clin Nutr 2000;71:962-8.

42. Yanez $\mathrm{P}$, Vásquez $\mathrm{CJ}$, Rodas L, et al. Erythrocyte folate content and serum folic acid and homocysteine levels in preeclamptic primigravidae teenagers living at high altitude. Arch Gynecol Obstet 2013;288:1011-5. 
43. Lachmeijer AM, Arngrímsson R, Bastiaans EJ, et al. Mutations in the gene for methylenetetrahydrofolate reductase, homocysteine levels, and vitamin status in women with a history of pre- eclampsia. Am J Obstet Gynecol 2001;184:394-402.

44. Oliveira KC, Verreschi ITN, Sugawara EK, et al. C677T and A1298C polymorphisms of MTHFR gene and their relation to homocysteine levels in Turner syndrome. Genet Test Mol Biomarkers 2012;16:396-400.

45. ACOG. Optimizing Protocols in Obstetrics. Key elements for the management of hypertensive crisis in pregnancy (In-patient). Available from: http://www.acog.org/rv/media/Districts/District\%20II/PDFs/Optimizing_Protocols_In_OB_HTN_Series_3\%20Version\%201.pdf?dmc1/41\&ts $1 / 420131010 T 0637065833$ [last accessed 12 Oct 2013].

46. Aliyu MH, Luke S, Kristensen $\mathrm{S}$, et al. Joint effect of obesity and teenage pregnancy on the risk of preeclampsia: a population-based study. J Adolesc Health 2010;46:77-82.

47. Mignini LE, Latthe PM, Villar J, et al. Mapping the theories of pre- eclampsia: the role of homocysteine. Obstet Gynecol 2005;105:411-25.

48. Madan J, Chen M, Goodman E, et al. Maternal obesity,gestational hypertension, and preterm delivery. J Matern Fetal Neonatal Med 2010;23:82-8.

49. Ursavas A, Karadag M, Nalci N, et al. Self-reported snoring, maternal obesity and neck circumference as risk factors for pregnancy-induced hypertension and pre- eclampsia. Respiration 2008;76:33-9.

50. Hendler I, Blackwell SC, Mehta SH, et al. The levels of leptin, adiponectin, and resistin in normal weight, overweight, and obese pregnant women with and without pre- eclampsia. Am J Obstet Gynecol 2005;193:979-83.

51. Boij R, Svensson J, Nilsson-Ekdahl K, et al. Biomarkers of coagulation, inflammation, and angiogenesis are independently associated with pre- eclampsia. Am J Reprod Immunol 2012;68:258-70.

52. Lynch AM, Eckel RH, Murphy JR, et al. Prepregnancy obesity and complement system activation in early pregnancy and the subsequent development of pre- eclampsia. Am J Obstet Gynecol 2012;206:428.e1-8.

53. Institute of Medicine. Weight gain during pregnancy: reexamining the guidelines. Washington, DC: National Academy Press; 2009.

54. Ben-Noun L, Sohar E, Laor A. Neck circumference as a simple screening measure for identifying overweight and obese patients. Obes Res 2001;9:470-7.

55. Hingorjo MR, Qureshi MA, Mehdi A. Neck circumference as a useful marker of obesity: a comparison with body mass index and waist circumference. J Pak Med Assoc 2012;62:36-40. 



\section{CHAPTER 5B}

Polymorphisms of the methylenetetrahydrofolate reductase gene (C677T and A1298C) in the placenta of pregnancies complicated with pre- eclampsia.

Chedraui P, Andrade ME, Salazar-Pousada D, Escobar GS, Hidalgo L, Ramirez C, Marc E.A. Spaanderman, Kramer BW, Gavilanes AWD.

Gynecol Endocrinol 2015; In press 


\section{ABSTRACT}

Background: Pre- eclampsia has been related to single-nucleotide polymorphisms (SNPS) of the methylenetetrahydrofolate reductase (MTHFR) gene; however, data regarding the placenta are still lacking.

Objective: To determine the frequency of C677T and A1298C SNPs of the MTHFR gene in the placenta of preedamptic pregnancies and healthy controls.

Methods: Genotyping of C677T and A1298C polymorphisms of the MTHFR gene using RFLP-PCR was performed to the placenta of 100 gestations ( $n=50$ complicated with pre- eclampsia and $n=50$ normal controls matched for parity and maternal age).

Results: Gestational age at birth and neonatal and placental weight were significantly lower in women with pre- eclampsia as compared to controls. The TT genotype of the C677T polymorphism was threefold more prevalent in preeclamptic placentas as compared to the placenta of controls ( $24.0 \%$ versus $8.0 \%, p=0.001$ ). Upon pooled analysis $(n=100)$, placental and neonatal weights were significantly lower in placentas displaying this genotype (TT, C677T) as compared with the CC genotype.

Conclusion: This study found that the frequency of the TT mutant genotype of the C677T polymorphism was higher in the placenta of pregnancies complicated with preeclampsia. There is a need for further research in this matter.

Keywords: Genetics, homocysteine, pre- eclampsia, placenta, polymorphisms, pregnancy 


\section{INTRODUCTION}

Pre- eclampsia (PE) is a frequent complication of pregnancy related to adverse maternal-fetal outcomes [1]. To date, the exact cause of PE remains undetermined; however, various key factors or abnormalities have been elucidated: genetic or environmental factors, inflammatory and immunologic factors, phenotypical cardiovascular mechanical risk factors and biochemical cardiometabolic risk factors amongst hyperhomocysteinemia [2-4].

Several single-nucleotide polymorphisms (SNPS) have been studied in pregnancies complicated with PE [5-7]. The methylenetetrahydrofolate reductase (MTHFR) enzyme is critical for the metabolism of homocysteine (HCY), catalyzing the NADPH-linked reduction of 5,10-MTHF to 5-MTHF, and subsequently the vitamin B12-dependent methylation of HCY to methionine [8]. Lower levels or activity of this MTHFR enzyme, due to specific gene mutations, induces mild to moderate increases in plasma HCY levels [9]. Two specific SNPS of the MTHFR gene have been reported: C677T (leading to valine substitution at amino acid 222) [10], and A1298C (leading to an alanine substitution at aminoacid 429) [11]. Both mutations have been studied in women with PE $[12,13]$. We previously reported that the prevalence of the CC mutant genotype of the A1298C polymorphism, yet not the TT mutant genotype of C677T, was higher among women with PE [12]; and this mutation was related to higher maternal plasma HCY levels. Not many studies have reported on these mutations in the placental tissue of gestations complicated with PE. Therefore, to complement our preliminary maternal findings [12], the present research aimed at determining the frequency of the C677T and A1298C SNPs of the MTHFR gene in the placenta of pregnancies complicated with PE and healthy pregnant controls.

\section{METHODS}

\section{Study design and participants}

The present research was carried out at the Institute of Biomedicine, Universidad Católica de Santiago de Guayaquil, Ecuador, with the support of the School for Oncology and Developmental Biology Maastricht (GROW), Maastricht University, the Netherlands. Women were recruited from the Enrique C. Sotomayor Obstetrics and Gynecology Hospital (Guayaquil, Ecuador), which is a major referral center providing maternal and neonatal healthcare to the low-income population. This facility has an important number of deliveries and provides care to many high-risk pregnancies.

Women with singleton gestations fulfilling PE criteria admitted for delivery to the High Risk Pregnancy Labor and Delivery Unit were invited to participate. Those without PE delivering in the Low Risk Labor Unit served as controls matched for parity and ma- 
ternal age. All subjects were informed about the study and its aims, providing signed consent of participation.

American Congress of Obstetricians and Gynecologists (ACOG) criteria were used to define $P E$ as a blood pressure $\geq 140 / 90 \mathrm{mmHg}$ and proteinuria + or more on at least two random samples $4 \mathrm{~h}$ apart [ 14]. PE was defined as severe if blood pressure was $\geq$ $160 / 110 \mathrm{mmHg}$ and proteinuria was +++ or more [14]. Maternal socio-demographic as well as obstetrical and neonatal data were recorded on a specific data sheet. The research protocol was reviewed and approved by the Institutional Review Board (IRB) of the Enrique C. Sotomayor Hospital.

\section{Placental sampling and SNP genotyping}

After delivery, the placenta was weighed and a $25 \mathrm{~g}$ sample was obtained and immediately stored at $-70^{\circ} \mathrm{C}$ until analysis. Subsequently, DNA was extracted from the placental sample using the PureLink genomic kit (Invitrogen ${ }^{\circledR}$, Carlsbad, CA), which was then amplified through conventional polymerase chain reaction (PCR) technique using the following primers: 5'-TGAA GGAGAAGGTGTCTGCGGGA-3' and 5'-AGGACGGTGCGG TGAGAGTG-3' for C677T; and 5'-TGATGAAATCGGCTC CCGCA-3' and 5'-TGATGATG AAATCGACTCCCGCA-3' for A1298C. The amplified product (a $198 \mathrm{bp}$ fragment of exon 4 of the MTHFR gene) was used for the genotyping of the C677T and A1298C polymorphisms using restriction fragment length polymorphism PCR (RFLP-PCR). Allelic distribution for C677T and A1298C SNPs was in the range of Hardy-Weinberg equilibrium.

\section{Statistical analysis}

Statistical analysis was performed using the Statistical Package for the Social Sciences version 22.0 (IBM SPSS, Armonk, NY). Data are presented as medians, interquartile ranges [IRQ], frequencies, percentages, odds ratios and 95\% confidence intervals. The Kolmogorov-Smimov test was used to determine the normality of data distribution. According to this, non parametric continuous data were compared with the MannWhitney U-test. Chi-square, Yates' corrected chi-square or Fisher's exact tests were used to compare percentages (including the comparison of genotype frequencies between cases and controls). A $p$ value of $<0.05$ was considered as statistically significant.

\section{RESULTS}

A total of 100 pregnant women were recruited during the study period ( $n=50$ cases of $\mathrm{PE}$ and $n=50$ controls). Socio-demographic and obstetrical/neonatal data of the studied women are depicted in Table 1 . C-section rate was higher among women with PE as compared to controls. Women with PE had more often adverse perinatal outcomes. 
Gestational age at birth and neonatal and placental weight were lower in PE cases. In addition, rates of preterm, low birth weight and low Apgar scores were significantly higher in PE women.

Table I. Socio-demographic and obstetrical/neonatal data of the studied women.

\begin{tabular}{|c|c|c|c|}
\hline Socio-demographic & $\begin{array}{l}\text { Cases } \\
n=50\end{array}$ & $\begin{array}{c}\text { Controls } \\
n=50\end{array}$ & $p$ Value* \\
\hline Age (years) & $25.5[13]$ & $26.0[10.5]$ & 0.91 \\
\hline Parity & $1.0[4]$ & $2.0[2.5]$ & 0.74 \\
\hline Number of prenatal visits & $4.0[5]$ & $5.0[4.5]$ & 0.62 \\
\hline \multicolumn{4}{|l|}{ Obstetrical data } \\
\hline Systolic blood pressure (mmHg) & $149.5[20.5]$ & $100.0[11.0]$ & 0.0001 \\
\hline Diastolic blood pressure (mmHg) & $100.0[10.5]$ & $65.0[11.0]$ & 0.0001 \\
\hline Severe pre- eclampsia & $43(86.0)$ & & \\
\hline Mild pre- eclampsia & $7(14.0)$ & & \\
\hline Delivery by c-section & $45(90.0)$ & $24(48.0)$ & $<0.001$ \\
\hline Placental weight (g) & $520.0[235.5]$ & $626.5[129.5]$ & 0.001 \\
\hline \multicolumn{4}{|l|}{ Neonatal data } \\
\hline Gestational age (weeks) & $37.5[5.0]$ & $39.0[1.5]$ & 0.0001 \\
\hline Neonatal birthweight (g) & $2,538[1,313.5]$ & $3,044[638.0]$ & 0.0001 \\
\hline Female gender & $24(48.0)$ & $19(38.0)$ & 0.41 \\
\hline Preterm birth & $19(38.0)$ & $2(1.0)$ & $<0.0001$ \\
\hline Low birth weight $(<2,500 \mathrm{~g})$ & $23(46.0)$ & $5(10.3)$ & 0.0001 \\
\hline Apgar $<7$ at first minute & $12(24.0)$ & $1(2.0)$ & 0.001 \\
\hline Apgar $<7$ in five minutes & $7(14.0)$ & $0(0.0)$ & 0.01 \\
\hline
\end{tabular}

Data are presented as medians [interquartile ranges] or frequencies (\%); * $p$ Value as determined depending on the case with the Mann-Whitney $U$ test or the chi-square, Yates' corrected chi-square or Fisher's exact test.

Genotype frequencies of the studied MTHFR gene polymorphisms (C677T and A1298C) in the placenta of cases and controls are depicted in Table 2. No significant differences were observed among cases and controls in relation to genotype frequencies for the A1298C polymorphism. Contrary to this, the mutant TT genotype of the C677T polymorphism was threefold more prevalent in preeclamptic placentas as compared to the placenta of controls (24.0\% versus 8.0\%, $p=0.001$ ). Pooled analysis $(n=100)$ showed that placental and neonatal weights were significantly lower in placentas displaying the TT genotype of the C677T polymorphism as compared with the CC genotype (Data not shown in the table). 
Table 2. Genotype frequencies of the studied MTHFR gene polymorphisms (C677T and A1298C) in the placenta of cases and controls.

\begin{tabular}{lccccc}
\hline Genotype & $\begin{array}{c}\text { Cases } \\
n=50\end{array}$ & $\begin{array}{c}\text { Controls } \\
n=50\end{array}$ & Odds ratio & $95 \% \mathrm{Cl}$ & $p$ Value \\
\hline C677T & & & & \\
CC & $15(30.0)$ & $20(40.0)$ & 1 & $0.45-3.10$ & 0.71 \\
CT & $23(46.0)$ & $26(52.0)$ & 1.18 & $1.09-14.89$ & 0.001 \\
TT & $12(24.0)$ & $4(8.0)$ & 4.0 & $0.63-3.87$ & 0.29 \\
CT+TT & $35(70.0)$ & $30(60.0)$ & 1.56 & & 0.47 \\
A1298C & $37(74.0)$ & $39(78.0)$ & 1 & $0.47-4.50$ & 0.70 \\
AA & $11(22.0)$ & $8(16.0)$ & 1.45 & $0.08-5.60$ & 0.63 \\
AC & $2(4.0)$ & $3(6.0)$ & 0.70 & $0.45-3.45$ & \\
CC & $13(26.0)$ & $11(22.0)$ & 1.25 & & \\
AC+CC & & & & & 0.45 \\
\hline
\end{tabular}

Data are presented as frequencies (\%), odds ratios and 95\% confidence intervals (Cl).

\section{DISCUSSION}

PE is one of the major complications of pregnancy and the leading cause of maternal and fetal morbidity and mortality [1]. Although the cause of PE remains unknown, studies have highlighted the fact that a failure in placentation very early in gestation leads to the release of several products and factors that cause the syndrome through a multiplicity of underlying pathophysiological mechanisms $[15,16]$. Despite this, the importance of genetics in the origin of the disease is currently gaining interest. Indeed, the most plausible genetic model postulates that the occurrence of the pathological phenotype in PE depends on the maternal genetic susceptibility, trophoblastic genetic load and various environmental factors [17].

Recent studies indicate that PE increases maternal and fetal future cardiovascular risk [18]. On the one hand, both traditional cardiovascular and cardiometabolic risk factors consistent with the metabolic syndrome have been linked to vascular derangements, pre- eclampsia and cardiovascular disease; and on the other hand, higher HCY levels been linked to PE development [19] and also adult cardiovascular risk [20]. Polymorphisms of the MTHFR gene (i.e. C677T and A1298C) cause lower enzyme activity resulting in a reduced remethylation of $\mathrm{HCY}$ to methionine, and consequently higher $\mathrm{HCY}$ blood levels [21]. We previously reported a higher prevalence of the CC mutant genotype of the $\mathrm{A} 1298 \mathrm{C}$ polymorphism in whole blood of women with PE. These women displayed higher plasma HCY levels. Contrary to this, the present study found a higher frequency of the TT mutated genotype of the C677T polymorphism in the placental tissue of those complicated with PE. There are no sufficient data related to genotypes of these MTHFR polymorphisms in placental material and the role that placental abnor- 
malities of folate metabolism could have in the pathogenesis of PE. Nevertheless, placental genotype and phenotype define the final set of metabolites reaching the fetus and from the fetus to the maternal circulation. In this sense, Mislanova et al. [22] determined a non-significant trend for a higher prevalence of the TT genotype of the C677T polymorphism in the placental samples of PE women as compared with controls. In essence, their finding is in correlation with ours; however, we did not quantify HCY in the placental samples. Their study [22] found a higher placental HCY content among PE complicated pregnancies expressing the placental CT genotype of the C677T polymorphism. Interestingly our study found that independent of presenting PE or not (pooled analysis $n=100$ ), placental and neonatal weights were significantly lower in placentas displaying the mutant TT genotype of the C677T polymorphism as compared with the CC normal genotype. Pre- eclampsia and fetal growth restriction are both considered placental syndromes [23], in which the maternal syndrome relates to excess of placental shedding whereas the fetal syndrome related to placental dysfunction. In this sense, the TT polymorphism seems to relate to both the maternal and fetal placental syndromes. On the one hand, if we assume a defective first trimester placental invasion to underlie the later maternal and fetal clinical sequelae, then apparently the TT genotype relates to faulty placental growth. On the other hand, if exaggerated placental damage leads to loss in function and increased detaching of placental debris, then also this TT genotype gives rise to extrinsic damage or intrinsic increased sensibility to stressors. In any case, the TT genotype seems to increase an overall risk of the placental syndrome. If we hypothesize that the related placental dysfunction is due to higher HCY production in those expressing the TT mutant type, then one should expect a positive effect of folic acid, pyridoxine and vitamin B12 over phenotypical placental modulation in the reduction of noxious HCY increased levels; nevertheless, this remains to be elucidated. Despite our findings, the causative role of MTHFR gene polymorphisms (in the mother or the placenta) for the development of PE is still a subject under debate and requires further research.

Finally, as for the limitations of the present study, one can mention the lack of determining the content of folate and that of other related metabolites in placenta that would have allowed determining functional phenotypical differences affecting both fetus and mother according to the genotype characterization. Despite these limitations, the present research has two strengths: (a) our data adds to the few assessing MTHFR gene polymorphisms in placental material of women complicated with PE and $(b)$ it is the first to provide this type of analysis among Latin American pregnant women. Certainly, our findings require further research.

In conclusion, this study found that the frequency of the TT mutant genotype of the C677T polymorphism was higher in the placenta of pregnancies complicated with PE. There is a need for further research in this regard. 


\section{Acknowledgements}

Authors thank the women who participated in this initiative.

\section{Declaration of interest}

The authors declare no conflicts of interest.

This research was supported by Sistema de Investigación y Desarrollo of the Universidad Católica de Santiago de Guayaquil Guayaquil Ecuador through grant No. SIU-1652729-2011 (Proyecto GenRAE: Genética de Resultantes Adversas del Embarazo). 


\section{REFERENCES}

1. Walker JJ. Pre-eclampsia. Lancet 2000;356:1260-5.

2. Valenzuela FJ, Pérez-Sepúlveda A, Torres MJ, et al. Pathogenesis of pre- eclampsia: the genetic component. J Pregnancy 2012;2012: 632732.

3. Barakonyi A, Miko E, Szereday L, et al. Cell death mechanisms and potentially cytotoxic natural immune cells in Human pregnancies complicated by pre- eclampsia. Reprod Sci 2014;21:155-66.

4. Taylor RN, de Groot CJ, Cho YK, Lim KH. Circulating factors as markers and mediators of endothelial cell dysfunction in preeclampsia. Semin Reprod Endocrinol 1998;16:17-31.

5. Chedraui P, Solis EJ, Bocci G, et al. Feto-placental nitric oxide, asymmetric dimethylarginine and vascular endothelial growth factor (VEGF) levels and VEGF gene polymorphisms in severe pre- eclampsia. J Matern Fetal Neonatal Med 2013;26:226-32.

6. El-Sherbiny WS, Nasr AS, Soliman A. Endothelial nitric oxide synthase (eNOS) (Glu298Asp) and urotensin II (UTS2 S89N) gene polymorphisms in pre- eclampsia: prediction and correlation with severity in Egyptian females. Hypertens Pregnancy 2013;32:292-303.

7. Song GG, Kim JH, Kim YH, et al. Associations between vascular endothelial growth factor gene polymorphisms and pre- eclampsia susceptibility: a meta-analysis. Hum Immunol 2013;74:1206-13.

8. Barbosa PR, Stabier SP, Machado AL, et al. Association between decreased vitamin levels and MTHFR, MTR and MTRR gene polymorphisms as deterrninants for elevated total homocysteine concentrations in pregnant women. Eur J Clin Nutr 2008;62:1010-21.

9. Klai S, Fekih-Mrissa N, El Housaini S, et al. Association of MTHFR A1298C polymorphism (but not of MTHFR C677T) with elevated homocysteine levels and placental vasculopathies. Blood Coagul Fibrinolysis 2011;22:374-8.

10. Frosst $\mathrm{P}, \mathrm{Blom} \mathrm{HJ}$, Milos $\mathrm{R}$, et al. A candidate genetic risk factor for vascular disease: a common mutation in methylenetetrahydrofolate reductase. Nat Genet 1995;10:111-13.

11. van der Put NM, Gabreels F, Stevens EM, et al. A second common mutation in the methylenetetrahydrofolate reductase gene: an additional risk factor for neural-tube defects? Am J Hum Genet 1998;62:1044-51.

12. Chedraui P, Salazar-Pousada D, Villao A, et al. Polymorphisms of the methylenetetrahydrofolate reductase gene (C677T and Al298C) in nulliparous wamen complicated with pre- eclampsia. Gynecol Endocrinol 2014;30:392-6.

13. Canto $\mathrm{P}$, Canto-Cetina $\mathrm{T}$, Juárez-Velázquez $\mathrm{R}$, et al. Methylenetetrahydrofolate reductase C677T and glutathione S-transferase P1 A313G are associated with a reduced risk of pre- eclampsia in MayaMestizo women. Hypertens Res 2008;31:1015-19.

14. American College of Obstetricians and Gynecologists. Hypertension in pregnancy. ACOG, 2013. Available from: http://www.acog.org/ Resources_And_Publications/Task_Force_and_Work_Group_Reports/Hypertension_in_Pregnancy.

15. Roberts JM, Hubel CA. The two stage model of pre- eclampsia: variations on the theme. Placenta 2009;30:S32-7.

16. Huppertz B. Placental origins of pre- eclampsia: challenging the current hypothesis. Hypertension 2008;51:970-5.

17. Lachmeijer AM, Dekker GA, Pals G, et al. Searching for pre- eclampsia genes: the current position. Eur J Obstet Gynecol Reprod Biol 2002;105:94-113.

18. Chen CW, Jaffe IZ, Karumanchi SA. Pre-eclampsia and cardiovascular disease. Cardiovasc Res 2014;101:579-86.

19. Hogg BB, Tamura T, Johnston KE, et al. Second-trimester plasma homocysteine levels and pregnancyinduced hypertension, pre- eclampsia, and intrauterine growth restriction. Am J Obstet Gynecol 2000; 183:805-9.

20. Guilliams TG. Homocysteine - a risk factor for vascular diseases. J Am Neutraceut Assoc 2004;7:11-16.

21. Thomas $\mathrm{P}$, Fenech $\mathrm{M}$. Methylenetetrahydrofolate reductase, common polymorphisms, and relation to disease. Vitam Horm 2008;79:375-92. 
22. Mislanova C, Martsenyuk O, Huppertz B, Obolenskaya M. Placental markers of folate-related metabolism in pre- eclampsia. Reproduction 2011;142:467-76.

23. Ray JG, Verrneulen MJ, Schull MJ, Redelmeier DA. Cardiovascular health after maternal placental syndromes (CHAMPS): population based retrospective cohort study. Lancet 2005;366:1797-803. 
CHAPTER 6

Discussion and summary 
PE is a serious problem occurring during women's reproductive years imposing a negative impact on maternal and fetal outcome [1]. Despite intensive research involved pathogenic mechanisms are still unknown and there is no treatment other than pregnancy termination. PE also exerts a negative impact on the healthcare system of both developed and non developed countries. Moreover, the poverty conditions observed in Latina American impose a greater challenge as the negative impact, in the mother, the fetus and the healthcare system seems to be greater. The present research aimed at assessing various biochemical and molecular markers related to vascular, anti-oxidative, endothelial, inflammatory and genetic abnormalities found in gestations complicated with PE.

Vascular homeostasis and inflammation during third trimester of preeclamptic women were analyzed in the study presented in Chapter 2, in which maternal plasma levels of two soluble anti-angiogenic factors (sFlt-1 and sEng) and four pro-inflammatory cytokines (IL-6, IL-8, G-CSF and TNF- $\alpha$ ) were measured in near term nulliparous women complicated with PE. These levels were compared to those found in matched normal nulliparous gestations. It was found that increased sFlt-1 and sEng levels in maternal plasma are consistent with vascular dysfunction found in gestations complicated with PE. Elevated anti-angiogenic levels of sFlt-1 and sEng seem to contribute to maternal vascular dysfunction by binding to and thus reducing circulating levels of angiogenic factors such as free VEGF and PLGF [2]. The resulting anti-angiogenic milieu is implicated in inducing systemic vascular damage, particularly as a target the kidney to induce hypertension and proteinuria of PE [1]. Contrary to expected, PE women displayed lowered IL-8 and G-CSF levels. Our data, regarding sFlt-1 and sEng are in correlation with those found by others in relation to third trimester complicated PE women [2-4]. To note is the fact that currently sFlt is being combined with other biochemical and biophysical markers for first trimester screening of PE [5].

During PE there is an observed increase in the rate of lipid peroxidation, increased lipid availability, and a decrease of several antioxidants such as alpha tocopherol, ascorbate, beta carotene and selenium [6]. In this sense, $\mathrm{CoQ}_{10}$ is a part of the non-enzymatic defense system against oxygen species (antioxidative function) [7], playing a key role in mitochondrial complexes I and III reaction mechanisms (electron transport) [8]. Two previous investigations have found lower $\mathrm{CoQ}_{10}$ plasma levels [9] and lower $\mathrm{CoQ}_{10}$ plasma together with higher placental $\mathrm{CoQ}_{10}$ content in women complicated with PE living at high altitude [10]. As a continuation, $\mathrm{CoQ}_{10}$ levels were measured both in plasma and placenta of normal pregnant and PE primigravid women residing either at high or low altitude (Chapter 3 ). Data analyzing $\mathrm{CoQ}_{10}$ content in plasma and placenta with altitude as a component in the equation is scarce in the literature. It was found that women with PE (high or low altitude) displayed high placental $\mathrm{CoQ}_{10}$ content, with significant lower plasma $\mathrm{CoQ}_{10}$ levels among those residing in high altitude. Correlating with our data, higher placental $\mathrm{CoQ}_{10}$ content was found among sea level residing Italian pregnant women with HELLP syndrome (a severe complication of pre- eclampsia) when 
compared to normal pregnancies; however, plasma levels were not measured [11]. Our data allows us to hypothesize that $\mathrm{CoQ}_{10}$ plasma levels are not directly related to placental $\mathrm{CoQ}_{10}$ content. Moreover, it is also plausible to assume that placental development is totally an energy dependent process and that $\mathrm{CoQ}_{10}$ could be an essential element in its physiological role. If this is true, then the next obvious questions to be considered should be: what occurs during PE? Are these high placental levels a late compensatory mechanism?

Placental dysfunction, due to defective spiral artery invasion, already present in the first trimester of women destined to develop PE, leads to a progressive maternal state of inflammation and endothelial dysfunction, which eventually predicts the severity of maternal fetal outcome [12]. Several factors may be important in the physiological mechanisms of placental angiogenesis and regulation of vascular tone, and these factors could have major roles in the pathogenesis of abnormal placental functioning. One of these factors is NO, the intracellular gaseous messenger synthesized by NOS from Larginine and oxygen. NO exerts diverse biological functions in several physiological and pathological processes, especially in vascular pathophysiology [13]. NO produced by syncytiotrophoblast-derived endothelial cells is thought to cause dilation of the human placental vasculature [14], and may act as a paracrine agent for the maintenance of uterine quiescence during pregnancy. Additionally, local placental NO generation may be essential to promote cytotrophoblast endovascular invasion, an essential feature of normal placentation [15]. Chapter 4 aimed at evidencing by means of two study the state of maternal and fetal endothelial dysfunction. In first study NO content in plasma and placenta was measured in the third trimester of PE complicated women as compared to normal control; however, again as a highlighted feature, the effect of high or low attitude was analyzed. Independent of the site of residency women with PE presented higher NO content in plasma and placenta, which is consistent with our previous findings [16]. When women were analyzed by site of residency a similar trend for higher plasma and placental NO levels were observed in PE cases. Nevertheless, higher plasma NO levels were found in those living at sea level and higher placental NO levels observed in those living at high altitude. It is important to mention the fact that studies measuring placental NO levels, either at sea level or at altitude, are lacking. Thus, it can be hypothesized that NO levels differ not only in the presence of PE, but are also dependent on the women's altitude of residence. It is worthy to mention that contradictory results are reported in the literature regarding $N O$ and $P E$, some indicating higher [16] and others lower maternal levels [17]. Although this may be due to measurement methods and/or analyzed metabolite, agreement exists that PE is related to an altered NO production (dysfunctional endothelia) and/or activity (compensatory endothelial mechanism).

In a subsequent study we further measured markers of endothelial function (NO, ADMA and VEGF) in the fetal circulation of women complicated with severe PE. In addition, genetic assessment was performed and DNA extracted from the umbilical vein to 
determine the frequency of VEGF gene single nucleotide polymorphisms. Important to mention is that molecular analysis of endothelial function has only been performed in women with PE in the maternal side [18]; hence, umbilical fetal circulation data are scarce or lacking. Our study found that women with severe PE displayed higher NO and ADMA fetal circulating levels (vein and artery) and lower VEGF umbilical vein levels, which is consistent with our maternal observations. Overall, the frequency of the studied VEGF gene polymorphisms did not differ among PE cases and controls; nevertheless, a significant trend toward lower umbilical vein VEGF levels was observed in PE cases in the presence of $-2578 \mathrm{CC}$ and -1154 AG genotypes. Elevated umbilical plasma NO levels may represent an adaptive response of the fetus and placenta to maintain adequate blood supply in face of increased uterine and systemic vascular resistances and to the alleged defective angiogenesis affecting placental circulation. Whether this change is cause or consequence of PE is not known, but may also be seen in other pathological conditions related to pregnancy, such as fetal growth restriction, suggesting that it may rather represent a fetal response to adverse conditions imposed to pregnancy [19].

There is increasing evidence that highlight the important role of genetics and epigenetics in the development and severity of the outcome of PE. SNPs are variations of the genome sequence, which may modify biological responses and the risk of certain diseases. Numerous SNPs have been studied in women with PE [20-22]. The MTHFR enzyme is critical for $\mathrm{HCy}$ metabolism, catalyzing the NADPH-linked reduction of 5,10MTHF to 5-MTHF, and subsequently the vitamin B12-dependent methylation of HCy to methionine [20]. A reduction in MTHFR levels or activity by specific gene mutations induces mild to moderate increases in plasma HCy levels, which may relate to placental dysfunction early during pregnancy [23]. Taking this into perspective two experiments were carried out and presented in Chapter 5. Two SNPs of the MTHFR gene were analyzed (C667T and A1298C) in plasma (the first study) and in placenta (second study) of women complicated with PE. The first study found that the prevalence of the CC mutant genotype of the $\mathrm{A} 1298 \mathrm{C}$ polymorphism was higher in plasma among PE women. This mutation among PE women was related to increased neck circumference (an indirect index of overweight/obesity) and higher HCy levels. No differences were found regarding the prevalence of the C677T polymorphisms among cases and control. In the second study, the prevalence of the same polymorphisms was subsequently analyzed in placental material of PE cases compared to controls. Contrary to the first study, frequency of the TT mutant genotype of the C677T polymorphism was higher in the placenta of pregnancies complicated with PE. Both mutations have been related to higher HCy content and subsequent development of PE via oxidative stress or endothelial dysfunction. 


\section{SUMMARY}

To date the exact cause of PE is unknown. Despite this, studies have shown that PE is a multifactorial disease related to pregnancy which involves various pathways and mechanisms that are interconnected. The present thesis presents important data that highlight the fact the PE is not only a vascular disease with three interesting contributions: a) higher sFlt-1 found in the third trimester have lead others to explore its predictive utility for first trimester PE screening together with other biochemical and biophysical aspects; b) the altitude of residency seems to be a factor imposing differences in the levels of $\mathrm{NO}$ and $\mathrm{CoQ}_{10}$; and c) our data confirm that endothelial dysfunction is also present in the fetal circulation. 


\section{REFERENCES}

1. Sibai BM, Dekker G, Kupferminic M. Pre-eclampsia. Lancet 2005;365:785-799.

2. Shibata E, Rajakumar A, Powers RW, Larkin RW, Gilmour C, Bodnar LM, Crombleholme WR, Ness RB, Roberts JM, Hubel CA. Soluble fms-like tyrosine kinase 1 is increased in pre- eclampsia but not in normotensive pregnancies with small-for-gestational-age neonates: relationship to circulating placental growth factor. J Clin Endocrinol Metab 2005;90:4895-903.

3. Woolcock J, Hennessy A, Xu B, Thornton C, Tooher J, Makris A, Ogle R. Soluble Flt-1 as a diagnostic marker of pre- eclampsia. Aust N Z J Obstet Gynaecol 2008;48:64-70.

4. Gu Y, Lewis DF, Wang Y. Placental productions and expressions of soluble endoglin, soluble fms-like tyrosine kinase receptor-1, and placental growth factor in normal and preeclamptic pregnancies. J Clin Endocrinol Metab 2008;93:260-266.

5. Kienast C, Moya W, Rodriguez O, Jijón A, Geipel A. Predictive value of angiogenic factors, clinical risk factors and uterine artery Doppler for pre-eclampsia and fetal growth restriction in second and third trimester pregnancies in an Ecuadorian population. J Matern Fetal Neonatal Med 2015; In press.

6. Spinnato JA, Livingston JC. Prevention of pre- eclampsia with antioxidants: evidence from randomized trials. Clin Obstet Gynecol 2005;48:416-29.

7. Lenaz G, Cavazzoni M, Genova ML, D’Aurelio M, Merlo Pich M, Pallotti F, Formiggini G, Marchetti M, Parenti Castelli G, Bovina C. Oxidative stress, antioxidant defences and aging. Biofactors 1998;8:195-204.

8. Brandt U, Okun JG. Role of deprotonation events in ubihydroquinone: cytochrome c oxidoreductase from bovine heart and yeast mitochondria. Biochemistry 1997;36:11234-40.

9. Teran E, Racines-Orbe M, Vivero S, Escudero C, Molina G, Calle A. Pre- eclampsia is associated with a decrease in plasma coenzyme $Q_{10}$ levels. Free Radic Biol Med 2003;35:1453-6.

10. Teran E, Vivero S, Racines-Orbe M, Castellanos A, Chuncha G, Enriquez G, Moya W. Coenzyme $Q_{10}$ is increased in placenta and cord blood during pre- eclampsia. Biofactors 2005;25:153-8.

11. Giannubilo SR, Tranquilli AL, Santolini C, Prinicipi F, Mancinelli R, Littarru GP. Placental CoQ ${ }_{10}$ levels in HELLP syndrome. Biofactors 2005;25:159-63.

12. Lyall F. Mechanisms regulating cytotrophoblast invasion in normal pregnancy and pre-eclampsia. Aust $\mathrm{N}$ Z J Obstet Gynaecol 2006;46:266-273.

13. Vatish M, Randeva HS, Grammatopoulos DK. Hormonal regulation of placental nitric oxide and pathogenesis of pre-eclampsia. Trends Mol Med 2006;12:223-33.

14. Bachetti T, Comini L, Curello S, Bastianon D, Palmieri M, Bresciani G, Callea F, Ferrari R. Coexpression and modulation of neuronal and endothelial nitric oxide synthase in human endothelial cells. J Mol Cell Cardiol 2004;37:939-45.

15. Many A, Hubel CA, Fisher SJ, Roberts JM, Zhou Y. Invasive cytotrophoblasts manifest evidence of oxidative stress in pre- eclampsia. Am J Pathol 2000;156:321-31.

16. Teran E, Escudero C, Moya W. Abnormal release of nitric oxide from nitrosoproteins during pre- eclampsia. Int J Gynecol Obstet 2006;92:260-1.

17. Gilbert JS, Ryan MJ, LaMarca BB, Sedeek M, Murphy SR, Granger JP. Pathophysiology of hypertension during pre- eclampsia: linking placental ischemia with endothelial dysfunction. Am J Physiol Heart Circ Physiol 2008;294:H541-50.

18. Cheng D, Hao Y, Zhou W, Ma Y. Vascular endothelial growth factor +936C/T, -634G/C, $-2578 C / A$, and 1154G/A polymorphisms with risk of pre- eclampsia: a meta-analysis. PLoS One 2013;8(11):e78173.

19. Ness RB, Sibai BM. Shared and disparate components of the pathophysiologies of fetal growth restriction and pre- eclampsia. Am J Obstet Gynecol 2006;195:40-49.

20. Barbosa PR, Stabler SP, Machado AL, Braga RC, Hirata RD, Hirata MH, Sampaio-Neto LF, Allen RH, Guerra-Shinohara EM. Association between decreased vitamin levels and MTHFR, MTR and MTRR gene polymorphisms as determinants for elevated total homocysteine concentrations in pregnant women. Eur J Clin Nutr 2008;62:1010-21. 
23. Klai S, Fekih-Mrissa N, El Housaini S, Kaabechi N, Nsiri B, Rachdi R, Gritli N. Association of MTHFR A1298C polymorphism (but not of MTHFR C677T) with elevated homocysteine levels and placental vasculopathies. Blood Coagul Fibrinolysis 2011;22:374-8. 
CHAPTER 7

Valorisation 


\section{PRE- ECLAMPSIA IS MORE THAN A VASCULAR DISEASE}

The studies reported in the present thesis underline the importance of several markers and genetic aspects that evidence key issues in the pathogenesis of pre- eclampsia (PE) which could in the near future serve as predictors of the development of the disease.

\section{RELEVANCE}

Approximately 5 to $14 \%$ of all pregnancies may be complicated with PE. It is a serious issue occurring during women's reproductive years. Despite attempts at prevention or intervention it is still a leading cause of maternal and fetal morbidity and mortality in both developed and non developed countries. There is no treatment for this disorder other than the termination of pregnancy which increases the rate of iatrogenic preterm births. Much research in the past has mainly focused on epidemiological, clinical and preventive aspects; today biochemical and molecular aspects seem to gain relevance as once we identify who will develop PE, intervention can be instated early, and although cure might not be feasible, at least its negative impact can be ameliorated. Although there have been advances in prenatal and neonatal care, prediction of PE is still shadowed by the lack of a unique predictive biochemical or molecular marker which could: a) allow its early detection and management and b) aid in the selection of appropriate candidates for new therapeutical approaches.

\section{INNOVATION}

Currently, the cause of PE is unknown; however, what we do know is that early diagnosis of PE improves maternal and fetal outcome. This thesis provides important insights to the understanding of several pathogenic pathways in the development of PE. PE in Latin America is a serious problem as it causes not only increased maternal fetal morbidity and mortality yet it imposes an important and significant burden to the healthcare system. Poverty conditions observed in Latin America together with inadequate prenatal care seem to increase the negative impact that PE has over female health and the healthcare system. Despite the limitations of the poverty conditions found in our country the present thesis sought at providing important insights in the search of a unique or various cost effective markers required for the screening and early detection and intervention of the problem of women of any socio-economic condition. In this sense, this thesis is innovative in its conception, first because it provides evidence that endothelial dysfunction is also present in the fetal circulation. Such data is still scarce or non existent. Second, it provides insights on various markers that evidence several pathogenic pathways of PE, highlighting the effect of altitude of residency in 
terms of $\mathrm{NO}$ and $\mathrm{CoQ}_{10}$ levels. The studied markers can be eventually validated in the near future for the early screening of PE. In this sense, the data presented in Chapter 2 regarding sFlt-1 and its higher levels found in PE women in 2009 definitively have lead others to study and validate this marker as a first trimester PE screening analyte together with other biochemical (i.e. placental growth factor, beta-HCG, alpha-fetoprotein, inhibin) and biophysical (i.e. uterine artery resistance o pulsatility index) aspects. This speaks about the originality of the contribution of our data, and despite eventual limitations our approach provides the basis for future novel investigation.

\section{ACTIVITIES/PRODUCTS}

Despite the fact that the biochemical markers and genetics aspects reported in this investigation seem promising in the prediction of $\mathrm{PE}$, issues still remain to be elucidated. Although sFlt-1 seems a promising predictive marker it still needs to be combined with other biochemical and physical aspects, therefore there is still an urgent need of finding a unique marker that can not only predict the disease yet define the one abnormality that is the cause of the disease and not the effect. The author would also like to highlight the important role that genetics and epigenetics may have in elucidating the cause of the disease. Future research should focus in the correlation between genetic abnormalities or phenotypes encountered in women with PE with biochemical abnormalities and clinical stages or outcome of the disease.

\section{SCHEDULE AND IMPLEMENTATION}

Further perspectives for the utility of the studied biochemical markers, especially sFlt-1 and genetic aspects seem not only promising yet intriguing. Indeed, the possibility to validate the effectiveness of an innovative novel therapeutical approach for PE based on biochemical and genetic markers instead of clinical criteria seems a major hot topic for the near future. Our data provides insights that seem to aid this promising perspective. 

CHAPTER 8

Acknowledgments 

Prof. Dr. Boris W. Kramer, Prof. Dr, Marc Spaanderman and Dr. Danilo Gavilanes have not only offered me their kind friendship yet also the opportunity to complete my research in the favorable setting of Maastricht University, for this I am eternally grateful. They have provided support to the assembly and structure of this thesis providing critical insights for the second study of Chapter 5. They are currently supporting research at our lab at the Institute of Biomedicine of the Medical Faculty of the Catholic University of Guayaquil Ecuador. Dr. Danilo Gavilanes has taken the liberty to personally visit and engage with our Institute and its personnel. His support is vital for our future research perspectives.

To my colleagues, friends and mentors Profs: Luis Hidalgo, Danilo Gavilanes, Faustino Pérez-López, thank you for their unique scientific and clinical advice vital for this work!

A special thanks to the co-authors of all of the studies composing this thesis, without their support this project would not have been possible.

For the past ten years, the authorities of the Universidad Católica de Santiago de Guayaquil have supported my research career, my administrative and scientific team, and the laboratory of the Institute of Biomedicine. Completing this dream would not have been possible without the support of the University authorities.

To my children, Peter and Alessandro, for the time I have subtracted from their lives in order to complete this scientific achievement, I will always be in debt with them.

And finally to the cornerstone of all my life achievements, my mother, for all she has given me, her sacrificed life has always been my inspiration. 

Curriculum Vitae 

Peter Chedraui was born on August 3rd, 1965, in New York City. He grew up in Astoria Queens until the age of 10, when he moved to Guayaquil, Ecuador to complete primary and secondary school. After this, he obtained his medical and master degree in science at the Universidad Católica de Santiago de Guayaquil. Subsequently he completed an OB GYN residency program at the Enrique C. Sotomayor Hospital of Guayaquil, Ecuador.

After completing his residency he was awarded a Fellowship sponsored by FIGO and ACOG in Maternal Fetal Medicine at NYU Medical Center under the tutorship of Dr. Charles J. Lockwood. Since 2005 he has been Chief of the High Risk Pregnancy Labor and Delivery Unit at Sotomayor Hospital. Since 2002 he has been Director of the Institute of Biomedicine, of the Universidad Católica and Adjunct professor at the same University.

$\mathrm{He}$ is a member of several National and International Scientific Societies, with more than 130 peer-reviewed publications supporting his scientific research career. He is currently President of the Ecuadorian Climacteric and Menopause Society, VicePresident of the Latin American Association of Gynecological Endocrinology, Re-Elected Board Member of the International Menopause Society, Elected Board member of the International Society of Gynecological Endocrinology and Editorial member of various international peer reviewed journals devoted to women's health.

He has garnished multiple grants from the Universidad Católica, the pharmaceutical industry and various private foundations. To date he is actively serving as a research collaborator for several international joint research programs.

His primary research interests are genetic aspects of pre- eclampsia and preterm birth and their impact over adult female health such as the metabolic syndrome and cardiovascular risk. In addition he is interested in the epidemiology of the menopause and other female healthcare issues of mid-life. 
Publications of the author in relation to female health (1999-2015)

1. Chedraui PA, Espinosa M, Pezo F. High dose vs. low dose oxytocin in active management of labor. Gynecol Endocrinol 1999;13:S128.

2. Chedraui PA, Insuasti DF. Intravenous nitroglycerin in the management of retained placenta. Int J Gynaecol Obstet 2000;70:S53.

3. Chedraui PA, Espinosa M. Transvaginal sonography in the prediction of endometrial pathology in perimenopausal women. Int J Gynaecol Obstet 2000;70:S13.

4. Leon G, Chedraui PA, San Miguel G. Prenatal diagnosis of Cantrell's pentalogy with conventional and three-dimensional sonography. J Matern Fetal Neonatal Med 2002;12:209-11.

5. Leon G, Hidalgo LA, Chedraui PA. Cervical pregnancy: transvaginal sonographic diagnosis and successful conservative surgical management after systemic methotrexate. Ultrasound Obstet Gynecol 2003;21:620-2.

6. Chedraui PA, Insuasti D. Intravenous nitroglycerin in the management of retained placenta. Gynecol Obstet Invest 2003;56:61-4.

7. Chedraui PA, Hidalgo LA, San Miguel G. Fatal intracranial hemorrhage in a pregnant patient with autoimmune thrombocytopenic purpura. J Perinat Med 2003;31:526-9.

8. Chedraui PA, San Miguel G. A case of leptospirosis and pregnancy. Arch Gynecol Obstet 2003;269:53-4.

9. Chedraui PA, Hidalgo LA, San Miguel G. Cost analysis in a high risk pregnancy Unit. Int J Gynaecol Obstet 2003;83:S53.

10. Barragán M, Hidalgo LA, Chedraui PA. Serum levels of vitamin B12 and folic acid in patients with preterm labour. Int J Gynaecol Obstet 2003;83:S:114.

11. Hidalgo LA, Peñafiel J, Chedraui PA. Management of cervical pregnancy: Risk factors for failed systemic methotrexate. J Perinat Med 2004;32:184-6.

12. Chedraui PA, Hidalgo LA, Chavez MJ. Determinant factors in Ecuador related to pregnancy among adolescents aged 15 or less. J Perinat Med 2004;32:337-341.

13. Blümel JE, Castelo-Branco C, Chedraui PA, Binfa L, Dowlani B, Gómez MS, Sarrá S. Patients' and clinicians' attitudes after the Women's Health Initiative Study. Menopause 2004;11:57-61.

14. Hidalgo LA, Chedraui PA, Chavez JC. Obstetrical and neonatal outcome in young adolescents of low socio-economic status: a case control study. Arch Gynecol Obstet 2005;271:207-11.

15. Paredes I, Hidalgo LA, Chedraui PA, Palma J, Eugenio J. Factors associated with inadequate prenatal care in Ecuadorian women. Int J Gynaecol Obstet 2005;88:168-72.

16. Sierra B, Hidalgo LA, Chedraui PA. Measuring climacteric symptoms in an Ecuadorian population with the Greene Climacteric Scale. Maturitas 2005;51:236-45.

17. Espinosa E, Hidalgo LA, Chedraui PA. The effect of malarial infection on maternalfetal outcome in Ecuador. J Matern Fetal Neonatal Med 2005;18:101-5. 
18. Hidalgo LA, Chedraui PA, Morocho N, Alvarado M, Chavez D, Huc A. Metabolic syndrome in Ecuadorian postmenopausal women. Climacteric 2005;58:94.

19. Hidalgo LA, Chedraui PA, Morocho N, Alvarado M, Chavez D, Huc A. Quality of life of postmenopausal women from Ecuador. Climacteric 2005;S8:84.

20. Hidalgo LA, Chedraui PA, Morocho N, Ross S, San Miguel G. The effect of red clover isoflavones over symptoms, lipids and vagina of postmenopausal women: A double blind randomized clinical trial. Gynecol Endocrinol 2005;21:257-64.

21. Blumel JE, Castelo-Branco C, Chedraui $P$, et al. Age at menopause presentation in Latin America. Menopause 2006;13:706-712.

22. Imhof M, Gocan A, Reithmayr F, Lipovac M, Schimitzek C, Chedraui P, Huber J. Effects of a red clover extract (MF11RCE) on endometrium and sex hormones in postmenopausal women. Maturitas 2006;55:76-81.

23. Chedraui P, Hidalgo L, Morocho N, Alvarado M, Chavez D, Huc A. Quality of life among postmenopausal Ecuadorian women participating in a metabolic syndrome screening program. Maturitas 2007;56:45-53.

24. Hidalgo L, Chedraui P, Morocho N, Alvarado M, Chavez D, Huc A. The metabolic syndrome among postmenopausal women in Ecuador. Gynecol Endocrinol 2006;22:447-54.

25. Chedraui P, Hidalgo L, Chavez D, Morocho N, Alvarado M, Huc A. Menopausal symptoms and associated risk factors among postmenopausal women screened for the metabolic syndrome. Arch Gynecol Obstet 2007;275:161-8.

26. Chedraui P, Hidalgo L, San Miguel G, Morocho N, Ross S. Red clover extract (MF11RCE) supplementation and postmenopausal vaginal and sexual health. Int J Gynaecol Obstet 2006;95:296-7.

27. Yanez D, Castelo-Branco C, Hidalgo L, Chedraui P. Sexual dysfunction and related risk factors in a cohort of middle-aged Ecuadorian women. J Obstet Gynaecol 2006;26:682-6.

28. Royer M, Blumel JE, Castelo-Branco C, Chedraui P, Danckers L, et al. The US National Cholesterol Education Programme Adult Treatment Panel III (NCEP ATP III): prevalence of the metabolic syndrome in postmenopausal Latin American women. Climacteric 2007;10:164-170.

29. Chedraui PA, van Ardenne R, Wendte JF, Quintero JC, Hidalgo L. Knowledge and practice of family planning and HIV-prevention behavior among just delivered adolescents in Ecuador: the problem of adolescent pregnancies. Arch Gynecol Obstet 2007;276:139-44

30. Leon P, Chedraui P, Hidalgo L, Ortiz F. Perceptions and attitudes toward the menopause among middle aged women of Guayaquil, Ecuador. Maturitas 2007;57:233238.

31. Chedraui P, Aguirre W, Hidalgo L, Fayad L. Assessing menopausal symptoms among healthy middle aged women with the Menopause Rating Scale. Maturitas 2007;57:271-278. 
32. Chang $X$, Chedraui $P$, Ross MG, et al. Vacuum assisted delivery in Ecuador for prolonged second stage of labor: maternal-neonatal outcome. J Matern Fetal Neonatal Med 2007;20:381-384.

33. Castelo-Branco C, Cancelo MJ, Chedraui P. Female sexual dysfunction in postmenopausal women. Expert Opinion Therapeutic Patents 2007; 17:639-647.

34. Chedraui P, Medina M, Moya W, Hidalgo L, Calle A, Terán E. Molecular identification of chlamydia trachomatis infection among gestations at risk for preterm birth in Ecuador. J Perinat Med 2007;35:S62.

35. Chedraui P, Hidalgo L, Medina M, Vivar C. Prediction of outcome after successful treatment of an episode of threatened preterm labor. J Perinat Med 2007;35:S133.

36. Barriga J, Castelo-Branco C, Chedraui P, Hidalgo L, Veas P. Educational and organizational interventions used to improve the knowledge of metabolic syndrome among postmenopausal women. Fertil Steril 2008;90:444-6.

37. Monterrosa A, Blümel JE, Chedraui P. Increased menopausal symptoms among Afro-Colombian women as assessed with the Menopause Rating Scale. Maturitas 2008;59:182-90.

38. Chedraui P. Pregnancy among young adolescents: trends, risk factors and maternal-perinatal outcome. J Perinat Med 2008;36:256-9.

39. Leon-Leon P, Chedraui P, Hidalgo L, Ortiz F, Castelo-Branco C. Hormone therapy for the management of the menopause in Ecuador: perception, use and knowledge among middle-aged women. Gynecol Endocrinol 2008;24:580-5.

40. Chedraui P, San Miguel G, Hidalgo L, Morocho N, Ross S. Effect of Trifolium pratense-derived isoflavones on the lipid profile of postmenopausal women with increased body mass index. Gynecol Endocrinol 2008;24:620-4.

41. Diaz J, Chedraui P, Hidalgo L, Medina M. The clinical utility of fetal fibronectin in the prediction of pre-term birth in a low socio-economic setting hospital in Ecuador. J Matern Fetal Neonatal Med 2008;13:1-5.

42. Medina M, Moya W, Hidalgo L, Calle A, Terán E, Chedraui P. Molecular identification of endocervical Chlamydia trachomatis infection among gestations at risk for preterm birth in Ecuador. Arch Gynecol Obstet 2009;279:9-10.

43. Teran E, Chedraui P, Vivero S, Villena F, Duchicela F, Nacevilla L. Plasma and placental nitric oxide levels in women with and without pre-eclampsia living at different altitudes. Int J Gynaecol Obstet 2009;104:140-2.

44. Chedraui P, Blümel JE, Baron G, Belzares E, Bencosme A, Calle A, Danckers L, Espinoza MT, Flores D, Gomez G, Hernandez-Bueno JA, Izaguirre H, Leon-Leon P, Lima S, Mezones-Holguin E, Monterrosa A, Mostajo D, Navarro D, Ojeda E, Onatra W, Royer M, Soto E, Tserotas K. Impaired quality of life among middle aged women: A multicentre Latin American study. Maturitas 2008;61:323-9. 
45. Teran E, Chedraui $P$, Racines-Orbe $M$, Vivero S, Duchicela F, Nacevilla L, Escobar GS, Schwager $G$, Calle A. Coenzyme $Q_{10}$ levels in women with pre- eclampsia living at different altitudes. Biofactors 2008;32:185-90.

46. Pérez-López FR, Chedraui P, Haya J. Vitamin D acquisition and breast cancer risk. Reprod Sci 2008;16:7-19.

47. Chedraui P, Pérez-López FR, San Miguel G, Avila C. Assessment of sexuality among middle aged women using the Female Sexual Function Index. Climacteric 2009;12:213-21.

48. Chedraui P, San Miguel G, Avila C. Quality of life impairment during the female menopausal transition is related to personal and partner factors. Gynecol Endocrinol 2009;25:130-5.

49. Chedraui P, Lockwood CJ, Schatz F, Buchwalder LF, Schwager G, Guerrero C, Escobar GS, Hidalgo L. Increased plasma soluble fms-like tyrosine kinase 1 (sFlt-1) and endoglin levels in pregnancies complicated with pre- eclampsia. J Matern Fetal Neonatal Med 2009;22:565-70.

50. Pérez-López FR, Haya J, Chedraui P. Vaccinium macrocarpon: an interesting option for women with recurrent urinary tract infections and other health benefits. J Obstet Gynaecol Res 2009;35:630-9.

51. Jara D, Fuenzalida A, Figueroa R, del Prado M, Flores D, Blumel JE, Chedraui P. Is the Menopause Rating Scale reliable for diagnosing sexual dysfunction in climacteric women? Maturitas 2009;62:321-3.

52. Chedraui P, Pérez-López FR, Morales B, Hidalgo L. Depressive symptoms among climacteric women is related to menopausal symptom intensity and partner factors. Climacteric 2009;12:395-403.

53. Monterrosa A, Blumel JE, Chedraui P. Quality of life impairment among postmenopausal women varies according to race. Gynecol Endocrinol 2009;25:491-7.

54. Chedraui P, Pérez-López FR, Blumel JE, Hidalgo L, Barriga J. Hyperglycemia in postmenopausal women screened for the metabolic syndrome was associated to increased sexual complaints. Gynecol Endcrinol 2010;26:86-92.

55. Blümel JE, Chedraui P, Baron G, Belzares E, Bencosme A, Calle A, et al. Sexual dysfunction in middle aged women: a multicenter Latin American study using the Female Sexual Function Index. Menopause 2009;16:1139-48.

56. Blümel JE, Chedraui P, Gili SA, Navarro A, Valenzuela K, Vallejo S. Is the Androgen Deficiency of Aging Men (ADAM) questionnaire useful for the screening of partial androgenic deficiency of aging men? Maturitas 2009;63:365-8.

57. Pérez-López FR, Chedraui P, Gilbert JJ, Pérez-Roncero G. Cardiovascular risk in menopausal women and prevalent related co-morbid conditions: facing the postWomen's Health Initiative era. Fertil Steril 2009;92:1171-86.

58. Pérez-López FR, Chedraui P, Haya J, Cuadros JL. Effects of the Mediterranean diet on longevity and age-related morbid conditions. Maturitas 2009;64:67-79. 
59. Pérez-López FR, Cuadros-López JL, Fernádez-Alonso AM, Cuadros-Celorrio AM, Sabatel-López RM, Chedraui P. Assessing fatal cardiovascular disease risk with the SCORE (Systematic Coronary Risk Evaluation) scale in post-menopausal women 10 years after different hormone treatment regimens. Gynecol Endocrinol 2010;26:533-8.

60. Chedraui P, Pérez-López FR, Mendoza M, Leimberg ML, Martínez MA, Vallarino V, Hidalgo L. Factors related to increased daytime sleepiness during the menopausal transition as evaluated by the Epworth sleepiness scale. Maturitas 2010;65:75-80.

61. Lipovac M, Chedraui P, Gruenhut C, Gocan A, Stammler M, Imhof M. Improvement of postmenopausal depressive and anxiety symptoms after treatment with isoflavones derived from red clover extracts. Maturitas 2010;65:258-61.

62. Chedraui P, Aguirre W, Calle A, Hidalgo L, León-León P, Miranda O, Martínez N, Mendoza M, Narváez J, Sánchez H, Schwager G, Quintero JC, Zambrano B, Aguilar A, Martínez MA, Rivera R, Ruilova I. Risk factors related to the presence and severity of hot flushes in mid-aged Ecuadorian women. Maturitas 2010;65:378-382.

63. Chedraui P, Pérez-López FR, Mendoza M, Morales B, Martinez MA, Salinas AM, Hidalgo L. Severe menopausal symptoms in middle-aged women are associated to female and male factors. Arch Gynecol Obstet 2010;281:879-85.

64. Pérez-López FR, Chedraui P, Cuadros-López JL. Bone Mass Gain during Puberty and Adolescence: Deconstructing Gender Characteristics. Curr Med Chem 2010;17:453-66.

65. Aguirre W, Chedraui P, Mendoza J, Ruilova I. Gabapentin vs. low-dose transdermal estradiol for treating post-menopausal women with moderate to very severe hot flushes. Gynecol Endocrinol 2010;26:333-7.

66. Chedraui P, Pérez-López FR, Mendoza M, Leimberg ML, Martinez MA, Vallarino V, Hidalgo L. Assessment of self-esteem in mid-aged women. Maturitas 2010;66:7782.

67. Ojeda E, Monterrosa A, Blümel JE, Escobar-López J, Chedraui P. Severe menopausal symptoms in mid-aged Latin American women can be related to their indigenous ethnic component. Climacteric 2011;13:157-63.

68. Chedraui P, Pérez-López FR, Aguirre W, Calle A, Hidalgo L, León-León P, Miranda O, Martínez N, Mendoza M, Narváez J, Sánchez H, Schwager G, Quintero JC, Zambrano B, Barrezueta J, Hernández D, Paredes JE. Beliefs regarding menopausal hot flushes among climacteric women as assessed with the Hot Flush Beliefs Scale. Maturitas 2010;66:298-304.

69. Pérez-López FR, Larrad-Mur L, Kallen A, Chedraui P, Taylor HS. Gender differences in cardiovascular disease: hormonal and biochemical influences. Reprod Sci 2010;17:511-31. 
70. Chedraui P, Pérez-López FR, Aguirre W, Calle A, Hidalgo L, León-León P, Miranda O, Martínez N, Mendoza M, Narváez J, Sánchez H, Schwager G, Quintero JC, Zambrano $B$, Leimberg ML, Vallarino $V$, Vega B. Perceived control over menopausal hot flushes in mid-aged women. Gynecol Endocrinol 2010;26:607-11.

71. Cuadros JL, Fernández-Alonso AM, Chedraui P, Cuadros AM, Sabatel RM, PérezLópez FR. Metabolic and hormonal parameters in post-menopausal women 10 years after transdermal oestradiol treatment, alone or combined to micronised oral progesterone. Gynecol Endocrinol 2011;27:156-62.

72. Pérez-López FR, Chedraui P, Troyano-Luque JM. Peri- and post-menopausal incidental adnexal masses and the risk of sporadic ovarian malignancy: new insights and clinical management. Gynecol Endocrinol 2010;26:631-43.

73. Chedraui P, San Miguel G, Schwager G. The effect of soy-derived isoflavones over hot flushes, menopausal symptoms and mood in climacteric women with increased body mass index. Gynecol Endocrinol 2010;27:307-13.

74. Pérez-López FR, Chedraui P. Chagas disease in pregnancy: a non-endemic problem in a globalized world. Arch Gynecol Obstet 2010;282:595-9.

75. Tserotas K, Hernandez L, Morera F, Pineda R, Chedraui P. Treatment for the menopause in Central America: use, knowledge, perceptions and attitudes among urban living middle-aged women. Gynecol Endocrinol 2011;27:504-11.

76. Chedraui P, Jaramillo W, Pérez-López FR, Escobar GS, Morocho N, Hidalgo L. Proinflammatory cytokine levels in postmenopausal women with the metabolic syndrome. Gynecol Endocrinol 2011;27:685-91.

77. Fernández-Alonso AM, Cuadros JL, Chedraui P, Mendoza M, Cuadros AM, PérezLópez FR. Obesity is related to increased menopausal symptoms among Spanish women. Menopause Int 2010;16:105-10.

78. Cuadros JL, Fernández-Alonso AM, Cuadros AM, Chedraui P, Pérez-López FR. Body mass index and its correlation to metabolic and hormone parameters in postmenopausal Spanish women. Gynecol Endocrinol 2011;27:678-84.

79. Chedraui P, Pérez-López FR, Mezones-Holguin E, San Miguel G, Avila C; Collaborative Group for Research of the Climacteric in Latin America (REDLINC). Assessing predictors of sexual function in mid-aged sexually active women. Maturitas 2011;68:387-90.

80. Pérez-López FR, Fernández-Alonso AM, Ferrando-Marco P, Salmerón-González MD, Dionis-Sánchez EC, Fiol-Ruiz G, Chedraui P. First Trimester Serum 25Hydroxyvitamin D Status and Factors Related to Lower Levels in Gravids Living in the Spanish Mediterranean Coast. Reprod Sci 2011;18:730-6.

81. Blümel JE, Chedraui P, Baron G, et al; Collaborative Group for Research of the Climacteric in Latin America (REDLINC). A large multinational study of vasomotor symptom prevalence, duration, and impact on quality of life in middle-aged women. Menopause 2011;18:778-85. 
82. Pérez-López FR, Chedraui P, Fernández-Alonso AM. Vitamin D and aging: beyond calcium and bone metabolism. Maturitas 2011;69:27-36.

83. Arakane M, Castillo C, Rosero MF, Peñafiel R, Pérez-López FR, Chedraui P. Factors relating to insomnia during the menopausal transition as evaluated by the Insomnia Severity Index. Maturitas 2011;69:157-61.

84. Escajadillo-Vargas N, Mezones-Holguín E, Castro-Castro J, Córdova-Marcelo W, Blümel JE, Pérez-López FR, Chedraui P. Sexual dysfunction risk and associated factors in young Peruvian university women. J Sex Med 2011;8:1701-9.

85. Fernández-Alonso AM, Valdera-Simbrón CJ, Fiol-Ruiz G, Rodríguez-Sánchez $F$, Chedraui P, Pérez-López FR. First trimester serum levels of 25-hydroxyvitamin D, free $\beta$-human chorionic gonadotropin, and pregnancy-associated plasma protein $A$ in Spanish women. Gynecol Endocrinol 2011;27:1061-4.

86. Terán E, Racines-Orbe M, Toapanta J, Valdivieso L, Vega Z, Vivero S, Moya W, Chedraui P, Pérez-López FR. Maternal plasma and amniotic fluid coenzyme $\mathrm{Q}_{10}$ levels in preterm and term gestations: a pilot study. Arch Gynecol Obstet 2011;283 Suppl 1:67-71.

87. Llaneza P, Fernández-Iñarrea JM, Arnott B, García-Portilla MP, Chedraui P, PérezLópez FR. Sexual Function Assessment in Postmenopausal Women with the 14Item Changes in Sexual Functioning Questionnaire. J Sex Med 2011;8:2144-2151.

88. Chedraui P. Effect of hormone therapy on lean body mass, falls and fractures. Climacteric 2011;14:403-5.

89. Lipovac M, Chedraui P, Gruenhut C, Gocan A, Kurz C, Neuber B, Imhof M. The effect of red clover isoflavone supplementation over vasomotor and menopausal symptoms in postmenopausal women. Gynecol Endocrinol 2012;28:203-7.

90. Fernández-Alonso AM, Fiol-Ruiz G, Chedraui P, Pérez-López FR. Lack of correlation between first trimester maternal serum 25-hydroxyvitamin $D$ levels and ultrasound measured crown-rump length and nuchal translucency. Arch Gynecol Obstet 2011;284:1585-8.

91. Fernández-Alonso AM, Dionis-Sánchez EC, Chedraui P, González-Salmerón MD, Pérez-López FR; Spanish Vitamin D and Women's Health Research Group. Firsttrimester maternal serum 25-hydroxyvitamin $D_{3}$ status and pregnancy outcome. Int J Gynaecol Obstet 2012;116:6-9.

92. Mezones-Holguin E, Córdova-Marcelo W, Lau-Chu-Fon F, Aguilar-Silva C, MoralesCabrera J, Bolaños-Díaz R, Pérez-López FR, Chedraui P. Association between sexual function and depression in sexually active, mid-aged, Peruvian women. Climacteric 2011;14:654-60.

93. Conventional ovarian cancer screening does not reduce its related mortality in postmenopausal women. Pérez-López FR, Chedraui P. Climacteric 2011;14:605-6.

94. Pérez-López FR, Fernández-Alonso AM, Mannella $P$, Chedraui P. Vitamin D, sunlight and longevity.Minerva Endocrinol. 2011 Sep;36(3):257-66. Review. 
95. Blümel JE, Legorreta $D$, Chedraui $P$, Ayala $F$, Bencosme A, Danckers L, Lange $D$, Espinoza MT, Gomez G, Grandia E, Izaguirre H, Manriquez V, Martino M, Navarro D, Ojeda E, Onatra W, Pozzo E, Prada M, Royer M, Saavedra JM, Sayegh F, Tserotas K, Vallejo MS, Zuñiga C; Collaborative Group for Research of the Climacteric in Latin America (REDLINC). Optimal waist circumference cutoff value for defining the metabolic syndrome in postmenopausal Latin American women. Menopause 2012;19:433-7.

96. Lipovac M, Chedraui P, Gruenhut C, Gocan A, Kurz C, Neuber B, Imhof M. Effect of Red Clover Isoflavones over Skin, Appendages, and Mucosal Status in Postmenopausal Women. Obstet Gynecol Int 2011;2011:949302.

97. Teran E, Briones F, Nicolalde V, Vivero S, Chedraui P, Pérez-López FR. Effect of intravenous hydralazine infusion on maternal plasma nitric oxide levels in gestations complicated with severe pre- eclampsia: a pilot study. Arch Gynecol Obstet 2012;285:1183-7.

98. Rodríguez MC, Chedraui P, Schwager G, Hidalgo L, Pérez-López FR. Assessment of sexuality after hysterectomy using the Female Sexual Function Index. J Obstet Gynaecol 2012;32:180-4.

99. Pérez-López FR, Chedraui P. Adherence to osteoporosis medications. Climacteric 2012;15:100-2.

100. Vassalle C, Simoncini T, Chedraui P, Pérez-López FR. Why sex matters: the biological mechanisms of cardiovascular disease. Gynecol Endocrinol 2012;28:746-51.

101. Fernández-Alonso AM, Trabalón-Pastor M, Chedraui P, Pérez-López FR. Factors related to insomnia and sleepiness in the late third trimester of pregnancy. Arch Gynecol Obstet 2012;286:55-61.

102. Chedraui P, Pérez-López FR, Sánchez H, Aguirre W, Martínez N, Miranda O, Plaza MS, Schwager G, Narváez J, Quintero JC, Zambrano B. Assessment of sexual function of mid-aged Ecuadorian women with the 6-item Female Sexual Function Index. Maturitas 2012;71:407-12.

103. Fernández-Alonso AM, Trabalón-Pastor M, Vara C, Chedraui P, Pérez-López FR; MenopAuse RIsk Assessment (MARIA) Research Group. Life satisfaction, loneliness and related factors during female midlife. Maturitas 2012;72:88-92.

104. Chedraui P, Pérez-López FR, Schwager G, Sánchez H, Aguirre W, Martínez N, Miranda O, Plaza MS, Astudillo C, Narváez J, Quintero JC, Zambrano B. Resilience and related factors during female Ecuadorian mid-life. Maturitas 2012;72:152-6.

105. Chedraui P, Escobar GS, Ramírez C, Pérez-López FR, Hidalgo L, Mannella P, Genazzani A, Simoncini T. Nitric oxide and pro-inflammatory cytokine serum levels in postmenopausal women with the metabolic syndrome. Gynecol Endocrinol 2012;28:787-91.

106. Enriquez M, Maruri G, Ezeta G, Hidalgo L, Pérez-López FR, Chedraui P. The B-Lynch technique for the management of intraoperative uterine atony. J Obstet Gynaecol 2012;32:338-41. 
107. Blümel JE, Chedraui P, Baron G, Belzares E, Bencosme A, Calle A, Danckers L, Espinoza MT, Flores D, Gomez G, Hernandez-Bueno JA, Izaguirre H, Leon-Leon P, Lima S, Mezones-Holguin E, Monterrosa A, Mostajo D, Navarro D, Ojeda E, Onatra W, Royer M, Soto E, Tserotas K, Vallejo MS; for the Collaborative Group for Research of the Climacteric in Latin America (REDLINC). Menopausal symptoms appear before the menopause and persist 5 years beyond: a detailed analysis of a multinational study. Climacteric 2012;15:542-51.

108. Monterrosa-Castro A, Romero-Pérez I, Marrugo-Flórez M, Fernández-Alonso AM, Chedraui P, Pérez-López FR. Quality of life in a large cohort of mid-aged Colombian women assessed using the Cervantes Scale. Menopause 2012;19:924-30.

109. Pérez-López FR, Fernández-Alonso AM, Chedraui P, Moreno LA. Hypovitaminosis D during pregnancy: are we ready to recommend vitamin D supplementation? Gynecol Endocrinol 2012;28:856-8.

110. Pita CP, Pazmiño S, Vallejo M, Salazar-Pousada D, Hidalgo L, Pérez-López FR, Chedraui P; Research Group for the Birth Humanization Project of the Enrique C. Sotomayor Hospital. Inhaled intrapartum analgesia using a 50-50 \% mixture of nitrous oxide-oxygen in a low-income hospital setting. Arch Gynecol Obstet 2012;286:627-31.

111. Blümel JE, Cano A, Mezones-Holguín E, Barón G, Bencosme A, Benítez Z, Bravo LM, Calle A, Flores D, Espinoza MT, Gómez G, Hernández-Bueno JA, Laribezcoa F, Martino M, Lima S, Monterrosa A, Mostajo D, Ojeda E, Onatra W, Sánchez H, Tserotas $\mathrm{K}$, Vallejo MS, Witis S, Zúñiga MC, Chedraui P. A multinational study of sleep disorders during female mid-life. Maturitas 2012;72:359-66.

112. Cuadros JL, Fernández-Alonso AM, Cuadros-Celorrio AM, Fernández-Luzón N, Guadix-Peinado MJ, del Cid-Martín N, Chedraui P, Pérez-López FR; MenopAuse RIsk Assessment (MARIA) Research Group. Perceived stress, insomnia and related factors in women around the menopause. Maturitas 2012;72:367-72.

113. Salazar-Pousada D, Astudillo C, Gonzaga M, Hidalgo L, Pérez-López FR, Chedraui P. Intimate partner violence and psychoemotional disturbance among pregnant women admitted to hospital with prenatal complications. Int J Gynaecol Obstet 2012;118:194-7.

114. Pérez-López FR, Fernández-Alonso AM, Trabalón-Pastor M, Vara C, Chedraui P; MenopAuse RIsk Assessment (MARIA) Research Group. Assessment of sexual function and related factors in mid-aged sexually active Spanish women with the sixitem Female Sex Function Index. Menopause 2012;19:1224-30.

115. Hunter MS, Gupta P, Chedraui P, Blümel JE, Tserotas K, Aguirre W, Palacios S, Sturdee DW. The International Menopause Study of Climate, Altitude, Temperature (IMS-CAT) and vasomotor symptoms. Climacteric 2013;16:8-16.

116. Davis SR, Castelo-Branco C, Chedraui P, Lumsden MA, Nappi RE, Shah D, Villaseca P; Writing Group of the International Menopause Society for World Menopause Day 2012. Understanding weight gain at menopause. Climacteric 2012;15:419-29. 
117. Chedraui P, Solis EJ, Bocci G, Gopal S, Russo E, Escobar GS, Hidalgo L, Pérez-López FR, Genazzani AR, Mannella P, Simoncini T. Feto-placental nitric oxide, asymmetric dimethylarginine and vascular endothelial growth factor (VEGF) levels and VEGF gene polymorphisms in severe pre- eclampsia. J Matern Fetal Neonatal Med 2013;26:226-32.

118. Pérez-López FR, Cuadros JL, Fernández-Alonso AM, Chedraui P, Sánchez-Borrego R, Monterrosa-Castro A. Urinary incontinence, related factors and menopauserelated quality of life in mid-aged women assessed with the Cervantes Scale. Maturitas 2012;73:369-72.

119. Monterrosa-Castro A, Marrugo-Flórez M, Romero-Pérez I, Fernández-Alonso AM, Chedraui P, Pérez-López FR. Assessment of sleep quality and correlates in a large cohort of Colombian women around menopause. Menopause 2013;20:464-469.

120. Chedraui P, San Miguel G, Villacreses D, Dominguez A, Jaramillo W, Escobar GS, Pérez-López FR, Genazzani AR, Simoncini T; Research Group for the Omega Women's Health Project. Assessment of insomnia and related risk factors in postmenopausal women screened for the metabolic syndrome. Maturitas 2013;74:154-9.

121. Dulón-Pérez A, Depiano E, Chedraui $P$, Monterrosa-Castro A. The menopause in Latin America. Maturitas 2013;74:291-2.

122. Monterrosa-Castro A, Marrugo-Flórez M, Romero-Pérez I, Chedraui P, FernándezAlonso AM, Pérez-López FR. Prevalence of insomnia and related factors in a large mid-aged female Colombian sample. Maturitas 2013;74:346-51.

123. Blümel JE, Chedraui P, Baron G, Belzares E, Bencosme A, Calle A, Danckers L, Espinoza MT, Flores D, Gomez G, Hernandez-Bueno JA, Izaguirre H, Leon-Leon P, Lima S, Mezones-Holguin E, Monterrosa A, Mostajo D, Navarro D, Ojeda E, Onatra W, Royer M, Soto E, Tserotas K, Vallejo MS. Menopause could be involved in the pathogenesis of muscle and joint aches in mid-aged women. Maturitas 2013;75:94-100.

124. Yanez P, Vásquez CJ, Rodas L, Durán A, Chedraui P, Liem KH, Pérez-López FR, Teran E. Erythrocyte folate content and serum folic acid and homocysteine levels in preeclamptic primigravidae teenagers living at high altitude. Arch Gynecol Obstet 2013;288:1011-5

125. Monterrosa-Castro A, Blümel JE, Portela-Buelvas K, Mezones-Holguín E, Barón G, Bencosme A, Benítez Z, Bravo LM, Calle A, Chedraui P, Flores D, Espinoza MT, Gómez G, Hernández-Bueno JA, Laribezcoa F, Lima S, Martino M, Mostajo D, Ojeda E, Onatra W, Sánchez H, Navarro D, Tserotas K, Vallejo MS, Witis S, Zuñiga MC; for the Collaborative Group for Research of the Climacteric in Latin America (REDLINC). Type II diabetes mellitus and menopause: a multinational study. Climacteric 2013;16:663-72.

126. Chedraui P, Pérez-López FR. Nutrition and health during mid-life: searching for solutions and meeting challenges for the aging population. Climacteric 2013;16:8595. 
127. Chedraui $P$, San Miguel G, Vintimilla-Sigüenza I, Villacreses $D$, Romero-Huete $L$, Domínguez A, Jaramillo W, Escobar GS, Pérez-López FR, Genazzani AR, Simoncini T; Research Group for Omega Women's Health Project. The metabolic syndrome and its components in postmenopausal women. Gynecol Endocrinol 2013;29:563-8.

128. Pérez-López FR, Pérez-Roncero G, Fernández-Iñarrea J, Fernández-Alonso AM, Chedraui P, Llaneza P; for The MARIA (MenopAuse RIsk Assessment) Research Group. Resilience, depressed mood, and menopausal symptoms in postmenopausal women. Menopause 2014;21:159-64.

129. Pérez-López FR, Fernández-Alonso AM, Pérez-Roncero G, Chedraui P, MonterrosaCastro A, Llaneza P. Assessment of menopause-related symptoms in mid-aged women with the 10-item Cervantes Scale. Maturitas 2013;76:151-4.

130. Blümel JE, Chedraui P, Barón G, Benítez Z, Flores D, Espinoza MT, Gomez G, González E, Hernández L, Lima S, Martino M, Montaño A, Monterrosa A, Mostajo D, Ojeda E, Onatra W, Robles C, Saavedra J, Sánchez H, Tserotas K, Vallejo MS, Vallejo C; for the Collaborative Group for Research of the Climacteric in Latin America (Redlinc). A multicentric study regarding the use of hormone therapy during female mid-age (REDLINC VI). Climacteric 2014; In press.

131. Ornat L, Martínez-Dearth R, Chedraui P, Pérez-López FR. Assessment of subjective sleep disturbance and related factors during female mid-life with the Jenkins Sleep Scale. Maturitas 2014;77:344-50.

132. Chedraui P, Escobar GS, Pérez-López FR, Palla G, Montt-Guevara M, Cecchi E, Genazzani AR, Simoncini T; Research Group for the Omega Women's Health Project. Angiogenesis, inflammation and endothelial function in postmenopausal women screened for the metabolic syndrome. Maturitas 2014;77:370-4.

133. Chedraui P, Salazar-Pousada D, Villao A, Escobar GS, Ramirez C, Hidalgo L, PérezLópez FR, Genazzani A, Simoncini T. Polymorphisms of the methylenetetrahydrofolate reductase gene (C677T and A1298C) in nulliparous women complicated with pre- eclampsia. Gynecol Endocrinol 2014;30:392-6.

134. Chedraui P, Pérez-López FR, Escobar GS, Palla G, Montt-Guevara M, Cecchi E, G enazzani AR, Simoncini T; Research Group for the Omega Women's Health Project. Circulating leptin, resistin, adiponectin, visfatin, adipsin and ghrelin levels and insulin resistance in postmenopausal women with and without the metabolic syndrome. Maturitas 2014;79:86-90.

135. Chedraui P, Pérez-López FR, Sánchez H, Sánchez P, Miranda O, Quispe P, MaderoTrelles T, Hidalgo L, Arboleda D, López G, Quintero JC. Application of the 10-item Cervantes Scale among mid-aged Ecuadorian women for the assessment of menopausal symptoms. Maturitas 2014;79:100-5.

136. Salazar-Pousada D, Chedraui P, Villao A, Pérez-Roncero GR, Hidalgo L. [Maternal and perinatal outcomes in nulliparous gestations with late onset pre- eclampsia: Comparative study with gestations without pre- eclampsia]. Enferm Clin 2014;24:345-50. 
137. Chedraui P, Pérez-López FR, Hidalgo L, Villacreses D, Domínguez A, Escobar GS, Genazzani AR, Simoncini T; Research Group for the Omega Women's Health Project. Evaluation of the presence and severity of menopausal symptoms among postmenopausal women screened for the metabolic syndrome. Gynecol Endocrinol 2014; In press.

138. Blümel JE, Chedraui P, Aedo S, Fica J, Mezones-Holguín E, Barón G, Bencosme A, Benítez Z, Bravo LM, Calle A, Flores D, Espinoza MT, Gómez G, Hernández-Bueno JA, Laribezcoa F, Martino M, Lima S, Monterrosa A, Mostajo D, Ojeda E, Onatra W, Sánchez H, Tserotas K, Vallejo MS, Witis S, Zúñiga MC. Obesity and its relation to depressive symptoms and sedentary lifestyle in middle-aged women. Maturitas 2015;80:100-5.

139. Chedraui P, Solis EJ, Pérez-López FR, Schatz F, Kayisli U, Escobar GS, Loja-Chango R, Hidalgo L, Lockwood CJ. Umbilical cord plasma interferon-induced protein 10 (IP10) and interferon-induced T cell alpha chemoattractant (ITAC) levels are lower in women with severe pre- eclampsia. J Perinat Med 2015; In press. 


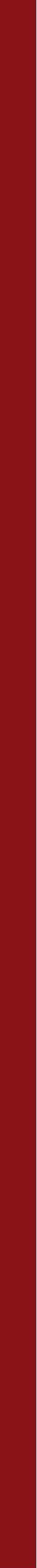

